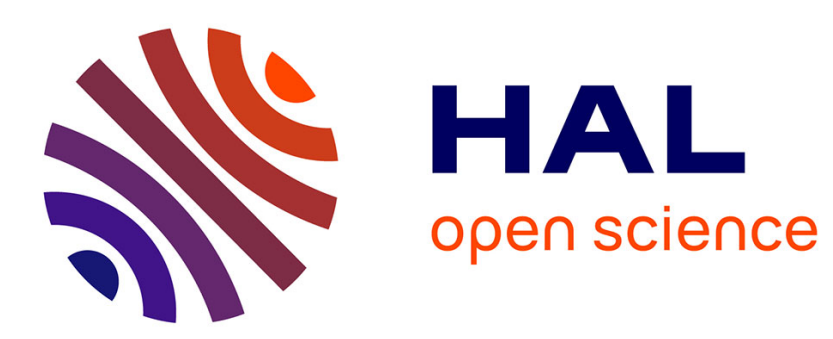

\title{
Control of Gelation and Network Properties of Cationically Copolymerized Mono- and Diglycidyl Ethers
}

Thomas Vidil, Michel Cloitre, François Tournilhac

\section{- To cite this version:}

Thomas Vidil, Michel Cloitre, François Tournilhac. Control of Gelation and Network Properties of Cationically Copolymerized Mono- and Diglycidyl Ethers. Macromolecules, 2018, 51 (14), pp.51215137. 10.1021/acs.macromol.8b00406 . hal-02135158

\section{HAL Id: hal-02135158 \\ https://hal.science/hal-02135158}

Submitted on 12 Dec 2019

HAL is a multi-disciplinary open access archive for the deposit and dissemination of scientific research documents, whether they are published or not. The documents may come from teaching and research institutions in France or abroad, or from public or private research centers.
L'archive ouverte pluridisciplinaire HAL, est destinée au dépôt et à la diffusion de documents scientifiques de niveau recherche, publiés ou non, émanant des établissements d'enseignement et de recherche français ou étrangers, des laboratoires publics ou privés. 


\title{
Control of gelation and network's properties of cationically copolymerized mono- and di-glycidyl ethers
}

\author{
Thomas Vidil, ${ }^{\dagger}$ Michel Cloître ${ }^{\dagger}$ and Francois Tournilhac ${ }^{\dagger *}$ \\ ${ }^{\dagger}$ Matière Molle et Chimie, UMR 7167 CNRS ESPCI Paris, PSL Research University, 10 rue \\ Vauquelin 75005 Paris, France. \\ *Corresponding author : francois.tournilhac@espci.fr
}

Manuscript published in Macromolecules 2018, 51, 5121-5137.

\begin{abstract}
The development of low temperature curing systems has become a major objective in thermoset technologies for both environmental and economic reasons. The use of protic and chelating additives have recently been underlined for the control of the cationic ring opening polymerization of epoxies, a curing mode that is very efficient at temperatures close from the ambient but that can easily runaway. In this paper, we propose to use this strategy to control the kinetics of the cationic copolymerization of a diepoxy monomer(diglycidyl ether of bisphenol A, DGEBA) with a monoepoxy monomer(phenyl glycidyl ether, PGE). The purpose of the study is to tune the crosslink density $\left(v_{e}\right)$ in order to control the mechanical properties of the materials. The sol-gel transition was first investigated in details at several frequencies by using the Fourier transform mechanical spectroscopy method (FTMS). We found that the gel time $\left(t_{g e l}\right)$ and the critical conversion $\left(\alpha_{g e l}\right)$ can be controlled to a great extent by promoting transfers and complexing cationic species involved in the polymerization mechanism. The FTMS method also gives some insight into the structure of the polymer clusters at the sol-gel transition. The results indicate that the various additives used to control the transition have mostly no influence on the clusters' structure. The properties of the fullycured networks were then investigated via swelling and dynamic mechanical measurements. Both methods indicate that $v_{e}$ is strongly influenced by the crosslinker content (DGEBA) but
\end{abstract}


also by the additive used to control the curing kinetics. Interestingly, the measurement of the tensile properties at large deformations demonstrates that the resulting system offers a series of materials with a wide range of mechanical properties.

\section{TOC}

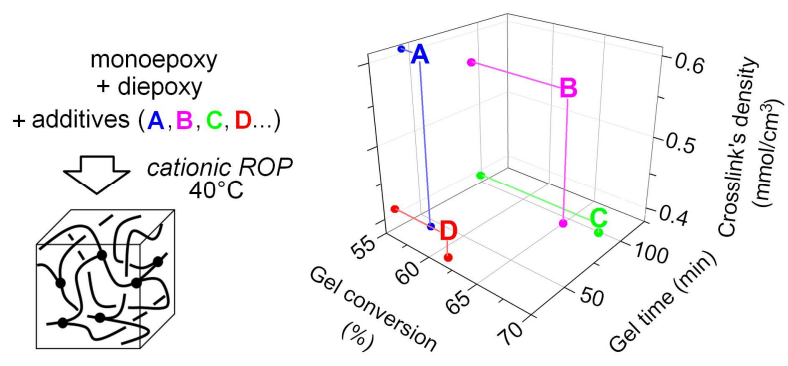

\section{Introduction}

In today's polymer market, thermoset polymers have become key-materials in many applications where high mechanical strength and chemical resistance are required. ${ }^{1,2}$ They are used in a myriad of industrial processes ranging from the insulation of small electronic components $^{3}$ to the fabrication of large parts for cars and aircrafts. ${ }^{4}$ The crosslinked structure of thermoset polymers results in their superior stability compared to thermoplastics. ${ }^{5,6}$ However, the proper control of their synthesis and network topology comes with two challenges. In particular, it is necessary to control the kinetics of the crosslinking reaction because the formation of the network is accompanied by a transition from a liquid to a solid: the gelation. ${ }^{6}$ The gel time, $t_{\text {gel }}$, is often considered as a reference to estimate the period of time during which the reactive mixture is still liquid and thus can be manipulated. On the other hand, it is also important to control the final properties of the fully cured network because each application has specific requirements. In thermoset technology, one key parameter is the crosslink's density, that is to say the density of elastically active chains in the network. ${ }^{5-10}$ It governs the mechanical strength and the elasticity of the material ${ }^{11}$ as well as 
its swelling properties by controlling the diffusion of solute within its mesh. ${ }^{12}$ Most of the time the crosslink's density is estimated by considering $M_{X}$, the total sample weight that contains one mole of elastically effective network chains, which in the case of an ideal network coincides with the molecular weight between crosslinks. ${ }^{7}$ It is directly related to the tightness or looseness of the networks.

Several methods have been used to control $t_{g e l}$ and $M_{X}$, in particular for epoxy-based thermoset. Indeed, the versatility of epoxide chemistry ${ }^{13}$ combined with the large number of commercially available epoxy monomers ${ }^{14}$ offer many options to control these parameters.

In the case of step polymerization, the prominent polymerization mode in thermoset technology, a common approach to control both $t_{g e l}$ and $M_{X}$ consists in playing with the functionality of the crosslinkers. ${ }^{15-17}$ In the foremost case of epoxy-amine reactive mixtures, diepoxides can be reacted with a mixture of mono- and di-amines where primary monoamines and primary diamines respectively act as bifunctional and tetrafunctional curing agents, leading to linear chain extension and crosslinking points. In these conditions, the [monoamine]/[diamine] ratio permits to adjust the size of the linear chains between crosslinking points, i.e. $M_{X} \cdot{ }^{18-20}$ Moreover $t_{g e l}$ is an increasing function of [monoamine] since gelation is directly related to the formation rate of the crosslinking points. Thus, in this approach, $M_{X}$ and $t_{g e l}$ are co-dependent.

Chain polymerization of epoxy monomers is also extensively used in the literature. In particular, the cationic ring opening polymerization (ROP) exhibits fast kinetics and is not oxygen sensitive. ${ }^{21-23}$ In recent years, these attractive features, combined to the continuous development of cationic initiators as curing agents of epoxy monomers, ${ }^{6}$ have been used to design advanced materials including photoresponsive, ${ }^{24,} 253 \mathrm{D}$-printed, ${ }^{26}$ or nanostructured thermosets. ${ }^{27}$ Interestingly, this polymerization mode undergoes transfers in presence of protic additives (e.g. water, alcohols) that can be used to control the kinetics of the curing 
reaction. $^{28-30,19}$ Indeed, in aprotic conditions, the classical activated chain end (ACE) propagation mode operates and yields weakly branched polymer chains that percolates in the early stages of the curing reactions resulting in short $t_{g e l}$ as well as small conversion at the gel point $\left(\alpha_{g e l}\right)$ (Figure 1A). In the presence of protic additives, protonated monomers are attacked by hydroxylated chain ends resulting in an activated monomer (AM) propagation mode which is accompanied by many transfers and branching. In the AM mode, $t_{g e l}$ is considerably delayed in comparison with the ACE mode and gelation is observed for higher values of $\alpha_{g e l}$ (Figure 1B). We recently demonstrated that chelating species such as linear and cyclic polyethers can be added to trap the protons during the transfers associated with the AM propagation mode. ${ }^{6,29,31}$ Once the protons are involved in a complexation equilibrium, their availability for the propagation of the ROP considerably decreases, resulting in an increase of $t_{\text {gel }}$. By combining protic additives and complexing polyethers, we proposed a general approach to control the two fundamental parameters of the gelation process for the curing of epoxy monomers in the cationic mode, i.e. $t_{g e l}$ and $\alpha_{g e l .}{ }^{6,31}$ Under certain conditions, this system offers the possibility to decorrelate the control of $t_{g e l}$ and $\alpha_{g e l}$.

It is still to be established how transfers and supramolecular complexation influence $M_{X}$ after completion of the curing reaction. The protic compounds used to initiate the AM mechanism are eventually inserted in the cured network ${ }^{32,33}$ and $M_{X}$ is also dependent on their chemical structure making it difficult to interpret the distinctive influence of the AM mechanism solely. On the other hand, the non-reactive complexing agents (i.e. aprotic polyethers - cyclic and linear) that are used to complex recirculating protons and that are not inserted in the final network, are believed to have no influence on the final structure of the thermoset. 


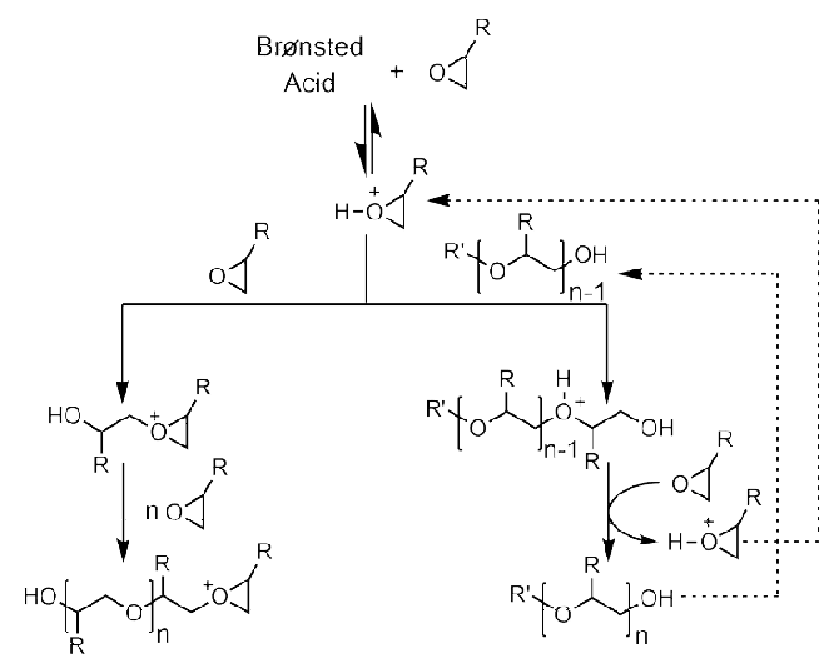

Activated chain end (ACE)

Activated monomer (AM)

Small $\alpha_{w}$
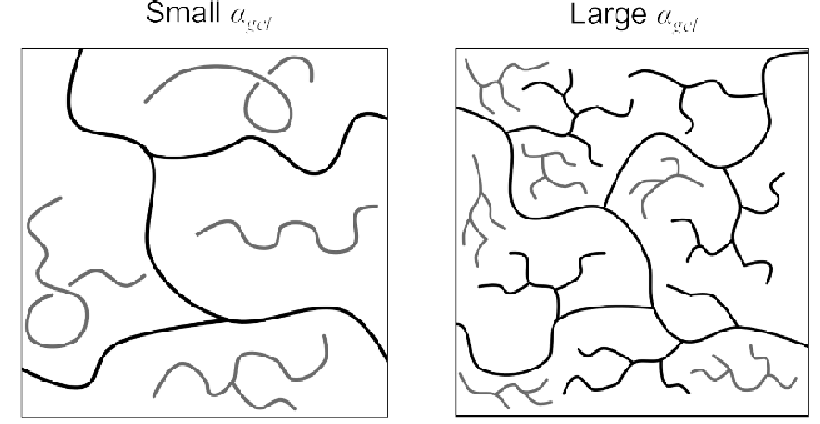

Figure 1: Mechanisms of the acid-initiated cationic ring-opening polymerization of epoxy monomers and schematic representation of the network architecture at the sol-gel transition when the substituent $\mathrm{R}$ contains another epoxy function (diepoxides). On the left side is depicted the activated chain end mechanism (ACE) with typically small conversion at the gel point $\left(\alpha_{g e l}\right)$. On the right side is represented the activated monomer mechanism with large $\alpha_{g e l}$.

Just like in step polymerization, $M_{X}$ can be controlled by playing with the functionality of the monomers. This strategy has been extensively used for producing thermosets via the free radical polymerization of vinylic and multivinylic monomers (e.g. styrene/divinylbenzene, ${ }^{34}$ acrylate/diacrylate, ${ }^{35}$ methacrylate/dimethacrylate $\left.{ }^{36}\right)$. Surprisingly, very few results have been reported regarding the cationic copolymerization of mono and poly-epoxides. Matsumuto and his group studied the copolymerization of 1,2 epoxycyclohexane $(\mathrm{ECH})$ as a monoepoxide and bis[3,4-epoxycyclohexylmethyl] adipate (BECHMA) as a diepoxide crosslinker. ${ }^{37}$ They discussed the mechanism of the three dimensional network formation on the basis of size exclusion chromatography (SEC) investigations but the properties of the resulting materials were not studied. Recently, Sangermano and collaborators reported the synthesis of a 
photodegradable epoxy network based on the copolymerization of a diepoxide containing a photolabile group and a monoepoxide, the glycidyl 2-methylphenyl ether. ${ }^{24}$ They investigated the influence of the monoepoxide content on the photodegradation properties of thin films but the mechanical properties of the materials were not characterized. From our view point, the copolymerization of a diepoxide and a monoepoxide is an interesting alternative for the systematic control of $M_{X}$ and thus of the toughness and swelling properties of the networks.

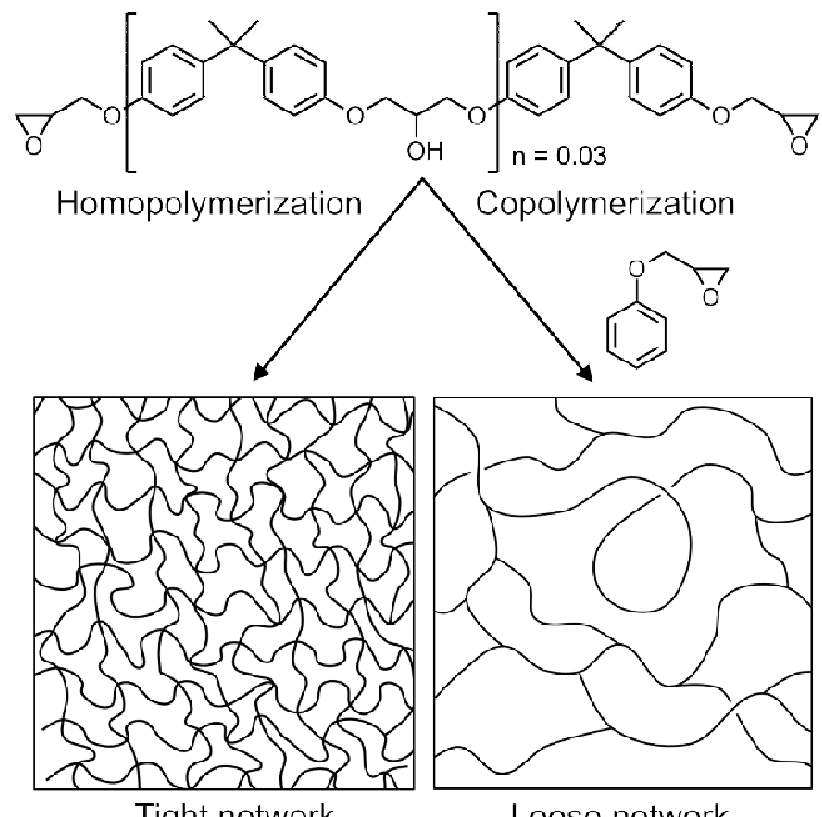

Tight network

Loose network

Figure 2: Control of the crosslink density of cationically cured epoxy networks through the copolymerization of mono- and di-glycidyl ethers (here DGEBA and PGE).

This paper is devoted to the study of the cationic crosslinking copolymerization of phenyl glycidyl ether (PGE) with diglycidyl ether of bisphenol A (DGEBA) (Figure 2). We propose a continuous investigation of the curing kinetics through rheometric and spectrometric monitoring of the copolymerization. In particular, the sol-gel transition is investigated in details at various frequencies. Results are interpreted from the view point of the percolation theory. The critical exponents of the sol-gel transition are evaluated and compared to literature data. The influence of a series of protic and/or chelating additives (Scheme 1) on $t_{g e l}$, $\alpha_{g e l}$ and the critical exponents is studied as well. Finally, the thermomechanical and swelling 
properties of the materials are investigated. The influences of the crosslinker content and of the nature of the additives are reported. $M_{X}$ values are estimated from mechanical and swelling experiments and the results are compared to the values expected for ideal networks.

\section{Experimental}

Fits and integrations of data were performed using the OriginPro® 8.0 software.

\subsection{Materials}

Diglycidyl ether of bisphenol A (DGEBA) produced by the Dow Chemical Company, with an average number of hydroxyl groups per molecule around 0.03, was used. Phenyl glycidyle ether (PGE), poly(ethylene glycol), $M_{n}=300 \mathrm{~g} \mathrm{~mol}^{-1}$ (HO-PEO-OH), monomethylated poly(ethylene glycol), $M_{n}=350 \mathrm{~g} \mathrm{~mol}^{-1}$ (MeO-PEO-OH), phenoxy propane-1,2-diol (PPD) were puchased from Sigma Aldrich. 4-chloroanilinium tetrafluoroborate $\left(4 \mathrm{CA}^{+}-\mathrm{BF}_{4}^{-}\right)$was prepared as previously described. ${ }^{31}$

\subsection{Sample preparation}

Reactive compositions incorporating $(100-x)$ wt $\%$ PGE and $x$ wt $\%$ DGEBA were prepared using $4 \mathrm{CA}^{+}-\mathrm{BF}_{4}^{-}$as an initiator in the presence or not of an additive (hydroxylated and/or chelating additives). First, the solid epoxy monomer DGEBA was dissolved in the liquid monomer PGE to give a viscous liquid. A predetermined amount of the additive (diol and/or polyether, 0.061 equiv/epoxy) was then added to the monomer and the resulting mixture was vigorously stirred to give a homogeneous and colorless sample. In a separate vial, the initiator (0.026 equiv/epoxy) was predissolved in acetone. The solution was then added to the previous mixture by means of a syringe. The resulting sample was vigorously stirred to give a homogeneous system and placed under vacuum for several minutes to evaporate the solvent. 
Aliquots of reactive compositions thereby obtained were then immediately studied by spectroscopic and rheological experiments. Films for swelling and mechanical measurements were obtained by curing the remaining part in a mold made of a brass frame sandwitched between two silicon paper sheets. The samples were cured 10 hours at $40{ }^{\circ} \mathrm{C}$ and postcured 2 hours at $120{ }^{\circ} \mathrm{C}$ with the help of a Carver heating press. FT-IR analyses of the resulting films indicate the total disappearance of the epoxy bending absorbance peak at $914 \mathrm{~cm}^{-1}$ (i.e. no residual monomers). Unmolded sheets were then punched in the form of circular, rectangular and dogbone samples for swelling and mechanical tests. Measurements were always performed within a few days after the synthesis of the materials. Moreover, the samples were stored in zip bags in-between each measurements in order to prevent any water uptake from atmospheric humidity.

\subsection{Monitoring of the curing process}

FT-IR measurements were performed using a Bruker Tensor 37 spectrometer. Curing at $40{ }^{\circ} \mathrm{C}$ was performed in situ using a Specac Goldengate temperature-controlled ATR cell. The epoxy conversion was calculated by measuring the decay of the epoxy bending absorbance peak at $914 \mathrm{~cm}^{-1}$ according to a method previously described in the litterature. ${ }^{29,31}$ In parallel, another sample of the same mixture was placed at $40{ }^{\circ} \mathrm{C}$ in the gap of an Anton Paar Physica MCR 501 rheometer equipped with $\phi=50 \mathrm{~mm}$ diameter disposable parallel plates and operating in the multiwave mode using Fourier transfrom mechanical spectroscopy (FTMS). A multiwave strain signal of $1 \%$ amplitude for the $1 \mathrm{rad} \mathrm{s}^{-1}$ component was applied in order to collect $G^{\prime}, G^{\prime \prime}$ data every 30 s for eight different frequencies: $1,2,4,8,16,32,64$, and $128 \mathrm{rad} \mathrm{s}^{-1}$.

A more detailed description of the experimental setups and additional information regarding the multiwave mode are available in the ESI. 


\subsection{Swelling experiments}

Circular samples $($ diameter $=6 \mathrm{~mm}$, thickness $=1.2 \mathrm{~mm}$ ) were immersed for 2 weeks in pyridine. The variation of the sample diameter was accurately measured by taking a numerical picture of the sample before and after complete swelling equilibrium (see ESI, supplementary Figure S5). The linear swelling ratio, given by $\lambda=D / D_{0}$ where $D$ and $D_{0}$ are the diameter of the circular sample before and after swelling was used to determine the polymer volume fraction, $v_{p}$, in the equilibrium swollen network, as given by $v_{p}=1 / \lambda^{3}$.

\subsection{Glass transition temperature $\left(T_{g}\right)$ from DSC}

Differential scanning calorimetry (DSC) experiments were performed using a TA DSC Q1000 analyzer. Samples of about 5 to $10 \mathrm{mg}$ were placed in standard aluminum T-zero pans with hermetic lids. Scans were conducted under an inert $\left(\mathrm{N}_{2}\right)$ atmosphere at a rate of $10{ }^{\circ} \mathrm{C} \min ^{-1}$. Glass transition temperatures, $T_{g}$ 's, were determined during the second heating ramp within the temperature range of $0{ }^{\circ} \mathrm{C}$ to $200{ }^{\circ} \mathrm{C}$.

\subsection{Elastic modulus from DMA}

Rectangular specimens of length $=25 \mathrm{~mm}$, width $=5 \mathrm{~mm}$, thickness $=1.2 \mathrm{~mm}$ dimensions were used to perform dynamic mechanical analysis (DMA) experiments in the tensile mode from $-100{ }^{\circ} \mathrm{C}$ to $+150{ }^{\circ} \mathrm{C}$ with a heating rate of $3{ }^{\circ} \mathrm{C} \min ^{-1}$. The dynamic moduli $E^{\prime}, E^{\prime \prime}$ and the damping factor, $\tan \delta=E^{\prime \prime} / E^{\prime}$ were measured as a function of temperature at a frequency of $1 \mathrm{~Hz}$ and an amplitude of $10 \mu \mathrm{m}$. Two samples, DGEBA ${ }_{15} \mathrm{PGE}_{85}$ and $\mathrm{DGEBA}_{25} \mathrm{PGE}_{75} \mathrm{PEO}$ were too sticky to perform DMA measurements.

\subsection{Large-strain mechanical properties}

Measurements were performed using dogbone shaped samples of working length: $25 \mathrm{~mm}$, 
width: $2 \mathrm{~mm}$, thickness: $1.2 \mathrm{~mm}$ dimensions. The load-elongation curves were recorded using an INSTRON 5564 tensile testing machine at a constant crosshead speed of $5 \mathrm{~mm} \mathrm{~min}^{-1}$. At room temperature, extensions were monitored with the help of an extensometer giving the true strain of the specimen. Measurements as a function of temperature were performed in an oven. In that case, the strain was determined from the crosshead displacement by taking the gauge length as the length of the parallel portions of the dogbone.

Every strain-stress curve is representative of a series of at least 3 similar measurements. The modulus (determined from least square fitting of the linear part of the curve), the elongation and stress at break $\left(\varepsilon_{b}, \sigma_{b}\right)$ and the yield strain and yield stress $\left(\varepsilon_{y}, \sigma_{y}\right)$ were all measured using the OriginPro® 8.0 software. The systematic error reported is the standard deviation observed within the series of at least 3 similar measurements. Again, DGEBA ${ }_{15} \mathrm{PGE}_{85}$ and DGEBA $_{25} \mathrm{PGE}_{75} \mathrm{PEO}$ were too sticky to perform proper tensile tests.

\section{Results and discussion}

\subsection{Chemistry}

Various types of polyoxylated molecules were used as additives for the cationic curing of mixtures of DGEBA and PGE initiated by $4 \mathrm{CA}^{+}-\mathrm{BF}_{4}{ }^{-}$. They differ by the type of skeleton and number of alcohol groups. The reagents are depicted in Scheme 1.

The studied systems will be noted DGEBA $\mathrm{PGE}_{100-x} \mathrm{Y}$, where $x$ is the weight content of DGEBA, and $\mathrm{Y}$ the additive; DGEBA $\mathrm{PGE}_{100-x}$ represents the neat system, i.e. free of any additive $\left(\mathrm{Y}=\right.$ none). The study of the curing kinetics was performed at $40{ }^{\circ} \mathrm{C}$ for various $x$ values in the presence of different additives Y. The influence of the crosslinker content, $x$, was investigated for the neat system $\operatorname{DGEBA}_{x} \mathrm{PGE}_{100-x}(x=15,25$ and $35 \mathrm{wt} \%)$ and for DGEBA $_{x} \mathrm{PGE}_{100-x}$ PEO ( $\mathrm{Y}=\mathrm{PEO}$ and $x=25,35$ and $45 \mathrm{wt} \%$ ). For the other additives, polymerization was performed at a single crosslinker content: $x=35 \mathrm{wt} \%$. 


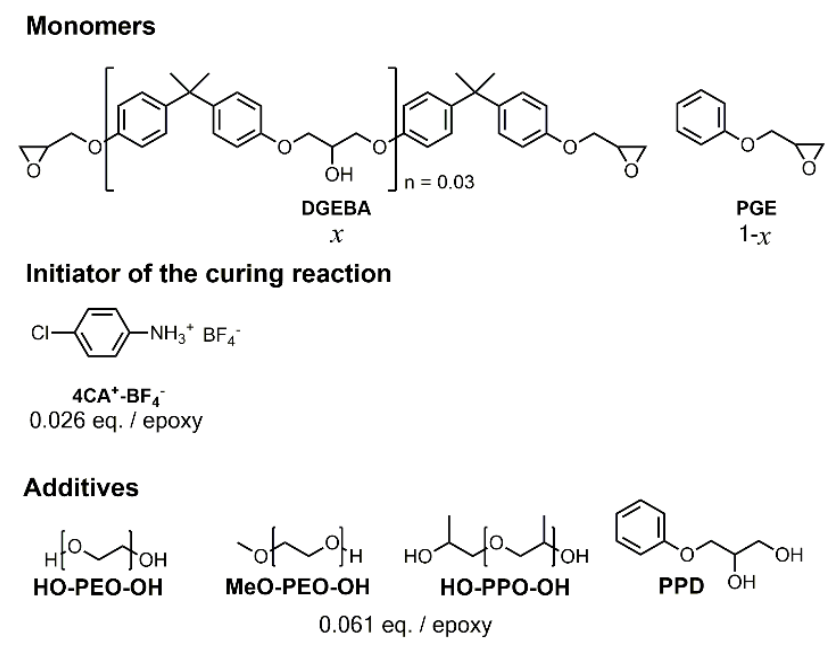

Scheme 1: The monomers, the initiator and the additives used in this study. PGE = Phenyl Glycidyl Ether, DGEBA = Diglycidyl Ether of Bisphenol A, $4 \mathrm{CA}^{+}-\mathrm{BF}_{4}{ }^{-}=4$-chloroanilinium tetrafluoroborate, HO-PEO-OH = Poly(ethylene glycol $)\left(300 \mathrm{~g} \mathrm{~mol}^{-1}\right), \mathrm{MeO}-\mathrm{PEO}-\mathrm{OH}=$ monomethylated Poly(ethylene glycol) $\left(350 \mathrm{~g} \mathrm{~mol}^{-1}\right), \mathrm{HO}-\mathrm{PPO}-\mathrm{OH}=\mathrm{Poly}$ (propylene glycol) $\left(400 \mathrm{~g} \mathrm{~mol}^{-1}\right), \mathrm{PPD}=3$-Phenoxy Propane-1,2-Diol

\subsection{Study of the sol-gel transition}

In order to detect the occurrence of gelation the elastic, $G^{\prime}$ and loss, $G^{\prime \prime}$, moduli are determined at several frequencies by Fourier transform mechanical spectroscopy (FTMS). ${ }^{38}$ FTMS enables the measurement of the complex moduli, $G^{\prime}(\omega)$ and $G^{\prime \prime}(\omega)$, at several frequencies simultaneously as the system structure evolves with time (the method is further described in the ESI). The gel point is revealed by the shape of $G^{\prime}$ and $G^{\prime \prime}$ variations as a function of $\omega$. According to the Winter and Chambon criterion ${ }^{39}$ (more information in the ESI), gelation is reached when $G^{\prime \prime}$ and $G^{\prime}$ are both proportional to $\omega^{n}$ with $n$ being the relaxation exponent.

Figure 3 shows the dependences of $G^{\prime}$ and $G^{\prime \prime}$, on the angular frequency, $\omega$, in the course of polymerization of $\mathrm{DGEBA}_{25} \mathrm{PGE}_{75}$ initiated by $4 \mathrm{CA}^{+}-\mathrm{BF}_{4}{ }^{-}$used at a concentration of 0.026 equiv. per epoxy function. The data are shifted along the horizontal axes by a factor $A$ in order to avoid overlapping. In the early stage of the reaction, $G^{\prime}$ is lower than $G^{\prime \prime}$ for the frequency range used in this study. As the reaction proceeds, $G^{\prime \prime}$ is approached and eventually crossed 
by $G^{\prime}$. This behavior is typical of the sol-gel transition. Following the above criterion, $t_{g e l}$ is estimated as the time at which the frequency dependence of $G^{\prime \prime}$ and $G^{\prime}$ are linear and parallel to each other in logarithmic axes. $n$ is taken as the slope of $G^{\prime}(\omega)$ and $G^{\prime \prime}(\omega)$ variations at $t=$ $t_{\text {gel }}$. The physical meaning of $n$ will be discussed later.

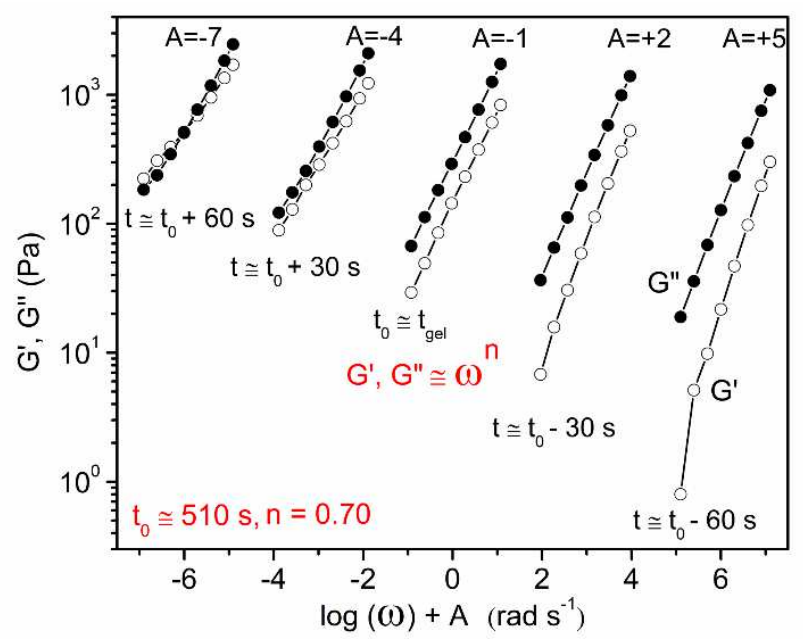

Figure 3: Angular frequency $(\omega)$ dependence of storage modulus $G^{\prime}$ (open symbols) and loss modulus, $G^{\prime \prime}$ (filled symbols) for the curing of $\mathrm{DGEBA}_{25} \mathrm{PGE}_{75}$ at $40{ }^{\circ} \mathrm{C}$ initiated by $4 \mathrm{CA}^{+}-$ $\mathrm{BF}_{4}{ }^{-}(0.026$ equiv. per epoxy function). The plots are represented for various times near the sol-gel transition. The parameter $t$ is the reaction time. The curves have been shifted by a factor $A$ to avoid overlapping.

Following the Winter and Chambon criterion, another way to determine the gel time is to plot the loss tangent, $\tan \delta$, against time, t. With $\tan \delta=G^{\prime \prime} / G^{\prime}$ and $G^{\prime \prime} \sim G^{\prime} \sim \omega^{n}$ for $t=t_{\text {gel }}$ then $\tan \delta$ is expected to be independent on $\omega$ at the gel point. Figure 4 illustrates the variation of $\tan \delta$ during cure as a function of time for the polymerization of $\mathrm{DGEBA}_{25} \mathrm{PGE}_{75}$. The different lines corresponding to the different frequencies intersect for $t=t_{g e l}$. By comparing this plot with the epoxy conversion profile as obtained by IR spectrometric measurements, it is possible to estimate the conversion at the gel point, $\alpha_{g e l}$. This is illustrated in the inset of Figure 4 for the case of $\mathrm{DGEBA}_{25} \mathrm{PGE}_{75}$ : in the plot representing the epoxy conversion, $\alpha$, as a function of time, $t$, the ordinate corresponding to $t=t_{\text {gel }}$ gives $\alpha=\alpha_{g e l}$. We find $t_{g e l}=510 \mathrm{~s}$, $n=0.70 \pm 0.01$ (error estimated according to a linear least square analysis) and $\alpha_{g e l}=47 \%$. 


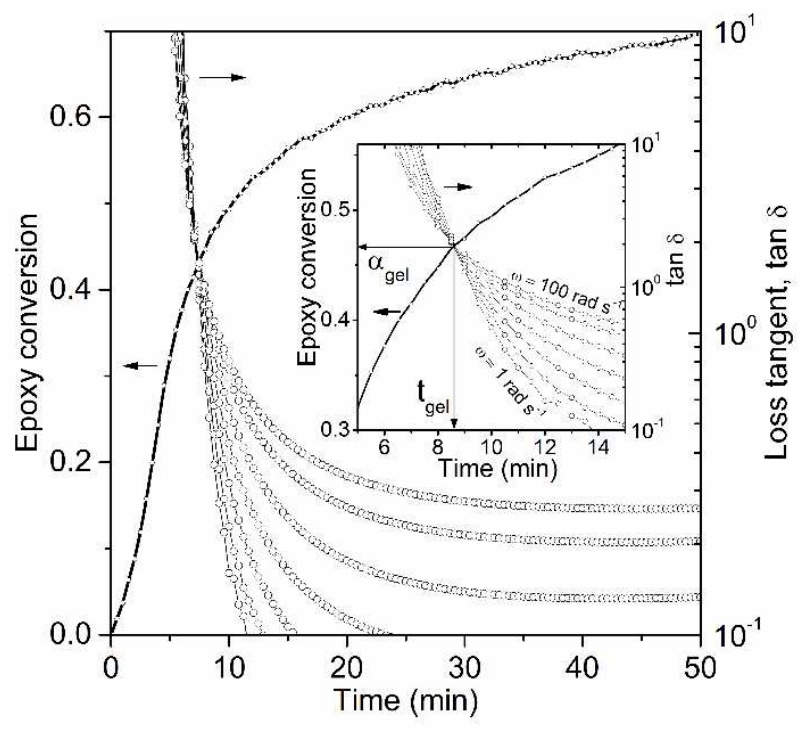

Figure 4: Time dependence of $\tan \delta$ at various angular frequencies (open circles) obtained by using the Fourier transform mechanical spectroscopy method (FTMS, $\omega=1,2,4,8,16,32$, 64, $128 \mathrm{rad} \mathrm{s}^{-1}$ ) and time dependence of the epoxy conversion (solid line) obtained by the decay of the IR absorbance at $914 \mathrm{~cm}^{-1}$ during the curing of $\mathrm{DGEBA}_{25} \mathrm{PGE}_{75}$ at $40{ }^{\circ} \mathrm{C}$ initiated by $4 \mathrm{CA}^{+}-\mathrm{BF}_{4}^{-}$(0.026 equiv. per epoxy function). The inset illustrates a magnification of the plots in the region close to the sol-gel transition.

The combination of rheometry data with the measurement of conversion enables the representation of the dynamic viscosity (taken as the real part of the complex viscosity) ${ }^{40,41}$ and the storage modulus as a function of $\varepsilon$, the relative distance to the gel point. For commodity we note $\varepsilon=\varepsilon_{\text {sol }}=\left(\alpha_{g e l}-\alpha\right) / \alpha$ in the pre-gel region and $\varepsilon=\varepsilon_{g e l}=\left(\alpha-\alpha_{g e l}\right) / \alpha_{g e l}$ in the post-gel region.

Figures 5a shows the time dependence of rheological properties during the curing reaction as a function of $\varepsilon$ for the polymerization of $\mathrm{DGEBA}_{25} \mathrm{PGE}_{75}$ at $40{ }^{\circ} \mathrm{C}$ and at the angular frequency $\omega=1 \mathrm{rad} \mathrm{s}^{-1}$. In the pre-gel region, curing is accompanied by a divergence of viscosity as $\varepsilon_{\text {sol }}$ approaches 0 . In the post-gel region, the increase of $\varepsilon_{g e l}$ results in a rapid buildup of the storage modulus, $G^{\prime}$. Figure $5 \mathrm{~b}$ represents the same data in log-log scale when considering a region restricted to the vicinity of the gel point $\left(0.03<\varepsilon_{\text {sol }}<2\right.$ for $\eta^{\prime}$ and $0.03<$ $\varepsilon_{g e l}<0.2$ for $G^{\prime}$ ). Clearly, both $\eta^{\prime}$ and $G^{\prime}$ exhibit a power law dependence on $\varepsilon, \eta^{\prime} \sim \varepsilon^{-k}$ and 
$G^{\prime} \sim \mathcal{E}^{z}$, as indicated by their linear dependency. The critical exponents $z$ and $k$ can be determined from a linear least square analysis. For $\mathrm{DGEBA}_{25} \mathrm{PGE}_{75}$, the example illustrated in Figure 5, we found $k=1.35 \pm 0.02$ and $z=2.65 \pm 0.08$. For each tested composition, the values of $t_{g e l}$, and $\alpha_{g e l}$ as well as those of $n, k$ and $z$, are reported in Table 1.
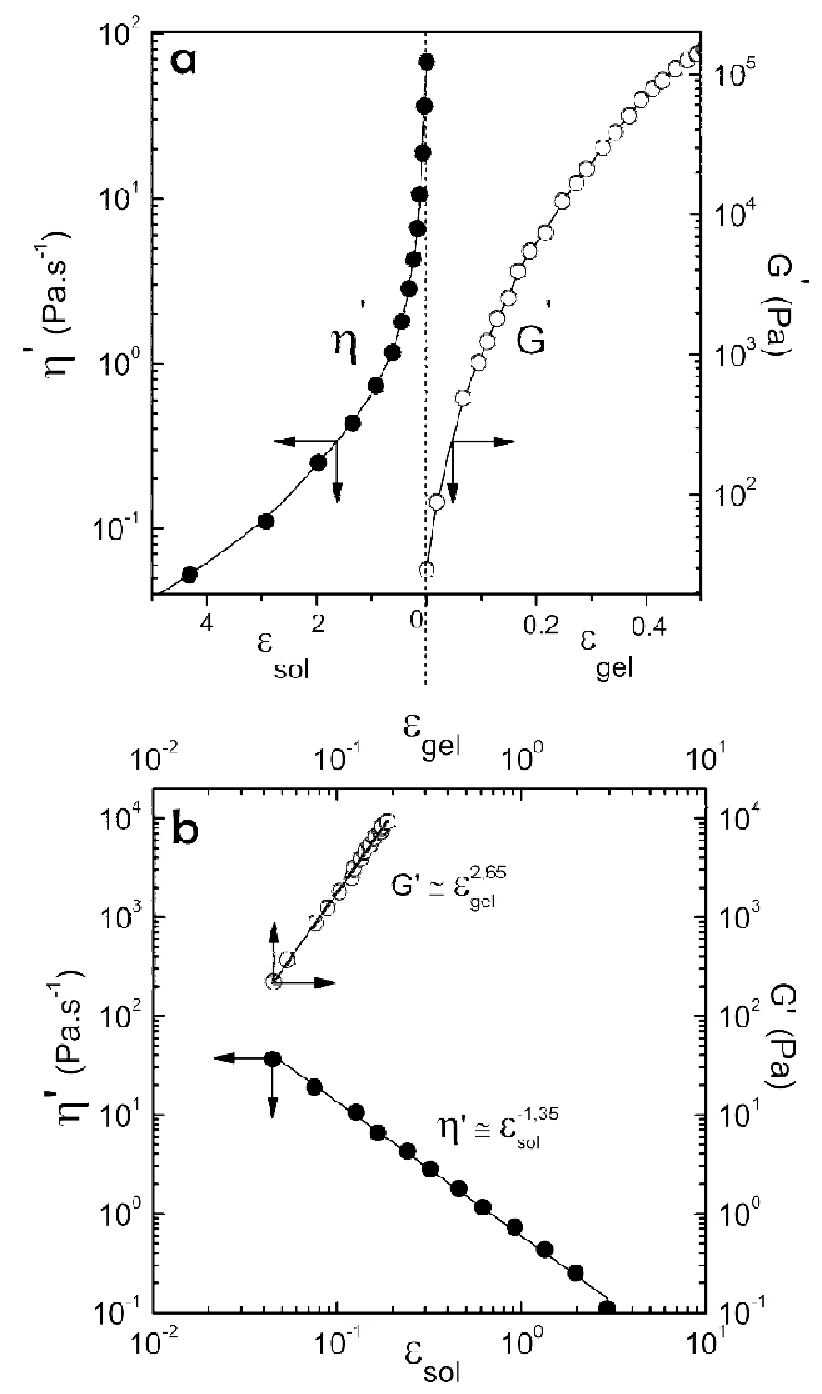

Figure 5: (a) Real part of the complex viscosity, $\eta^{\prime}$, as a function of $\varepsilon$ in the pregel region (filled symbols, $\varepsilon=\varepsilon_{\text {sol }}$ ) and storage modulus, $G^{\prime}$, as a function of $\varepsilon$ in the postgel region (open symbols, $\varepsilon=\varepsilon_{\text {gel }}$ ) for the curing of DGEBA ${ }_{25} \mathrm{PGE}_{75}$ at $40{ }^{\circ} \mathrm{C}$ initiated by $4 \mathrm{CA}^{+}-\mathrm{BF}_{4}{ }^{-}$ (0.026 equiv. per epoxy function). The data were obtained by FTMS $(\omega=1,2,4,8,16,32$, 64, $128 \mathrm{rad} \mathrm{s}^{-1}$ ) and the plot represents $\eta^{\prime}$ and $G^{\prime}$ for $\omega=1 \mathrm{rad} \mathrm{s}^{-1}$. (b) Linear least square analysis of the real part of the complex viscosity, $\eta^{\prime}$, as a function of $\varepsilon_{\text {sol }}$ (filled symbols) and storage modulus, $G^{\prime}$, as a function of $\varepsilon_{\text {gel }}$ (open symbols), in the vicinity of the gel point for the same system using the same method. The plot represents $\eta^{\prime}$ and $G^{\prime}$ for $\omega=1 \mathrm{rad} \mathrm{s}^{-1} . \eta^{\prime}$ and $G^{\prime}$ exhibit a power law dependence allowing the determination of the critical exponent $k$ and $z$ where $\eta^{\prime}=\varepsilon_{\text {sol }}{ }^{k}$ and $G^{\prime}=\varepsilon_{\text {gel }}$. 
Table 1 : Gel time, gel conversion, critical exponents and glass transition temperature for the curing of $\mathrm{DGEBA}_{x} \mathrm{PGE}_{100-x} \mathrm{Y}$ at $40{ }^{\circ} \mathrm{C}$ initiated by $4 \mathrm{CA}^{+}-\mathrm{BF}_{4}{ }^{-}(0.026$ equiv. per epoxy function). The gel time $\left(t_{g e l}\right)$, and the critical exponent $n$ are obtained by FTMS $(\omega=1,2,4,8$, $\left.16,32,64,128 \mathrm{rad} \mathrm{s}^{-1}\right)$. The critical conversion $\left(\alpha_{g e l}\right)$ and the critical exponents $k$ and $z$ are obtained by combination of FTMS and IR data (see Figure 4 and 5). The glass transition temperatures obtained by dynamic scanning calorimetry (DSC) for $\mathrm{DGEBA}_{x} \mathrm{PGE}_{100-x} \mathrm{Y}$ cured at $40{ }^{\circ} \mathrm{C}$ for 10 hours and postcured at $120{ }^{\circ} \mathrm{C}$ for 2 hours. (a) For these samples $\left(\mathrm{DGEBA}_{100} \mathrm{PGE}_{0} \mathrm{Y}\right)$ vitrification interferes with the sol-gel transition making FTMS unreliable; gelation was detected by the crossover of $G^{\prime}$ and $G^{\prime \prime}$ traces at $1 \mathrm{rad} \mathrm{s}^{-1}$ (shear strain $=1 \%)$. (b) For these samples $\left(\mathrm{DGEBA}_{100} \mathrm{PGE}_{0} \mathrm{Y}\right)$, the resulting network is very tight and there is no clear $T_{g}$ transition on the DSC traces.

\begin{tabular}{|c|c|c|c|c|c|c|}
\hline Materials & $t_{g e l}(\min )$ & $\alpha_{g e l}(\%)$ & $n$ & $k$ & $z$ & $T_{g}\left({ }^{\circ} \mathrm{C}\right)$ \\
\hline DGEBA $_{15} \mathrm{PGE}_{85}$ & 63 & 73 & $0.72 \pm 0.01$ & $1.38 \pm 0.03$ & $2.60 \pm 0.02$ & 10 \\
\hline DGEBA $_{25} \mathrm{PGE}_{75}$ & 8.5 & 47 & $0.70 \pm 0.01$ & $1.35 \pm 0.02$ & $2.65 \pm 0.08$ & 18 \\
\hline DGEBA $_{35} \mathrm{PGE}_{65}$ & 6.5 & 32 & $0.70 \pm 0.02$ & $0.90 \pm 0.02$ & $2.2 \pm 0.09$ & 31 \\
\hline DGEBA $_{100}$ PGE $_{0}$ & $2^{c}$ & $7^{\mathrm{c}}$ & $\mathrm{NA}^{a}$ & $\mathrm{NA}^{a}$ & $\mathrm{NA}^{a}$ & $\mathrm{NA}^{b}$ \\
\hline $\mathrm{DGEBA}_{25} \mathrm{PGE}_{75} \mathrm{PEO}$ & 130 & 77 & $0.82 \pm 0.04$ & $1.45 \pm 0.06$ & $2.57 \pm 0.04$ & 6 \\
\hline DGEBA $_{35} \mathrm{PGE}_{65} \mathrm{PEO}$ & 99 & 68 & $0.83 \pm 0.04$ & $1.36 \pm 0.04$ & $2.69 \pm 0.07$ & 16 \\
\hline DGEBA $_{45} \mathrm{PGE}_{55} \mathrm{PEO}$ & 78 & 46 & $0.98 \pm 0.09$ & $1.47 \pm 0.02$ & $2.62 \pm 0.09$ & 22 \\
\hline DGEBA $_{100} \mathrm{PGE}_{0} \mathrm{PEO}$ & $73^{\mathrm{c}}$ & $43^{\mathrm{c}}$ & $\mathrm{NA}^{a}$ & $\mathrm{NA}^{a}$ & $\mathrm{NA}^{a}$ & $\mathrm{NA}^{b}$ \\
\hline $\mathrm{DGEBA}_{35} \mathrm{PGE}_{65} \mathrm{MeOPEO}$ & 94 & 65 & $0.75 \pm 0.01$ & $1.39 \pm 0.07$ & $2.44 \pm 0.02$ & 10 \\
\hline DGEBA $_{100} \mathrm{PGE}_{0} \mathrm{MeOPEO}$ & $53^{\mathrm{c}}$ & $30^{\mathrm{c}}$ & $\mathrm{NA}^{a}$ & $\mathrm{NA}^{a}$ & $\mathrm{NA}^{a}$ & $\mathrm{NA}^{b}$ \\
\hline $\mathrm{DGEBA}_{35} \mathrm{PGE}_{65} \mathrm{PPO}$ & 32 & 61 & $0.74 \pm 0.01$ & $1.64 \pm 0.05$ & $2.68 \pm 0.01$ & 12 \\
\hline DGEBA $_{100} \mathrm{PGE}_{0} \mathrm{PPO}$ & $29^{\mathrm{c}}$ & $46^{\mathrm{c}}$ & $\mathrm{NA}^{a}$ & $\mathrm{NA}^{a}$ & $\mathrm{NA}^{a}$ & $\mathrm{NA}^{b}$ \\
\hline $\mathrm{DGEBA}_{35} \mathrm{PGE}_{65} \mathrm{PPD}$ & 45 & 57 & $0.70 \pm 0.01$ & $1.34 \pm 0.07$ & $2.44 \pm 0.02$ & 26 \\
\hline
\end{tabular}

\section{$\underline{\text { Gel times and Critical conversion }}$}

As shown in Table 1, the increase of PGE content induces a considerable increase of $t_{g e l}$ and $\alpha_{g e l}$ for all DGEBA $\mathrm{PGE}_{100-x}$ and $\mathrm{DGEBA}_{x} \mathrm{PGE}_{100-x} \mathrm{Y}$ compositions. This was expected as a decrease of $x$ results in a decrease of the average functionnality per monomer unit and consequently of the occurrence of cross-linkages formation between the chains of the growing network. Thus, varying $x$ provides an interesting lever to control the temporal programming of the polymerization as well as the structure of the gel at the sol-gel transition. For instance, $\alpha_{g e l}$ increases from $47 \%$ to $73 \%$ when $x$ decreases from $25 \%\left(\mathrm{DGEBA}_{25} \mathrm{PGE}_{75}\right)$ to $15 \%$ $\left(\mathrm{DGEBA}_{15} \mathrm{PGE}_{85}\right)$. It is interesting to note that these values correlate well with those reported by Matsumuto et al. for the cationic copolymerization of 1,2 epoxycyclohexane $(\mathrm{ECH})$ with bis[3,4-epoxycyclohexylmethyl] adipate (BECHMA). ${ }^{37}$ They found $\alpha_{g e l}$ values of $69 \%$ and $49 \%$ for $\mathrm{BECHMA}_{10} \mathrm{ECH}_{90}$ and $\mathrm{BECHMA}_{20} \mathrm{ECH}_{80}$, respectively. 
Beyond the classical effect of $x$ on the average functionality per monomer unit, $t_{g e l}$ and $\alpha_{g e l}$ are also strongly impacted by the additive Y. For a given value of $x$ in Table $1, \alpha_{g e l}$ measured for $\mathrm{DGEBA}_{x} \mathrm{PGE}_{100-x} \mathrm{Y}$ (where $\mathrm{Y}$ is a protic additive) is always at least $20 \%$ higher than in the case of the neat system, DGEBA $\mathrm{PGE}_{100-x}$. This is illustrative of the transfers promoted by the AM mechanism in the presence of hydroxyl groups as mentioned earlier in the introduction. In this paper, the precise measurement of $\alpha_{g e l}$ provides an interesting way to rationalize these observations. Indeed, by considering the mathematical methods developed for the modelisation of the network formation for the ideal chainwise copolymerization of bifunctional and $f$-functional monomers, ${ }^{5} \alpha_{g e l}$ can be estimated according to Eq. (1):

$$
\alpha_{\text {gel }}=(1-q) /\left[(f-2) a_{f}(q+\xi / 2)\right\rfloor \quad \text { Eq. (1) }
$$

where $a_{f}$ is the molar fraction of the $f$-functional monomers (in this study, the f-functional monomer is DGEBA and $f=4) q$, is the probability that the active end of the propagating chain adds another monomer to the growing chain and $\xi$, the probability that the termination of active species takes place through a mechanism resulting in longer chains than the active chains before termination. In this model, $\alpha_{g e l}$ depends not only on $x$, through $a_{f}$, but also on the characteristics of the polymerization reaction, through $q$ and $\xi$. Using the $\alpha_{g e l}$ values reported in Table 1, $q$ was calculated in the two limit cases $\xi=1$ (terminations with increase of chain size) and $\xi=0$ (terminations without increase of chain size). Calculation is reported in the ESI. The results should be considered with care because the ideal model used to obtain Eq. (1) does not take into account cyclisation, an important side reaction in the case of cationic ROP. ${ }^{37}$ However, it is evident that the $q$ value would be hardly superior to 0.9 whatever the $x$ values or the $\mathrm{Y}$ additives one considers. As a comparison, the free-radical polymerizations of vinyl monomers typically afford $q$ values very close to unity. ${ }^{5}$ Here, the 
lower values of $q$ calculated for the cationic copolymerization of DGEBA and PGE are illustrative of the many terminations and transfers occurring during this polymerization mode which can in no way be assimilated to a living cationic polymerization. A practical consequence is that gelation in these systems takes place at rather high conversions and the networks thereby formed are expected to carry an important number of defects, independently from the presence of an additive $\mathrm{Y}$ or not. For a given value of $x$, when a protic additive $\mathrm{Y}$ is added to the system, the value of $q$ calculated for $\mathrm{DGEBA}_{x} \mathrm{PGE}_{100-x} \mathrm{Y}$ is even lower than in the case of the neat system, DGEBA $\mathrm{PGE}_{100-x}$, illustrating an increase of the number of termination and transfer reactions as a consequence of the promotion of the AM mechanism. By taking a deeper look at the values of $t_{\mathrm{gel}}$, which cannot be predicted by the model used to derive Eq. (1), it appears that it is also strongly impacted by the chemical structure of the additive Y. As an example, for $x=35 \mathrm{wt} \%$, $t_{g e l}$ is increased from $45 \mathrm{~min}$, for $\mathrm{DGEBA}_{x} \mathrm{PGE}_{100-x} \mathrm{PPD}$, to 99 min for $\mathrm{DGEBA}_{x} \mathrm{PGE}_{100-x}$ PEO. This significant lengthening of the pot life was previously rationalized by considering the ability of PEO to complex the anilinium cation used as the initiator of the polymerization. ${ }^{6,29,31}$ The structure of the complex is illustrated in Scheme 2a. Under this protected form, the releasing rate of the Brønsted acid $\mathrm{HBF}_{4}$ is considerably decreased and the polymerization rate is decreased as well. Thus, HO-PEO-OH can affect the cationic ROP of epoxy monomers through 2 different ways: the promotion of transfer reactions via its $-\mathrm{OH}$ end groups and the complexation of the ammonium moiety of the initiator via its polyether backbone. 


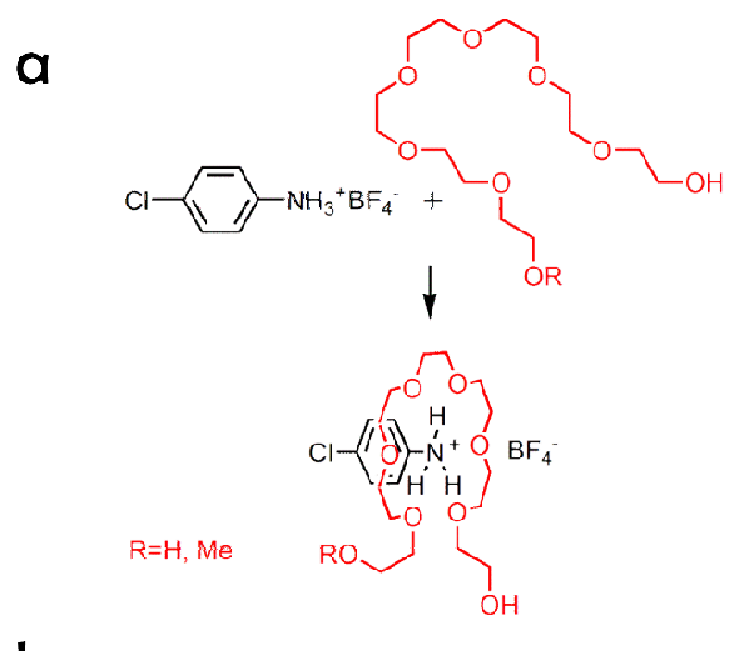

b

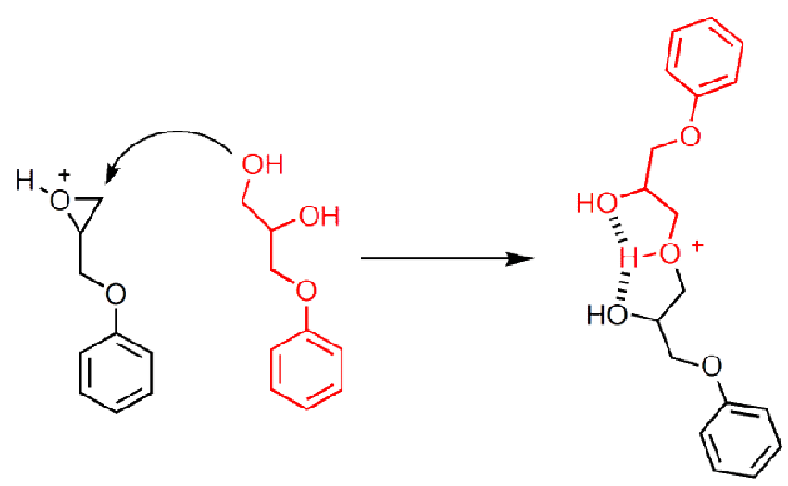

Scheme 2: (a) Stabilization of the initiator $4 \mathrm{CA}^{+}-\mathrm{BF}_{4}^{-}$by complexation of the ammonium moiety through the formation of three hydrogen bonds with the polyether backbone of the poly(ethylene oxide) additive, PEO (b) Intramolecular stabilization of the linear oxonium ion resulting from the attack of an activated monomer by the vicinal diol, PPD. The oxonium ion is possibly stabilized by formation of two hydrogen bonds between the proton of the cationic center and the two hydroxyl groups in $\beta$-position.

By studying the influence of the additive, $\mathrm{Y}$, for $\mathrm{DGEBA}_{35} \mathrm{PGE}_{65} \mathrm{Y}$, it is possible to evaluate the respective role played by the hydroxyl groups and the polyoxide chains of HO-PEO-OH. The chart of Figure 6 represents the $\left(\alpha_{g e l}, t_{g e l}\right)$ coordinates associated to the tested additives, all used at 0.061 equiv. per epoxy function. Several regions can be distinguished. Reactive mixtures containing $\mathrm{HO}-\mathrm{PEO}-\mathrm{OH}$ and $\mathrm{MeO}-\mathrm{PEO}-\mathrm{OH}$ are both located in the right upper corner. For these compounds, the protic hydroxyle functions and complexing poly(ethyleneoxide) skeleton both concur to produce large $\alpha_{g e l}$ and $t_{g e l}$ values as already observed in the homopolymerization of DGEBA (grey diamonds in Figure 6). ${ }^{29}$ Evidently, the copolymerization with the comonomer, PGE, permits to obtain even larger values of $\alpha_{g e l}$ and, 
$t_{\text {gel }}$. It is worth noting that $\mathrm{HO}-\mathrm{PEO}-\mathrm{OH}$ and $\mathrm{MeO}-\mathrm{PEO}-\mathrm{OH}$ have very similar $\left(\alpha_{g e l}, t_{g e l}\right)$ coordinates proving that the number of hydroxyl function of the additive have little influence on the gelation.

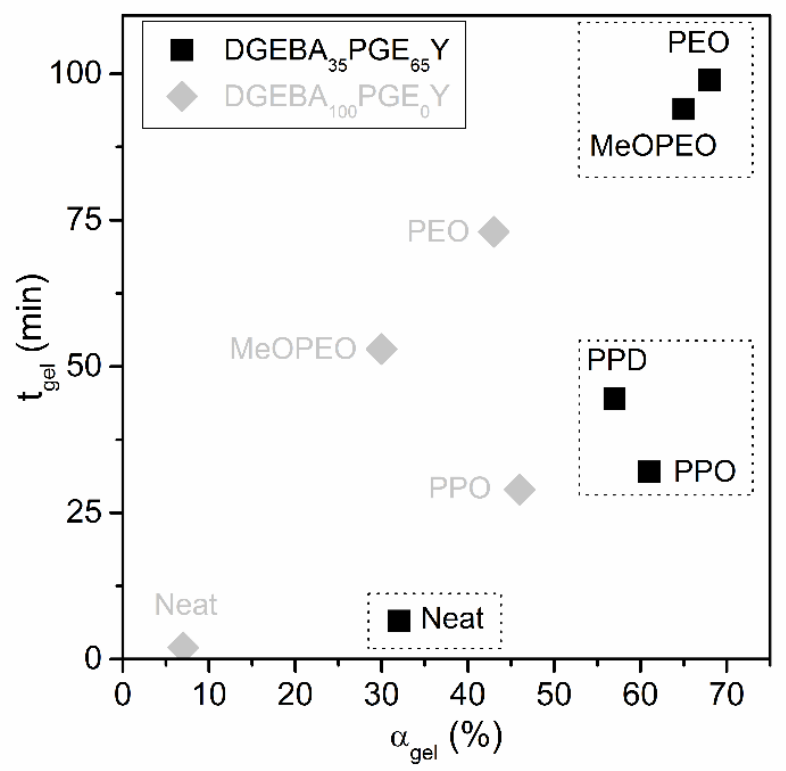

Figure 6: $\left(\alpha_{\text {gel }}, t_{\text {gel }}\right)$ coordinates for the curing of $\mathrm{DGEBA}_{35} \mathrm{PGE}_{65} \mathrm{Y}$ (black squares) and DGEBA $_{100} \mathrm{PGE}_{0} \mathrm{Y}$ (grey diamonds) at $40{ }^{\circ} \mathrm{C}$ initiated by $4 \mathrm{CA}^{+}-\mathrm{BF}_{4}{ }^{-}(0.026$ equiv. per epoxy function). The data points are labeled with $\mathrm{Y}$. Y $=$ NA (neat), PPD, PPO, MeO-PEO-OH and HO-PEO-OH. For DGEBA ${ }_{35} \mathrm{PGE}_{65} \mathrm{Y}$ the gel time $\left(t_{\text {gel }}\right)$ was obtained by using the WinterChambon criterion with the data obtained by FTMS $\left(\omega=1,2,4,8,16,32,64,128 \mathrm{rad} \mathrm{s}^{-1}\right)$ and the critical conversion $\left(\alpha_{g e l}\right)$ was obtained by using the value of $t_{g e l}$ and the evolution of the epoxy conversion as a function of time (see Figure 4). For $\operatorname{DGEBA}_{100} \mathrm{PGE}_{0}(\mathrm{Y}=\mathrm{NA})$, the sol-gel transition was monitored at a frequency of $1 \mathrm{rad} \mathrm{s}^{-1}$ and $t_{\text {gel }}$ was determined as the point of crossover of the storage modulus $G^{\prime}$ and the loss modulus $G^{\prime \prime}$.

Formulations containing HO-PPO-OH and PPD are located in a different region of the chart.

Like HO-PEO-OH and MeO-PEO-OH, their $\alpha_{g e l}$ coordinate is much higher than that of the neat system suggesting that their hydroxyl groups are effectively initiating the AM mechanism that promotes transfers.

However, both HO-PPO-OH and PPD have shorter $t_{\text {gel }}$ than HO-PEO-OH and MeO-PEO-OH. The lack of poly(ethyleneoxide) backbone for both HO-PPO-OH and PPD supports well the idea that the decrease of $t_{g e l}$ with these two additives is correlated to their inability to complex the anilium cation $\left(4 \mathrm{CA}^{+}-\mathrm{BF}_{4}^{-}\right)$used for the polymerization initiation.

In the case of HO-PPO-OH, the poly(propyleneoxide) backbone of the additive is too 
hindered to effectively complex $4 \mathrm{CA}^{+}-\mathrm{BF}_{4}^{-}$. This was previously reported in the literature for the cationic homopolymerization of DGEBA. ${ }^{29}$ PPD is lacking a polyoxylated backbone making the complexation of $4 \mathrm{CA}^{+}-\mathrm{BF}_{4}{ }^{-}$impossible from the view point of stereochemistry. However, it is noteworthy that $t_{g e l}$ with PPD is 1.5 times longer than in the case of HO-PPO$\mathrm{OH}$. This observation may be ascribed to the 1,2 diol moiety of PPD. It has been previously reported that protons can be intramolecularly stabilized within the linear oxonium resulting from the attack of 1,2 diol on an activated monomer (Scheme $2 b) .{ }^{42,43}$ This may explain why PPD results in a gel time that is intermediate between the values observed with the strongly chelating polyethers (PEO, monomethylated or not) and the non-chelating polyether (PPO). Overall, these results are in good accordance with the effect of protic and polyether additives reported in the case of DGEBA homopolymerization (grey diamonds in Figure 6). ${ }^{29}$ They demonstrate that the promotion of the AM mechanism and the supramolecular complexation of active cationic species, together with copolymerization with a monoepoxide, are valuable tools to control the gelation of epoxy monomers when di-glycidyl ethers are copolymerized with mono-glycidyl ethers.

\section{$\underline{\text { Critical exponents }}$}

The power law dependences of $\eta^{\prime}$ and $G^{\prime}$ in the vicinity of the gel point are in accordance with the theoretical studies of the sol-gel transition where the gelation process obeys the percolation laws (more information in the ESI). ${ }^{44,45}$ In particular, in the percolation model based on the Rouse description, ${ }^{46}$ the theory predicts the values of the critical exponents $n, k$ and $z$ at the gel point:

$$
n=2 / 3=0.67, k=4 / 3=1.33 \text { and } z=8 / 3=2.67 \text {. }
$$

Values in very close agreement with these predictions were reported for epoxy networks 
formed by step-growth polymerization..$^{40,41,46-48}$ For the polyaddition of diglycidyl ether of 1,4-butanediol and 4,9-dioxa-1,12-dodecanediamine, Eloundou et al. found: ${ }^{41}$

$$
n=0.70 \pm 0.02, k=1.44 \pm 0.03, z=2.65 \pm 0.02 \text {. }
$$

Similar values were also reported for the gelation of epoxy monomers polymerized by cationic ring opening polymerization. Mortimer et al. studied the critical exponents for the cationic ROP of a trifunctional epoxides and found power law dependences with critical exponents in close agreement with the percolation theory in the Rouse limit. ${ }^{49}$

$$
n=0.64 \pm 0.03, k=1.33 \pm 0.03, z=2.26 \text {. }
$$

For DGEBA $\mathrm{PGE}_{100-x}$ (neat system), the critical exponents are also in very close agreement with these predictions. For instance, when $x=25 \mathrm{wt} \%$ :

$$
n=0.70 \pm 0.01, k=1.35 \pm 0.02, z=2.65 \pm 0.08 .
$$

Thus, the values found for DGEBA ${ }_{25} \mathrm{PGE}_{75}$ correlates well with the theory and with the measures made by others for both step- and chain-growth polymerizations.

When considering the DGEBA $\mathrm{PGE}_{100-x}$ series, it appears that $n$ is almost unaffected by $x$ (see Table 1). On the contrary, $k$ and $z$ values decrease as $x$ is increased. It is noteworthy that $x$ is correlated to the $T_{g}$ of the fully crosslinked network (values of $T_{g}$ as measured by DSC are reported in Table 1). Several authors have reported discrepancies in the critical exponents' values due to interferences between gelation and vitrification. ${ }^{40,49}$ For instance, Eloundou et al. studied the temperature dependence of the critical exponents for a high- $T_{g}$ epoxy amine system. ${ }^{40}$ As the curing temperature is decreased close to or below the glass transition temperature of the growing network, they observed a decrease of both $k$ and $z$ below the values predicted by the percolation model. In our study, increasing $x$ results in an increase of 
the $T_{g}$ of the epoxy network close to the curing temperature $\left(40{ }^{\circ} \mathrm{C}\right)$ with the same influence on $k$ and $z$.

When considering the influence of the additive $\mathrm{Y}$, it appears that the $k$ and $z$ exponents are mostly unaffected. On the other hand, $n$ values are substantially higher for DGEBA $_{x} \mathrm{PGE}_{100-x} \mathrm{PEO}$ as compared to the other additives. Figure 7 represents the evolution of $n$ as a function of $100-x$ (PGE wt $\%)$ for the different compositions, DGEBA $_{x}$ PGE $_{100-x} \mathrm{Y}$, used in this study.

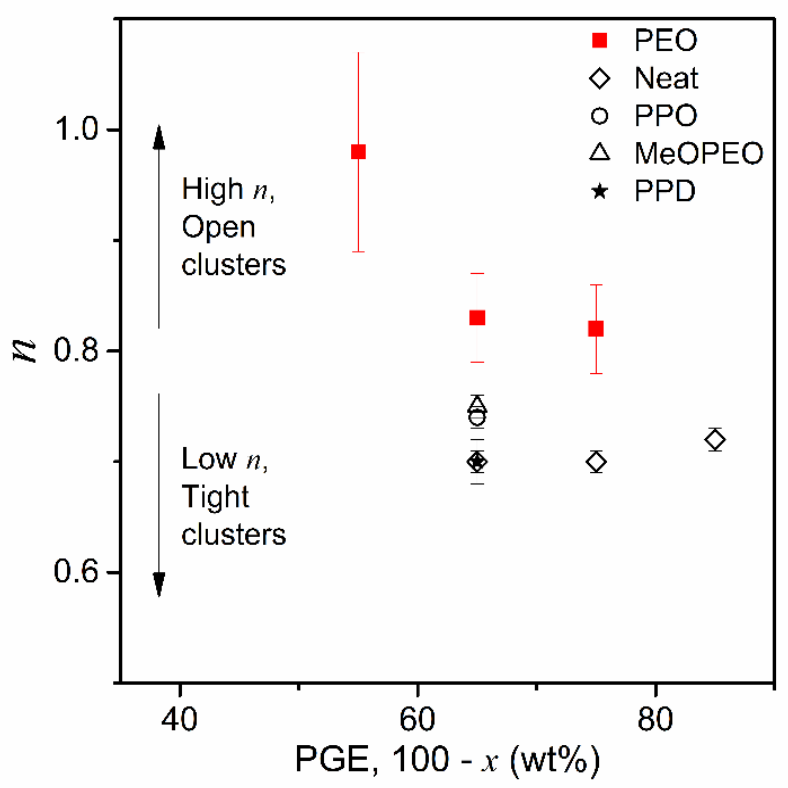

Figure 7: Evolution of the critical exponent, $n$, as a function of $100-x$ (PGE wt $\%$ ) for the gelation of $\mathrm{DGEBA}_{x} \mathrm{PGE}_{100-x} \mathrm{Y}$, cured at $40{ }^{\circ} \mathrm{C}$ with $4 \mathrm{CA}^{+}-\mathrm{BF}_{4}{ }^{-}(0.026$ equiv. per epoxy function). The values of $n$ are determined by using the Winter-Chambon criterion with the data obtained by FTMS $\left(\omega=1,2,4,8,16,32,64,128 \mathrm{rad} \mathrm{s}^{-1}\right)$.

Interestingly, in the percolation model, the critical exponent $n$ may be related to the fractal dimension of the molecular clusters at the gel point, $d_{f}$. This exponent relates the mass $M$ of an object to its spatial size $R$ according to Eq. (2): ${ }^{50}$

$$
R^{d f} \sim M \quad \text { Eq. (2) }
$$


Muthukumar developed a model in which the fractal dimension of the molecular clusters, $d_{f}$, is related to the critical exponent $n$, via Eq. (3). ${ }^{50}$

$$
n=\frac{d\left(d+2-2 d_{f}\right)}{2\left(d+2-d_{f}\right)}
$$

where $d$ is the space dimension (here $d=3$ ). According to this theory, a looser (resp. tighter) structure will lead to a lower (resp. higher) value of $d_{f}$ and a higher (resp. lower) value of $n$. Thus, by using this formula, it is possible to estimate the influence of the chemical composition of the system on the molecular dimension of the network during the sol-gel transition.

In particular, Muthukumar's equation gives $d_{f} \sim 1.7$ for $\mathrm{DGEBA}_{x} \mathrm{PGE}_{100-x}$ and $d_{f} \sim 1.5$ for DGEBA $_{x} \mathrm{PGE}_{100-x} \mathrm{PEO}$. Thus, according to this theory, the structure of the molecular clusters of DGEBA $_{x} \mathrm{PGE}_{100-x} \mathrm{PEO}$ at the sol-gel transition is looser than the structure of their counterparts in DGEBA $\mathrm{PGE}_{100-x}$. This may be explained by two reasons: (i), the very flexible poly(ether) backbone of HO-PEO-OH may be responsible for an expansion of the molecular clusters as compared to the neat system. This would result in a more "open" structure and thus in a decrease of the fractal dimension, or (ii), the transfers associated with the AM mechanism (promoted by the hydroxyl groups of HO-PEO-OH) could result in less densely filled clusters with the same consequences on $d_{f}$.

For DGEBA ${ }_{35} \mathrm{PGE}_{65} \mathrm{PPD}, n$ is unchanged as compared to the neat system DGEBA ${ }_{35} \mathrm{PGE}_{65}$, despite the initiation of the AM mechanism confirmed by a high conversion at the gel point, $\alpha_{g e l}=57 \%$. This suggests that the fractal structure of the molecular clusters is not affected by the transfers observed during the AM mechanism. Thus, the increase of $n$ with DGEBA $_{x} \mathrm{PGE}_{100-x} \mathrm{PEO}$ is probably not correlated with the effect of the hydroxyl moieties of HO-PEO-OH.

When using HO-PPO-OH and MeO-PEO-OH, two other polyoxylated additives with polyether backbones of similar length as HO-PEO-OH, a slight increase of $n$ is also observed 
but in a lesser extent than HO-PEO-OH. This supports the idea that the fractal dimension of the molecular cluster is mostly impacted by the structure of the additive: when an additive with a chemical structure similar to the monomers is used (e.g. PPD), $n$ is unchanged. However, all the polyoxylated additives (e.g. PEO, PPO, MeOPEO) result in an increase of $n$ with an amplitude that seems to be dependent on the flexibility of their polyether backbones and their ability to be inserted in the growing network.

Indeed, the moderate increase of $n$ observed in the case of HO-PPO-OH and MeO-PEO-OH may be ascribed to their reduced capacity to expand the molecular clusters. For instance, the poly(propyleneoxide) backbone of $\mathrm{HO}-\mathrm{PPO}-\mathrm{OH}$ is bulkier and less flexible than the poly(ethyleneoxide) backbone of HO-PEO-OH. MeO-PEO-OH is a mono-functional alcohol that is not inserted in elastically active chains when reacting with the oxiranium cation involved in the polymerization propagation.

In the end, our results demonstrate the steadiness of the critical exponent, $n$, whether the AM mechanism is initiated or not. They also suggest that the fractal structure of the growing network is mostly impacted by the chemical structure of the additives used to control the solgel transition.

One possible explanation to these observations can be formulated by considering the mechanism of the network build-up. Indeed, in their study regarding the cationic copolymerization of 1,2 epoxycyclohexane (ECH) as a monoepoxide and bis[3,4epoxycyclohexylmethyl] adipate (BECHMA) as a diepoxide crosslinker, Matsumoto et al. demonstrate that intramolecular and intermolecular reactions result in the formation of highly branched network polymer precursors (NPPs), whose structure is core-shell type dendritic. They possess a number of freely mobile dangling chains as a shell part. It is the intermolecular reactions between the dangling chains of NPPs that result in the formation of the macroscopic gel. It is possible that the initiation of the AM mechanism primarily impacts 
the inner structure of the core-shell type NPPs with very little influence on the molecular dynamics of the larger clusters resulting from their aggregation.Knowing that the critical exponent, $n$, is associated to the relaxation of the molecular object formed during the sol-gel transition, i.e. the larger clusters, the value of $n$ might not reflect the influence of the propagation mechanism (ACE or AM) on the structure of the growing network in the early stage of the reaction (i.e. the core of the NPPs).

\subsection{Structure-property relationship of the cured network}

\section{$\underline{\text { Swelling }}$}

We previously introduced, $M_{X}$, the total sample weight that contains one mole of elastically effective network chains. The rigorous definition of the crosslink density of a thermosetting material is "the number of moles of elastically effective network chains per volume of sample". ${ }^{7}$ It is usually noted $v_{e}$. According to this definition, $M_{X}$ is related to $v_{e}$ via Eq. (4):

$$
M_{X}=\frac{\rho}{v_{e}} \quad \text { Eq. (4) }
$$

Where $\rho$ is the density of the material.

$M_{X}$ is usually preferred to $v_{e}$ because it can be calculated in the case of an ideal network even if the density of the polymer is unknown. The calculated estimations of $M_{X}$, noted $M_{X, c}$, corresponds to the molecular weight of an elastically effective network chain assuming that the network is free of any defects (i.e. ideal). With this in mind, the comparison between an experimental estimation of $M_{X}$ and $M_{X, c}$ is a good approach to probe the extent of "non-ideal" phenomena in the network structure, including loops (resulting from cyclization), dangling chains (unreacted on one of their ends), and sol chains (unreacted on either ends and thus unattached to the network).

The values of $M_{X, c}$ for the compositions tested in this work are reported in Table 2 (more information regarding the calculation method in the ESI) and the equilibrium swelling method 
was used to measure an experimental estimation of $M_{X}, M_{X, s}$. The swelling experiments were performed in pyridine for all the samples. Indeed, the calculated values of the solubility parameters, $\delta$, of $\mathrm{DGEBA}_{x} \mathrm{PGE}_{100-x} \mathrm{Y}$ are almost independent of $x$ and $\mathrm{Y}(\delta(x, \mathrm{Y}) \in[22.1-$ 22.3] $\mathrm{MPa}^{1 / 2}$, calculation reported in ESI) and are very close from the solubility parameter of pyridine $\left(\delta_{\text {pyridine }}=21.9 \mathrm{MPa}^{1 / 2}\right) \cdot{ }^{51}$ This was experimentally confirmed by a rapid screening of three different solvents with increasing solubility parameters: toluene $\left(\delta_{\text {toluene }}=18.2\right.$ $\left.\mathrm{MPa}^{1 / 2}\right),{ }^{51}$ dichloromethane $\left(\delta_{\text {dichloromethane }}=19 \mathrm{MPa}^{1 / 2}\right)^{51}$ and pyridine $\left(\delta_{\text {pyridine }}=21.9\right.$ $\left.\mathrm{MPa}^{1 / 2}\right) .{ }^{51}$ For all $\mathrm{DGEBA}_{x} \mathrm{PGE}_{100-x} \mathrm{Y}$ samples, pyridine gave the largest swelling ratio (results are reported in the ESI).

The swelling ratio (= volume of swollen sample/volume of dry sample) was determined by measuring the linear swelling ratio of circular samples. The variation of the sample diameter is accurately measured and the swelling ratio is given by $\lambda=D / D_{0}$ where $D$ is the diameter of the swollen sample (after 2 weeks of immersion) and $D_{0}$ is the diameter of the unswollen network (See ESI, Figure S5). The polymer volume fraction, $v_{p}$, in the equilibrium swollen network is then given by $v_{p}=1 / \lambda^{3}$, and the crosslink density is calculated by injecting $v_{p}$ in the Flory-Rehner equation: ${ }^{52-55}$

$$
M_{X, s}=\frac{V_{s} \rho_{p}\left(\frac{v_{p}}{2}-v_{c}^{\frac{2}{3}} v_{p}^{\frac{1}{3}}\right)}{\ln \left(1-v_{p}\right)+\chi v_{p}^{2}+v_{p}} \text { Eq. (5) }
$$

Where $M_{X, s}$ is the total sample weight that contains one mole of elastically effective network chains obtained via the equilibrium swelling method, $\chi$ is the polymer-solvent interaction parameter, $v_{c}$ is the polymer volume fraction in the network obtained after the curing reaction and that is partially swollen by the residual soluble fraction, ${ }^{56} \rho_{p}$ is the density of the polymer network and $V_{S}$ is the molar volume of the solvent. $v_{c}$ is introduced to take into account the presence of the soluble fraction inside the cured network. The measurement of the soluble fraction, $w_{\mathrm{s}}$, is discussed below. Details regarding the estimation of $v_{c}, \chi$ and $\rho_{p}$ are provided 
in the ESI.

The values of $\lambda, v_{p}$ and $M_{X, s}$ for all $\mathrm{DGEBA}_{x} \mathrm{PGE}_{100-x} \mathrm{Y}$ compositions are reported in Table 2. It is worth noting that none of the networks is soluble in pyridine. This supports well the idea that all the samples are effectively cross-linked and can be considered as true thermosetting materials. As expected, the equilibrium dimension and $M_{X, s}$ are found to be strongly dependent on the initial composition of the curing mixture.

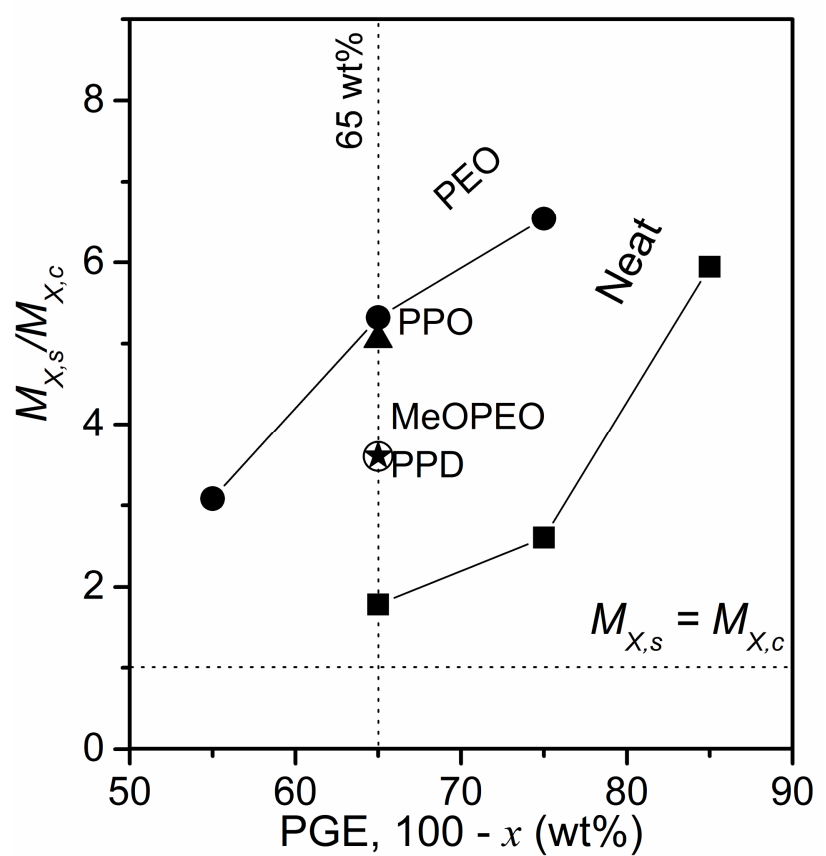

Figure 8: Ratio between experimental $\left(M_{X, s}\right)$ and calculated $\left(M_{X, c}\right)$ values of the total sample weight that contains one mole of elastically effective network chains for different DGEBA $_{x} \mathrm{PGE}_{100-x} \mathrm{Y}$ networks. $M_{X, s}$ is measured by swelling experiments in pyridine, a good solvent of the system. $M_{X, c}$ is calculated assuming the formation of an ideal network. All samples were cured 10 hours at $40{ }^{\circ} \mathrm{C}$ and postcured 2 hours at $120{ }^{\circ} \mathrm{C}$ prior to measurement.

Figure 8 represents the ratio between the total sample weight that contains one mole of elastically effective network chains obtained by swelling equilibrium measurements $\left(M_{X, s}\right)$ and by calculation assuming the formation of an ideal network $\left(M_{X, c}\right)$ versus $100-x$ (PGE wt $\%$ ) for DGEBA $_{x} \mathrm{PGE}_{100-x}$ and DGEBA $_{x} \mathrm{PGE}_{100-x} \mathrm{PEO}$. In both cases, $M_{X, s} / M_{X, c}$ is an increasing function of $100-x$, the weight fraction of the mono-epoxy, PGE, which means that $M_{X, s}$ is deviated from its theoretical values as the cross-linker (DGEBA) content, $x$, is 
decreased. This is interpreted as a general illustration of the effect of transfers in cationic polymerization of oxiranes. Indeed, the typical degree of polymerization for the cationic ROP of epoxy is low as previously illustrated with the estimation of the parameter $q$, the probability that the active end of the propagating chain adds another monomer to the growing chain. Thus, when the cross-linker content decreases, the number of dangling chains rapidly increases and $M_{X, s}$ increases as well. In the case of $\mathrm{DGEBA}_{x} \mathrm{PGE}_{100-x} \mathrm{PEO}$, the deviation from the theory is observed for much lower values of $x$. This is most probably due to an increased number of transfers in the presence of the protic hydroxyl groups of the additive. Moreover, for a given value of $x, M_{X, s}$ is much higher in the case of $\mathrm{DGEBA}_{x} \mathrm{PGE}_{100-x} \mathrm{PEO}$ as compared to $\mathrm{DGEBA}_{x} \mathrm{PGE}_{100-x}$. Again, this is illustrative of the effect of the transfers promoted by the additive. The effective insertion of PEO inside elastically active chains probably contributes to the increase of $M_{X, s}$ as well.

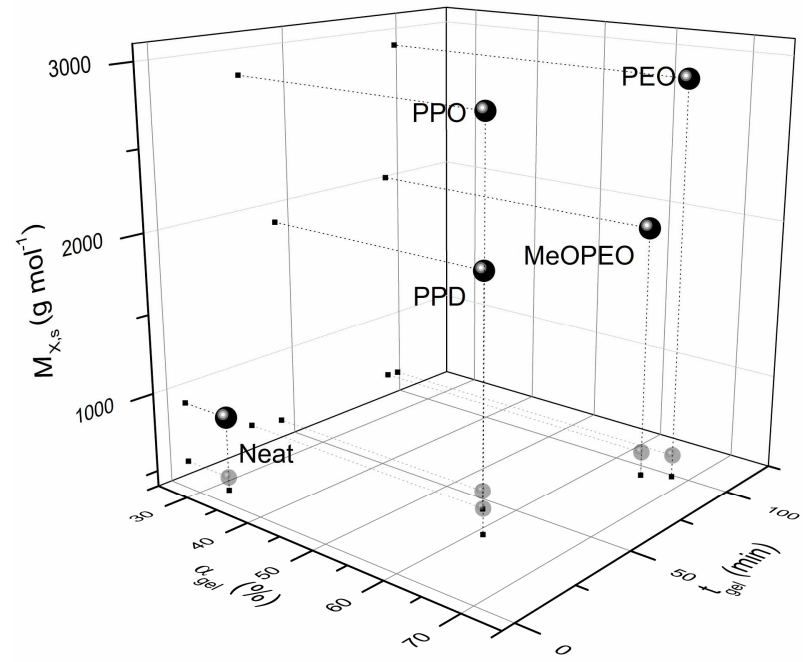

Figure 9: $\left(\alpha_{g e l}, t_{g e l}, M_{X, s}\right)$ coordinates for the curing of $\mathrm{DGEBA}_{35} \mathrm{PGE}_{65} \mathrm{Y}$ at $40{ }^{\circ} \mathrm{C}$ initiated by $4 \mathrm{CA}^{+}-\mathrm{BF}_{4}^{-}$(0.026 equiv. per epoxy function). The data points are labeled with $\mathrm{Y} . \mathrm{Y}=\mathrm{NA}$ (neat), PPD, PPO, MeO-PEO-OH and HO-PEO-OH. The grey points correspond to the $\left(\alpha_{g e l}\right.$, $\left.t_{g e l}, M_{X, c}\right)$ coordinates. The gel time $\left(t_{g e l}\right)$ was determined by using the Winter-Chambon with the data obtained by FTMS $\left(\omega=1,2,4,8,16,32,64,128 \mathrm{rad} \mathrm{s}^{-1}\right)$ and the critical conversion $\left(\alpha_{g e l}\right)$ was obtained by using the value of $t_{g e l}$ and the evolution of the epoxy conversion as a function of time (see Figure 4). $M_{X, s}$ is measured after swelling equilibrium in pyridine, a good solvent of the thermoset, for the samples cured 10 hours at $40{ }^{\circ} \mathrm{C}$ and postcured 2 hours at $120{ }^{\circ} \mathrm{C}$ prior to measurement. 
The influence of the various additives, Y, was investigated as well. The values of $M_{X, s} / M_{X, c}$ for $\mathrm{DGEBA}_{35} \mathrm{PGE}_{65} \mathrm{Y}$ with $\mathrm{Y}=\mathrm{PPD}, \mathrm{PPO}$ and $\mathrm{MeOPEO}$ are reported in the graph of Figure 8 . They are distributed between the lower limit defined by DGEBA ${ }_{35} \mathrm{PGE}_{65}$ and the upper limit defined by $\mathrm{DGEBA}_{35} \mathrm{PGE}_{65} \mathrm{PEO}$. Another way to illustrate this result is to assign $\left(\alpha_{g e l}, t_{g e l}\right.$, $M_{X, s}$ ) coordinates to the different $\mathrm{DGEBA}_{35} \mathrm{PGE}_{65} \mathrm{Y}$ systems. They are plotted in the $3 \mathrm{D}$ chart of Figure 9. For all the hydroxylated additive, $\mathrm{Y}, M_{X, s}$ for $\mathrm{DGEBA}_{35} \mathrm{PGE}_{65} \mathrm{Y}$ is much higher than $M_{X, s}$ for the neat system DGEBA ${ }_{35} \mathrm{PGE}_{65}$ (of at least $1000 \mathrm{~g} \mathrm{~mol}^{-1}$ ). This demonstrates that $M_{X}$ is systematically impacted when a protic additive is added to the system. Polyether diols (HO-PEO-OH and HO-PPO-OH) gives the highest values of $M_{X, s}$. They are approximately $1000 \mathrm{~g} \mathrm{~mol}^{-1}$ higher than the values measured with the mono-alcohol (MeOPEO-OH) or small molecular diol (PPD).

The discrepancies of $M_{X, s}$ observed from one additive to the other can be interpreted in terms of functionality and/or nucleophilic strength of the additives. For instance, the effective concentration of hydroxyl groups in $\mathrm{DGEBA}_{35} \mathrm{PGE}_{65} \mathrm{MeOPEO}$ is twice smaller as compared to the other systems, $\mathrm{DGEBA}_{35} \mathrm{PGE}_{65} \mathrm{Y}$. Thus, it is possible that, overall, less transfers are promoted during the curing reaction. In the case of PPD, the 1,2-diol structure of the additive decreases the nucleophilic strength of its alcohol functions as compared to the other additives, Y. Thus, their ability to attack oxiranium cations and to promote transfers is reduced.

Overall, the 3D chart of Figure 9 demonstrates that the use of protic and/or polyoxylated additives for the cationic polymerization of epoxy monomers permits to control to a great extent not only the sol-gel transition, i.e. $\left(\alpha_{g e l}, t_{g e l}\right)$, but also the structure of the resulting network after completion of the crosslinking reaction, i.e. $\left(M_{X, s}\right)$.

For all the additives $\mathrm{Y}$, it is noteworthy that $M_{X, s}$ is strongly deviated from its calculated counterparts, $M_{X, c}$ (Table 2 and grey data points in Figure 9). This could be related to a 
massive loss of crosslinking molecules, DGEBA, into the sol fraction, $w_{s} . w_{s}$ was measured for each sample in order to estimate the proportion of sol chains and loops. The values, obtained by comparing the weight of the sample before swelling equilibrium and after 2 weeks in pyridine followed by overnight vacuum drying, are reported in Table 2. Similar values were obtained after swelling the samples in a large excess of toluene at $70^{\circ} \mathrm{C}$ during 5 days (see Table S3), providing a good indication that all the soluble fraction is extracted from the network during these experiments. If one considers the influence of the cross-linker content, $x, w_{s}$ is increased as $x$ is decreased. This is expected and it is classically observed for lightly cross-linked polystyrene matrices for instance. ${ }^{57}$ Additionally, the use of a hydroxylated additive, $\mathrm{Y}$, is also accompanied by an increase of $w_{s}$.

For $x \geq 35 \mathrm{wt} \%, w_{s}$ values are ranged between 1 and $7 \%$. This correlates well with classical values reported for crosslinked networks obtained via step and chain polymerizations. ${ }^{58-61}$ Thus, the protic additives are not responsible for excessive sol fraction in this case.

For lower values of $x(x=25 \mathrm{wt} \%$ and $x=15 \mathrm{wt} \%)$, large values of $w_{s}$ were measured. This is the case for $\mathrm{DGEBA}_{15} \mathrm{PGE}_{85}$ and $\mathrm{DGEBA}_{25} \mathrm{PGE}_{75} \mathrm{PEO}$ whose soluble fraction are $18 \%$ and $14 \%$ respectively. If one considers the homopolymerization of PGE with or without PEO, i.e. DGEBA $_{0} \mathrm{PGE}_{100}$ and $\mathrm{DGEBA}_{0} \mathrm{PGE}_{100} \mathrm{PEO}$, the analyses of the crude viscous polymer obtained after completion of the reaction indicates a number average molecular weight, $M_{n} \sim$ $2500 \mathrm{~g} \mathrm{~mol}^{-1}$, for both system (as measured by size exclusion chromatography, experimental details are available in the ESI). Interestingly, for both $\mathrm{DGEBA}_{15} \mathrm{PGE}_{85}$ and $\mathrm{DGEBA}_{25} \mathrm{PGE}_{75} \mathrm{PEO}, M_{X, s}$ are much larger than $2500 \mathrm{~g} \mathrm{~mol}^{-1}$, while $M_{X, s} \leq 2500 \mathrm{~g} \mathrm{~mol}^{-1}$ for all the other $\mathrm{DGEBA}_{x} \mathrm{PGE}_{100-x} \mathrm{Y}$ compositions. Thus, the increase of the sol fraction in the case of DGEBA $_{15} \mathrm{PGE}_{85}$ and $\mathrm{DGEBA}_{25} \mathrm{PGE}_{75} \mathrm{PEO}$ seems to illustrate the decrease of the probability that linear chains of PGE gets incorporated into the network because their typical size is smaller than the typical size of the chain of the network, i.e. of the polymer strands 
between two crosslink points. Thus, the experimental observations obtained from the swelling experiments are consistent with the formation of free poly(PGE) molecules that would stay in the soluble fraction.

Table 2: Properties of the $D_{G E B A} P E_{100-x} Y$ networks. (a) Calculated values of the molecular weight between crosslinks assuming an ideal network $\left(M_{X, c}\right)$. (b) Values of the linear swelling ratio $(\lambda)$ of circular samples after immersion in pyridine for 2 weeks. (c) Values of the total sample weight that contains one mole of elastically effective network chains $\left(M_{X, s}\right)$ obtained by injecting the value of $\lambda$ in the Flory-Rehner equation (Eq. (5)). (d) Values of the sol-fraction $\left(w_{s}\right)$ obtained by weighting the samples before and after swelling in pyridine for 2 weeks. (e) Value of the storage modulus in the rubbery plateau at $100{ }^{\circ} \mathrm{C}$ $\left(E_{r}{ }^{\prime}(100)\right)$ obtained by DMA of rectangular samples $(25 \times 5 \mathrm{~mm})$ in the tension mode with an oscillatory deformation ( $\mathrm{f}=1 \mathrm{~Hz}, \varepsilon=1 \%$ ). (f) Experimental estimation of the total sample weight that contains one mole of elastically effective network chains obtained by using the value of $E_{r}{ }^{\prime}(100)$ in Eq. (7). (g) The temperature, $T_{\alpha}$, of the maximum of the alpha relaxation, $\alpha$, associated with the glass transition. (h) Height and (i) full-width-at-half-maximum (FWHM) of the $\tan \delta$ peak (fitted with an asymmetric double sigmoid function). (j) not analyzed by DMA.

\begin{tabular}{|c|c|c|c|c|c|c|c|c|c|}
\hline \multirow[b]{2}{*}{ Materials } & \multirow{2}{*}{\begin{tabular}{|c|} 
Calculated \\
$M_{X, c}$ \\
$\left(\mathrm{~g} \mathrm{~mol}^{-1}\right)^{a}$
\end{tabular}} & \multicolumn{3}{|c|}{ Swelling equilibrium } & \multicolumn{5}{|c|}{ DMA } \\
\hline & & $\lambda^{b}$ & $\begin{array}{c}M_{X, s} \\
\left(\mathrm{~g} \mathrm{~mol}^{-1}\right)^{c}\end{array}$ & $\begin{array}{c}w_{s} \\
(\%)^{d}\end{array}$ & $\begin{array}{c}E_{r}{ }^{\prime}(100) \\
(\mathrm{MPa})^{e}\end{array}$ & $\begin{array}{c}M_{X, d} \\
\left(\mathrm{~g} \mathrm{~mol}^{-1}\right)^{f}\end{array}$ & $\begin{array}{c}T_{\alpha} \\
\left({ }^{\circ} \mathrm{C}\right)^{g}\end{array}$ & $\begin{array}{c}\text { Height } \\
\text { of } \tan \delta \\
\text { peak }^{h}\end{array}$ & $\begin{array}{c}\text { FWHM } \\
\text { of } \tan \delta \\
\text { peak }^{i}\end{array}$ \\
\hline DGEBA $_{15} \mathrm{PGE}_{85}$ & 1135 & 1.83 & 6760 & 18 & $\mathrm{NA}^{j}$ & $\mathrm{NA}^{j}$ & $\mathrm{NA}^{j}$ & $\mathrm{NA}^{j}$ & $\mathrm{NA}^{j}$ \\
\hline DGEBA $_{25} \mathrm{PGE}_{75}$ & 681 & 1.48 & 1780 & 7.9 & 1.57 & 6780 & 40 & 2.4 & 14.7 \\
\hline DGEBA $_{35}$ PGE $_{65}$ & 486 & 1.34 & 872 & 0.9 & 3.64 & 3000 & 49 & 1.9 & 14.0 \\
\hline $\mathrm{DGEBA}_{25} \mathrm{PGE}_{75} \mathrm{PEO}$ & 761 & 1.74 & 4980 & 14 & $\mathrm{NA}^{j}$ & $\mathrm{NA}^{j}$ & $\mathrm{NA}^{j}$ & $\mathrm{NA}^{j}$ & $\mathrm{~N} \mathrm{~A}^{j-}$ \\
\hline DGEBA $_{35} \mathrm{PGE}_{65} \mathrm{PEO}$ & 543 & 1.58 & 2890 & 5.3 & 1.59 & 6760 & 34 & 2.2 & 15.8 \\
\hline DGEBA $_{45} \mathrm{PGE}_{55} \mathrm{PEO}$ & 422 & 1.42 & 1300 & 4.5 & 4.15 & 2600 & 30 & 1.7 & 16.9 \\
\hline DGEBA ${ }_{35}$ PGE 65 MeOPEO & 553 & 1.51 & 1990 & 6.9 & $\mathrm{NA}^{j}$ & $\mathrm{NA}^{j}$ & $\mathrm{NA}^{j}$ & $\mathrm{NA}$ & $\mathrm{NA}^{j}$ \\
\hline $\mathrm{DGEBA}_{35} \mathrm{PGE}_{65} \mathrm{PPO}$ & $562^{-}$ & 1.58 & 2840 & 3.2 & $\mathrm{NA}^{j}$ & $\mathrm{NA}^{j}$ & $\mathrm{NA}^{j}$ & $\mathrm{~N} \bar{A}^{j}$ & $\mathrm{~N} \bar{A}^{j}$ \\
\hline $\mathrm{DGEBA}_{35} \mathrm{PGE}_{65} \mathrm{PPD}$ & 518 & 1.49 & 1870 & $5.7^{-}$ & 2.73 & 3920 & 48 & 2.2 & 15.7 \\
\hline
\end{tabular}

\section{Dynamic mechanical analysis}

Figure 10a illustrates the variation of the viscoelastic properties with temperature for DGEBA $_{35} \mathrm{PGE}_{65}$ and $\mathrm{DGEBA}_{25} \mathrm{PGE}_{75}$. The modulus in the glassy state is nearly identical for the two networks and the rubbery plateau of $\mathrm{DGEBA}_{25} \mathrm{PGE}_{75}$ is approximately $400 \mathrm{MPa}$ below the plateau of $\mathrm{DGEBA}_{35} \mathrm{PGE}_{65}$. Similarly, the temperature, $T_{\alpha}$, of the maximum of the main relaxation peak, $\alpha$, associated with the glass transition is strongly influenced by the amount of crosslinker, $x . \quad T_{\alpha}$ for DGEBA $_{25} \mathrm{PGE}_{75}$ is $13{ }^{\circ} \mathrm{C}$ below $T_{\alpha}$ measured for DGEBA $_{35} \mathrm{PGE}_{65}$. The values of $T_{\alpha}$ and $E_{r(100)}^{\prime}$, the rubbery modulus at $100{ }^{\circ} \mathrm{C}$, are listed in 
Table 2. $T_{\alpha}$ and $E_{r(100)}^{\prime}$ decrease as $x$ is decreased. It is consistent with the increase of the chains' flexibility and the number of their possible conformations as the crosslink density is decreased, i.e. as $M_{X}$ increases. The characteristics of the tan $\delta$ peaks (inset of Figure 10a) correlates with these observations as well. The intensity of the maximum of the $\tan \delta$ peak reflects the mobility of the polymer chain segments at this temperature. ${ }^{62,63}$ Here, we note a clear increase of the height of the tan $\delta$ peak from DGEBA ${ }_{35} \mathrm{PGE}_{65}$ to $\mathrm{DGEBA}_{25} \mathrm{PGE}_{75}$ that is consistent with a decrease of the crosslink density. Moreover, the width of the $\tan \delta$ peak is classically related to the heterogeneity of the network. ${ }^{10,64}$ Indeed, the coexistence of regions with different crosslinked structures in the same network results in a broader distribution of relaxation times and a wider $\tan \delta$ peak. We note a small increase of the full-width-at-halfmaximum $(\mathrm{FWHM})$ of the $\tan \delta$ peaks in the case of $\mathrm{DGEBA}_{25} \mathrm{PGE}_{75}$. This observation is consistent with an increase of "non-ideal" phenomena in the network structure as the crosslinker content $x$ is decreased from $35 \mathrm{wt} \%$ to $25 \mathrm{wt} \%$. The formation of loops and dangling chains have already been correlated to an increase of heterogeneity in polymer networks. ${ }^{65}$ Here, it is also in agreement with the results obtained via swelling equilibrium experiments where we observed that $M_{X, s} / M_{X, c}$ increases as $x$ is decreased. The increase of the deviation of the ratio between the experimental estimation of $M_{X}\left(M_{X, s}\right)$ and the calculated value of $M_{X}\left(M_{X, c}\right)$ assuming the formation of an ideal network was another illustration of a larger number of non-ideal structures in the polymer network, including loops and dangling chains. In addition to those classical non-ideal structures, it is also noteworthy that the network properties are strongly influenced by the dispersity of the strand length. ${ }^{66}$ The cationic copolymerization of mono- and di-epoxy monomers is an uncontrolled crosslinking process that will result in the formation of a polydisperse network with shorter and longer chains. Thus, the resulting networks are intrinsically inhomogeneous and the polydispersity will increase as the mono- to di-epoxy ratio increase, i.e. as the possibility to form long 
strands increases. This is also contributing to the enlargement of the $\tan \delta$ peaks as $x$ is decreased.

Another experimental estimation of $M_{X}$ can be obtained from the variation of the viscoelastic properties with temperature. Indeed, in the rubber elasticity theory, the rubbery modulus, $E_{r}^{\prime}$, is related to the crosslink density $v_{e}$ by the following relationship: ${ }^{54,55,67}$

$$
E_{r}^{\prime}=3 v_{e} v_{c}^{\frac{1}{3}} k T \quad \text { Eq. (6) }
$$

Where $k$ is the Boltzman constant and $T$ is the temperature in Kelvin and $v_{c}$ is the polymer volume fraction in the network obtained after the curing reaction (see Eq. (5)). $v_{c}$ is introduced to take into account the presence of the soluble fraction inside the cured network. ${ }^{68}$ Given the relation between $v_{e}$ and $M_{X}$ (Eq. (4)), it comes:

$$
M_{X, d}=\frac{3 \rho v_{c}^{\frac{1}{3}} R T}{E_{r}^{\prime}} \quad \text { Eq. (7) }
$$

Where $M_{X, d}$ is the total sample weight that contains one mole of elastically effective network chains obtained via DMA measurements, $R$ is the gas constant, $\rho$ is the density of the polymer network and $E_{r}^{\prime}$ is the modulus measured in the rubbery plateau (in our case at $100{ }^{\circ} \mathrm{C}$ for every sample).

The values of $M_{X, d}$ obtained with Eq. (7) are reported in Table 2. $M_{X, d}$ is larger than $M_{X, s}$, the estimation of $M_{X}$ obtained via swelling equilibrium measurements. However the ratio between $M_{X, d}$ and $M_{X, c}$, the calculated value of $M_{X}$ assuming the formation of an ideal network, vary in the same way than the ratio between $M_{X, s}$ and $M_{X, c} . M_{X, d} / M_{X, c}$ is an increasing function of 100 $-x$. Thus, the DMA measurements confirms that a larger amount of non-ideal structures, including loops and dangling chains, are formed when the crosslinker content is decreased.

The difference between $M_{X, d}$ and $M_{X, s}$ might possibly be explained by considering that $E_{r}^{\prime}$ (the dynamic storage modulus used to determine $M_{X, d}$ ) results from a dynamic stretching of the network strands under small deformation while $\lambda$ ( the linear swelling ratio used to determine 
$\left.M_{X, s}\right)$ is obtained after stretching of the network strands in an equilibrium conformation. In particular, Eq. (6) is obtained in the affine network model where the end of network strands are fixed in space and are displaced affinely with the whole network. ${ }^{54}$ In real networks, the ends of network strands are joined at crosslink junctions that can fluctuate around their average positions. ${ }^{55}$ Taking these fluctuations into account, for instance by considering a phantom network model, would lead to a better estimation of $v_{e}{ }^{55,69}$ However, this is out of the scope of the present study.
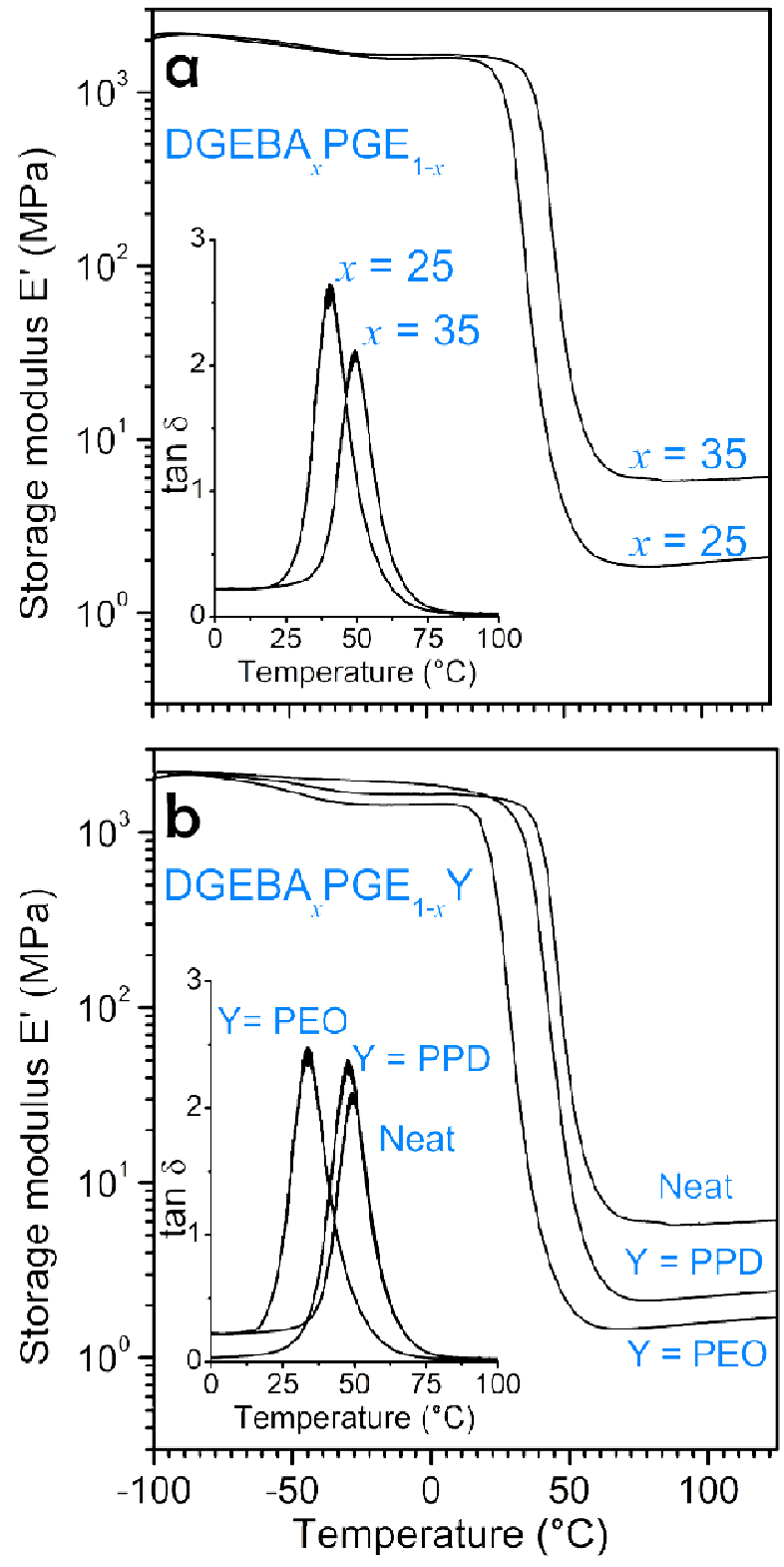

Figure 10: (a) Storage modulus $\left(E^{\prime}\right)$ versus temperature $\left(-100{ }^{\circ} \mathrm{C} \leq T \leq 125{ }^{\circ} \mathrm{C}\right.$ ) for (a) DGEBA $_{x} \mathrm{PGE}_{100-x}$ with $x=35$ and 25 wt $\%$ and for (b) $\mathrm{DGEBA}_{35} \mathrm{PGE}_{65} \mathrm{Y}$ with $\mathrm{Y}=$ none, PPD 
and PEO. Data are obtained by DMA of rectangular specimens $(25 \mathrm{~mm} \times 5 \mathrm{~mm})$ performed in the tensile mode with a heating rate of $3{ }^{\circ} \mathrm{C} \mathrm{min}^{-1}$, a frequency of $1 \mathrm{~Hz}$ and an amplitude of 10 $\mu \mathrm{m}$. The insets represent the corresponding $\tan \delta$ peak on a narrower temperature window $\left(0{ }^{\circ} \mathrm{C} \leq \mathrm{T} \leq 100{ }^{\circ} \mathrm{C}\right)$. All samples were cured 10 hours at $40{ }^{\circ} \mathrm{C}$ and postcured 2 hours at $120{ }^{\circ} \mathrm{C}$ prior to measurement.

Figure $10 \mathrm{~b}$ illustrates the variation of the viscoelastic properties with temperature for DGEBA $_{35} \mathrm{PGE}_{65}$ and $\mathrm{DGEBA}_{35} \mathrm{PGE}_{65} \mathrm{Y}$ with $\mathrm{Y}=\mathrm{PPD}$ and $\mathrm{Y}=\mathrm{PEO}$. The values of $T_{\alpha}, E_{r(100)}^{\prime}$ and $M_{X, d}$ (determined using $E_{r(100)}^{\prime}$ and Eq. (7)) as well as the height and FWHM of the corresponding $\tan \delta$ peaks are all reported in Table 2 for both additives.

$T_{\alpha}$ and $E_{r}^{\prime}$ decrease upon addition of $\mathrm{Y}$ and the lowest values are observed for $\mathrm{Y}=\mathrm{PEO}$. Again this is consistent with the evolution of the molecular weight between cross-linking, $M_{X, d} . M_{X, d}$ is much larger for $\mathrm{Y}=\mathrm{PEO}$ and $\mathrm{Y}=\mathrm{PPD}$ than for the neat system. Moreover, $M_{X, d}(\mathrm{PPD})$ is smaller than $M_{X, d}(\mathrm{PEO})$. The same observation was done with the estimation of $M_{X}$ obtained from swelling equilibrium experiments, $M_{X, s}$. In particular, $M_{X, s}(\mathrm{PEO}) / M_{X, s}(\mathrm{PPD})$ $=1.5$ and $M_{X, d}(\mathrm{PEO}) / M_{X, d}(\mathrm{PPD})=1.7$. These two values are very close confirming that swelling and DMA measurements provide estimations of $M_{X}$ that vary with the same trend as a function of $x$ and Y.

Finally the ratio of $M_{X, d}(\mathrm{Y})$ with $M_{X, c}(\mathrm{Y})$, the calculated value of $M_{X}$, is much larger in the case of $\mathrm{Y}=\mathrm{PPD}$ and $\mathrm{Y}=\mathrm{PEO}$ compared to the neat system. Again this was previously observed with $M_{X, s}$ and it is consistent with an increased number of loops and dangling chains as a consequence of the transfers promoted by PPD and PEO. The height and the FWMH of the $\tan \delta$ peak are also substantially higher for the networks containing PPD and PEO. This supports the idea that the crosslink density of the resulting network is lower, providing polymer chains with improved mobility, and that the networks contains more defects most probably as a consequence of the transfers initiated by PPD and PEO.

Thus, the viscoelastic properties of the networks obtained via DMA measurements confirms the effect of $x$ and Y observed via swelling equilibrium measurements. They also provide an 
insight into the heterogeneity of the networks by considering the width of the tan $\delta$ peaks.

\section{$\underline{\text { Mechanical properties at large deformations }}$}

Figure 11a illustrates the stress-strain behavior for $\mathrm{DGEBA}_{x} \mathrm{PGE}_{100-x}$ with $x=100,35$ and 25 wt $\%$. Clearly, DGEBA ${ }_{100} \mathrm{PGE}_{0}$ exhibits a brittle fracture evidenced by a nearly linear increase of the stress until an abrupt failure of the sample. This is illustrative of the very restrained molecular mobility within the densely crosslinked material.

In contrast, for $\mathrm{DGEBA}_{35} \mathrm{PGE}_{65}$, the profile is typical of a ductile fracture with four distinct regions: (1) the linear viscoelastic response (i.e., glassy deformation) (2) yielding (i.e., plastic deformation) (3) strain softening, and (4) strain hardening. The four steps are indicated on the stress-strain curve of DGEBA ${ }_{35} \mathrm{PGE}_{65}$ in Figure 11a. Strain softening and hardening results in a significant postyield flow that participates in an effective toughening of the matrix. Thus, copolymerization of mono- and di-glycidyl ethers provides tougher glassy networks. The physics of each of the region of the stress-strain curve is described in detail elsewhere. ${ }^{70-72}$ 

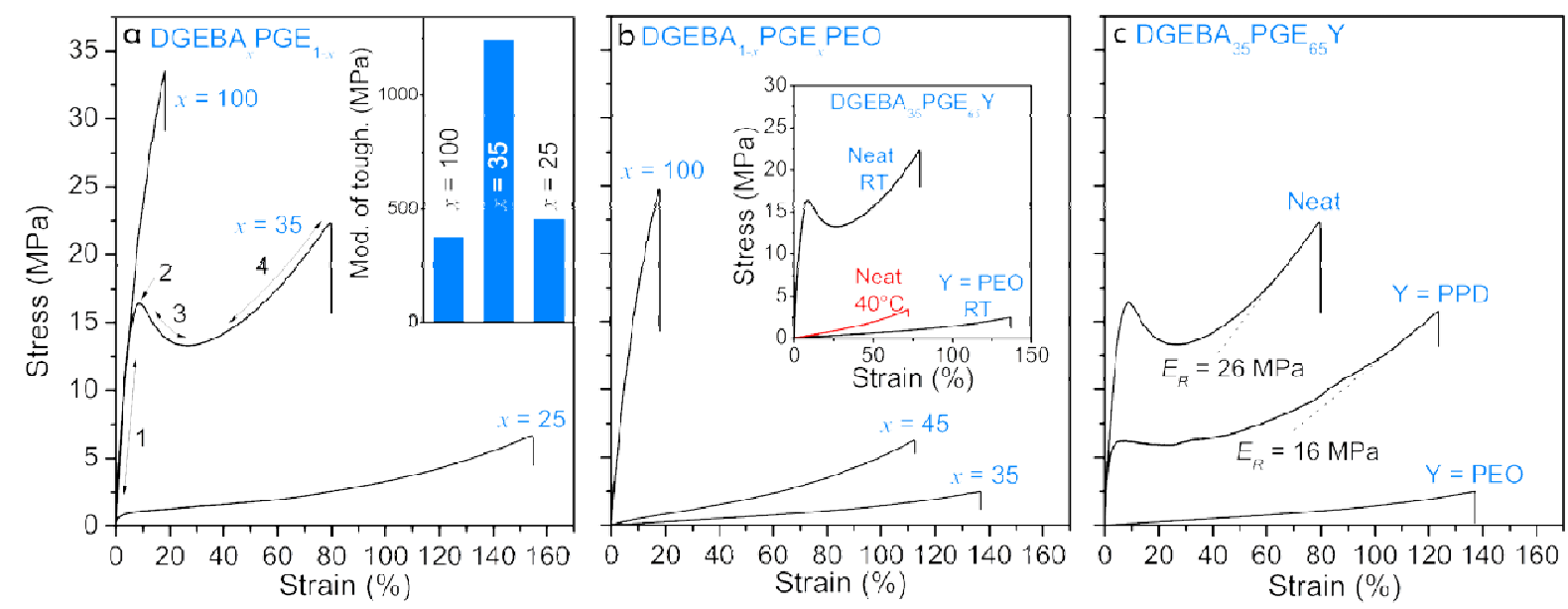

Figure 11: (a) Stress-strain profiles for $\mathrm{DGEBA}_{x} \mathrm{PGE}_{100-x}$ networks with $x=100,35$ and $25 \mathrm{wt} \%$. The inset represents the modulus of toughness obtained by integrating the area under the stress-strain curves. (b) Stress-strain profiles for DGEBA $\mathrm{PGE}_{100-x} \mathrm{PEO}$ networks with $x=100,45$ and $35 \mathrm{wt} \%$. The inset represents the stress-strain profiles of DGEBA ${ }_{35} \mathrm{PGE}_{65}$ and $\mathrm{DGEBA}_{35} \mathrm{PGE}_{65} \mathrm{PEO}$ obtained at room temperature (black line) as compared to the tensile profile of $\mathrm{DGEBA}_{35} \mathrm{PGE}_{65}$ obtained for $T=$ $40{ }^{\circ} \mathrm{C}$ (red line). (c) Stress-strain profiles for DGEBA ${ }_{35} \mathrm{PGE}_{65} \mathrm{Y}$ with $\mathrm{Y}=$ none, PPD and PEO. For DGEBA $_{35} \mathrm{PGE}_{65}$ and $\mathrm{DGEBA}_{35} \mathrm{PGE}_{65} \mathrm{PPD}$ the post-yielding is linearly fitted in order to estimate the apparent rubbery modulus, $E_{R}$. All samples were cured 10 hours at $40{ }^{\circ} \mathrm{C}$ and postcured 2 hours at 120 ${ }^{\circ} \mathrm{C}$ prior to measurement.

Briefly, the linear viscoelastic region (1) involves short range glassy deformation including bending stretching and small angular rotation of the network strands. These are the classical phenomena occurring in hard glassy polymers at small-strains. DGEBA ${ }_{35} \mathrm{PGE}_{65}$ and DGEBA $_{100} \mathrm{PGE}_{0}$ exhibit a very similar behavior in this region. As a result, their tensile moduli are very similar (see Table 3). The yielding region (2) results from cooperative chain motions without significant increase of their length. It is now well established that yielding is the main source of energy absorption before failure in high- $T_{g}$ crosslinked materials. ${ }^{5}$ Many studies have been performed in order to understand the influence of network structure on yielding. ${ }^{73-}$ ${ }^{76}$ Authors varied the crosslink's density and the stiffness of the chains of thermoset networks. It was concluded that the yield stress depends mainly on the difference between the testing temperature and $T_{g}$. Therefore, crosslink's density affects yielding through its influence on the $T_{g}$, by varying the constraint on the molecular segment and not by increasing the molecular weight, $M_{X}$, between two consecutive crosslink points. In the case of cationic 
copolymerization, the presence of dangling ends, as evidenced in the previous section, is certainly playing a role by providing additional mobility to the chains. Strain softening (3) results from shear-induced changes in the structure of the glass. ${ }^{77}$ It is still unclear how the structure of the network influences this phenomenon and it will not be discussed here. Strain hardening (4) results from glassy polymer chains experiencing sufficient mobility to be stretched between their crosslinks. As a consequence of this phenomenon, it is thought that an entropic "back stress" produces a dramatic increase of $\sigma$. Thus, entire network chains are involved and become oriented with the applied stress. Clearly, strain hardening is related to the crosslink's density, $M_{X}$. To our knowledge, strain hardening has been rarely reported for extended epoxy-amine networks ${ }^{78,79}$ and it is much more documented for glassy thermoplastic. $^{80,81}$ Here, the results show that copolymerization of DGEBA with PGE provides networks with molecular chains of sufficient length to experience an entropic "back stress".

As the crosslink's density is further decreased, the $T_{g}$ of the material becomes smaller than the testing temperature (room temperature, $T \sim 22{ }^{\circ} \mathrm{C}$ ) and the material exhibit a "rubber-like" tensile profile. DGEBA ${ }_{25} \mathrm{PGE}_{75}\left(T_{g}=18{ }^{\circ} \mathrm{C}\right.$, see table 1$)$ exhibits a tensile behavior similar to conventional rubbery materials with low tensile modulus (406 MPa) and stress at break (about $6 \mathrm{MPa}$ ) as well as high elongation at break (about 150\%) (see Figure 11a and Table 3).

Thus the progressive decrease of the crosslinker content permits to experience the three main fracture regimes of a thermoset: (i) the brittle fracture at high crosslinker content $(x=100$ wt $\%$ ) with a high stress at break but a very small elongation, (ii) the ductile fracture, with a yielding and a post-yielding flow, at intermediate crosslinker content $(x=35 \mathrm{wt} \%)$ and finally (iii) the rubbery fracture at lower crosslinker content $(x=25 \mathrm{wt} \%)$ with a high deformation at break for a rather moderate stress.

In thermoset technology, a ductile behaviour with yield point and large post-yield deformation 
before fracture is commonly presented as the most desirable. Indeed, in this configuration, there is a good compromise between the extent of the strain and the stress at break so that toughness is maximal. This is further illustrated by considering the modulus of toughness, which defines the energy needed to break the material and is measured by integrating the area under the stress-strain curve. ${ }^{82}$ The inset of Figure 11a represents the modulus of toughness of $\operatorname{DGEBA}_{x} \mathrm{PGE}_{100-x}$ for $x=100,35$ and $25 \mathrm{wt} \%$. Clearly, it is maximal when yielding is operative, i.e. for $x=35 \mathrm{wt} \%$.

Table 3: Tensile properties of the $\operatorname{DGEBA}_{x} \mathrm{PGE}_{100-x} \mathrm{Y}$ networks. (a) Values of the molecular weight between crosslink $\left(M_{X, s}\right)$ obtained by swelling equilibrium experiment in pyridine. $(b)$ The temperature, $T_{\alpha}$, of the maximum of the alpha relaxation, $\alpha$, associated with the glass transition obtained by DMA of rectangular samples. (c) Tensile modulus (E) of the polymer networks obtained by fitting the linear region of the stress-strain curve for $\varepsilon \rightarrow 0 \%$ using OriginPro ${ }^{\circledR}$ 8.0. $(d)$ Yield stress $\left(\sigma_{\mathrm{y}}\right)$ and $(e)$ yield strain $\left(\varepsilon_{\mathrm{y}}\right)$ corresponding to the coordinate of the yield point of the stress-strain profile of the materials. $(f)$ Stress at break $\left(\sigma_{b}\right)$ and $(g)$ strain at break $\left(\varepsilon_{\mathrm{b}}\right)$ corresponding to the failure of the materials. $(h)$ These samples cannot be manipulated after swelling in pyridine. They break under very small mechanical stress making the measurement of the linear swelling ratio, $\lambda$, too difficult. ( $i$ ) These samples do not undergo a plastic deformation. There is no yield point on their stress-strain profile.

\begin{tabular}{|c|c|c|c|c|c|c|c|}
\hline Materials & $M_{X, s}\left(\mathrm{~g} \mathrm{~mol}^{-1}\right)^{a}$ & $T_{a}\left({ }^{\circ} \mathrm{C}\right)^{b}$ & $\mathrm{E}(\mathrm{MPa})^{c}$ & $\sigma_{\mathrm{y}}(\mathrm{MPa})^{d}$ & $\varepsilon_{\mathrm{y}}(\%)^{e}$ & $\sigma_{\mathrm{b}}(\mathrm{MPa})^{f}$ & $\varepsilon_{\mathrm{b}}(\%)^{g}$ \\
\hline DGEBA $_{25} \mathrm{PGE}_{75}$ & 1780 & 40 & $406 \pm 37$ & $\mathrm{NA}^{i}$ & $\mathrm{NA}^{i}$ & $6.2 \pm 0.5$ & $145 \pm 9$ \\
\hline DGEBA $_{35} \mathrm{PGE}_{65}$ & 872 & 49 & $565 \pm 8$ & $18 \pm 2$ & $8.8 \pm 0.2$ & $23 \pm 1$ & $79 \pm 1$ \\
\hline DGEBA $_{100} \mathrm{PGE}_{0}$ & $\mathrm{NA}^{h}$ & 93 & $791 \pm 10$ & $\mathrm{NA}^{i}$ & $\mathrm{NA}^{i}$ & $34 \pm 4$ & $18 \pm 2$ \\
\hline $\mathrm{DGEBA}_{35} \mathrm{PGE}_{65} \mathrm{PEO}$ & 2890 & $34^{-}$ & $2.6 \pm 0.5$ & $\mathrm{NA}^{i}$ & $\mathrm{NA}^{i}$ & $2.3 \pm 0.2$ & $128 \pm 9$ \\
\hline DGEBA $_{45} \mathrm{P}$ & 1300 & 30 & 4.4 & $\mathrm{NA}^{i}$ & $\mathrm{NA}^{i}$ & $6.0 \pm 0.7$ & $109 \pm 4$ \\
\hline $\mathrm{DGEBA}_{100} \mathrm{PGE}_{0} \mathrm{PEO}$ & $\mathrm{NA}^{h}$ & 72 & $460 \pm 14$ & $\mathrm{NA}^{i}$ & $\mathrm{NA}^{i}$ & $25 \pm 3$ & $18 \pm 4$ \\
\hline $\mathrm{DGEBA}_{35} \mathrm{PGE}_{65} \mathrm{PPD}$ & 1870 & $48^{-}$ & $486 \pm 25$ & $6 \pm 1$ & $7.5 \pm 1.5$ & $15 \pm 1$ & $120 \pm 4$ \\
\hline
\end{tabular}

Very few studies have been devoted to the measurements of large-strain mechanical properties of epoxy thermosets in their rubbery state where the mechanical properties are usually less interesting. ${ }^{59,83-85}$ Strain and stress at break are generally reported as being very weak because of the moderate chain extensibility combined to the decrease of the intermolecular forces. It is worth noting that the copolymerization of DGEBA and PGE yields rubbery networks with pretty good properties as exemplified by DGEBA ${ }_{25} \mathrm{PGE}_{75}$. However, in that case, the material is used very near $T_{g}$ so that it is not strictly used in its rubbery state. This is illustrated by running cyclic loadings on this material. Figure S8 (see ESI) shows a 
residual plastic deformation indicating that the material is used in the vicinity of $T_{g}$.

Overall, from this first set of experiments it can be concluded that the effect of the crosslinker content is dominated by the variation of the materials' $T_{g}$. In order to identify the part play by the variation of the entire chains' length, one has to compare material in their rubbery state or in the strain-hardening region of the post yielding flow. Moreover, experiments must be performed at the appropriate temperature, i.e. at constant $T-T_{g}$, so that the variation of segmental mobility, from one material to the other, is compensated.

Figure $11 \mathrm{~b}$ and $11 \mathrm{c}$ illustrate the influence of the additives, Y, on the stress-strain behavior of DGEBA $_{x} \mathrm{PGE}_{100-x} \mathrm{Y}$ materials. Two representative protic additives were used: PPD whose molecular formula is very similar to the monomer, PGE, and PEO which is made of an oligomeric polyoxide backbone (see Scheme 1).

In both cases, the additive is expected to impact the mechanical behavior of the network through two distinctive phenomena: (1) the promotion of the AM mechanism that results in transfers and thus in the variation of the crosslink's density (influence on chain length and $T_{g}$ ) and (2) the incorporation of the additives within the networks' chains that results in the variation of the chains stiffness (influence on $T_{g}$ ) and the crosslink's density (influence on chain length and $T_{g}$ ).

From our previous observations, we know that the AM mechanism is less efficiently promoted by PPD as compared to PEO. Furthermore, the incorporation of PPD within the network's chains will be of very limited impact. Indeed, PPD structure (size and chemical nature) is similar to PGE and DGEBA. Instead, PEO exhibits a very flexible oligomeric backbone free of any bulky substituent. Thus, the chains' stiffness will be significantly impacted in the presence of PEO. Moreover, the oligomeric size of PEO will result in a decrease of the crosslink's density. 
In a first series of experiments, PEO was investigated at constant concentration ( 0.061 equiv. epoxy) for various values of $x$. Figure $11 \mathrm{~b}$ illustrates the stress-strain profiles of DGEBA $_{x} \mathrm{PGE}_{100-x} \mathrm{PEO}$ for $x=100,45$ and $35 \mathrm{wt} \%$. It is worth noting that, even at relatively high crosslinker concentration $(x=45 \mathrm{wt} \%)$, the $T_{g}$ of the materials is sufficiently low $\left(T_{g}=\right.$ $25{ }^{\circ} \mathrm{C}$, see Table 3) to observe a rubber like behavior. In that case, the material submitted to cyclic loading does not show residual deformation (see ESI, Figure S9). It behaves as a true rubber. When comparing DGEBA ${ }_{45} \mathrm{PGE}_{55} \mathrm{PEO}$ and $\mathrm{DGEBA}_{35} \mathrm{PGE}_{65} \mathrm{PEO}$, the evolution of the ultimate properties ( $\sigma_{b}$ and $\varepsilon_{b}$, see Table 3 ) is consistent with the evolution of $M_{X}$, that is $\sigma_{b}$ is decreased and $\varepsilon_{b}$ is increased from DGEBA ${ }_{45} \mathrm{PGE}_{55} \mathrm{PEO}\left(M_{X, s}=1300 \mathrm{~g} \mathrm{~mol}^{-1}\right)$ to $\mathrm{DGEBA}_{35} \mathrm{PGE}_{65} \mathrm{PEO}\left(M_{X, s}=2890 \mathrm{~g} \mathrm{~mol}^{-1}\right)$. This is consistent with the expected influence of PEO.

In order to have a clearer picture of the impact of PEO on the mechanical properties of the networks, DGEBA ${ }_{35} \mathrm{PGE}_{65}$ and $\mathrm{DGEBA}_{35} \mathrm{PGE}_{65} \mathrm{PEO}$ were also compared in similar $T-T_{g}$ conditions. To this end, DGEBA ${ }_{35} \mathrm{PGE}_{65}$ was tested at $40{ }^{\circ} \mathrm{C}$. The inset of Figure $11 \mathrm{~b}$ illustrates the tensile profile of $\mathrm{DGEBA}_{35} \mathrm{PGE}_{65}$ at $40{ }^{\circ} \mathrm{C}\left(T-T_{g}=9{ }^{\circ} \mathrm{C}\right)$ as compared to the tensile profile of $\mathrm{DGEBA}_{35} \mathrm{PGE}_{65} \mathrm{PEO}$ at room temperature $\left(T-T_{g}=6{ }^{\circ} \mathrm{C}\right)$. In this condition, DGEBA $_{35} \mathrm{PGE}_{65}$ behaves as a rubber with a deformation at break twice smaller than DGEBA $_{35} \mathrm{PGE}_{65} \mathrm{PEO}$. This time, the difference can be interpreted in term of chain length. In particular, the large increase of the deformation at break in the presence of PEO is consistent with the decrease of crosslink's density observed in the previous section $\left(M_{X, s}=872 \mathrm{~g} \mathrm{~mol}^{-1}\right.$ for $\mathrm{DGEBA}_{35} \mathrm{PGE}_{65}$ and $M_{X, s}=2890 \mathrm{~g} \mathrm{~mol}^{-1}$ for $\left.\mathrm{DGEBA}_{35} \mathrm{PGE}_{65} \mathrm{PEO}\right)$. It is noteworthy that there is no direct correlation between the respective increasing factors of the deformation at break and $M_{X, s}$. This is certainly due to the dispersity of the strand length as mentioned earlier during the analysis of the results obtained via DMA. Indeed, the stress-strain relationship is strongly dependent not only on the 
average crosslinking density (i.e. $M_{X, s}$ ) but also on the non-uniformity of the network strand length. In particular, the deformation at break is primarily controlled by the stretching of the shorter strands. Thus, a larger chain polydispersity may explain why the deformation at break of DGEBA ${ }_{35} \mathrm{PGE}_{65} \mathrm{PEO}$ is only increased by a factor of $\sim 2$ while $M_{X, s}$ is actually increased by a factor of $\sim 3$.

Figure 11c compares the influence of PEO and PPD for $x=35 \mathrm{wt} \%$. The tensile profiles of DGEBA $_{35} \mathrm{PGE}_{65} \mathrm{PPD}$ and $\mathrm{DGEBA}_{35} \mathrm{PGE}_{65} \mathrm{PEO}$ are also compared to the profile of the neat system, DGEBA ${ }_{35} \mathrm{PGE}_{65}$. As previously described, $\mathrm{DGEBA}_{35} \mathrm{PGE}_{65} \mathrm{PEO}$ exhibits a rubberlike behavior with a low stress at break and a large elongation. Instead, DGEBA ${ }_{35} \mathrm{PGE}_{65} \mathrm{PPD}$ is still in the glassy state with a $T_{g}$ very similar to DGEBA $_{35} \mathrm{PGE}_{65}$ (see Table 3 ). This is consistent with the limited impact of PPD on the chain stiffness. As a result, the tensile profile of DGEBA $_{35} \mathrm{PGE}_{65} \mathrm{PPD}$ exhibits a yield point and an extensive post-yield flow.

Contrarily to $\mathrm{DGEBA}_{35} \mathrm{PGE}_{65}$, strain softening is almost inexistent. Strain hardening is effective but at a slower rate as compared to $\mathrm{DGEBA}_{35} \mathrm{PGE}_{65}$ and on a larger strain region. A common way to characterize the post-yielding flow of glassy materials is to consider the slope of the strain hardening region as a tensile modulus, $E_{R}$. $E_{R}$ characterizes the "rubber-like" response of the material during the hardening. ${ }^{80}$ This is illustrated in Figure $11 \mathrm{~b}$ where the strain hardening regions have been linearly fitted to yield $E_{R}$.

The presence of PPD is accompanied by a decrease of $E_{R}$ and an increase of $\varepsilon_{b}$ consistent with the decrease of the crosslink's density observed during swelling experiments $\left(M_{X, s}=872 \mathrm{~g}\right.$ $\mathrm{mol}^{-1}$ for $\mathrm{DGEBA}_{35} \mathrm{PGE}_{65}$ and $M_{X, s}=1870 \mathrm{~g} \mathrm{~mol}^{-1}$ for $\left.\mathrm{DGEBA}_{35} \mathrm{PGE}_{65} \mathrm{PPD}\right)$. Given the small difference between the $T_{g}$ of $\mathrm{DGEBA}_{35} \mathrm{PGE}_{65}$ and $\mathrm{DGEBA}_{35} \mathrm{PGE}_{65} \mathrm{PPD}$, the variation of $E_{R}$ and $\varepsilon_{b}$ is most probably illustrative of the influence of the chain length in the glassy state.

To conclude PEO and PPD can be used as additives to control the mechanical properties of DGEBA $_{x} \mathrm{PGE}_{100-x} \mathrm{Y}$ in the rubbery state, above $T_{g}$, and in the post yielding flow of a ductile 
fracture, below $T_{g}$. More importantly, this study demonstrates that the cationic copolymerization of mono- and di-glycidyl ethers and its control with small amounts of hydroxyl additives can be used as a tool to tune the toughness of common epoxy thermosets (i.e. DGEBA) at the expense of a decrease of the $T_{g}$ of the network. In this sense, this strategy, along many other recent works, ${ }^{17,86-88}$ is part of an ongoing research topic devoted to the control of the topology of epoxy networks to obtain tougher materials.

\section{Conclusions}

The cationic cross-linking copolymerization of PGE with DGEBA was studied. The sol-gel transition of the curing reaction was investigated in rheology at various frequencies by using the FTMS method and the gel points were determined according to the Winter and Chambon criterion. The epoxy conversion was monitored in parallel through IR measurements. Several hydroxylated and chelating additives were tested in order to control $t_{g e l}$ and $\alpha_{g e l}$.

To sum up, we control the cationic ROP and the gelation of epoxy reactive systems by three independent means: $i$ ) the addition of diols, that act as transfer agents and get inserted into the network, $i$ ) the addition of polyethers, that act as chelating agent of cationic reactive species and $\mathrm{iii}$ ) the combination of mono-epoxides, that promote chain-extension, and di-epoxides, that promote branching. The addition of hydroxyl groups results in a large increase of $\alpha_{g e l}$ due to the promotion of the AM propagation mechanism. On the other hand, chelating additives considerably increase $t_{g e l}$ as a result of the complexation of the cationic active centers. Eventually, increasing the mono-epoxides to di-epoxides ratio is another way to increase both $\alpha_{g e l}$ and $t_{g e l}$ by playing with the average functionality. This way, while keeping curing temperature equal to $40{ }^{\circ} \mathrm{C}$ in all cases, we are able to cover a wide range of gel times $(2-120$ min), gel conversions $(7-77 \%)$ and mechanical properties of the final networks (fragile, ductile, elastomeric). 
IR spectroscopy together with multiwave rheology permit to finely detect the sol-gel transition, according to the Winter-Chambon criterion, and give access to the critical exponents. We found that, despite the wide range of accessible curing profiles and networks, the variations of the viscosity and the elastic modulus near the gel point obey quite constant power laws throughout the series. Surprisingly, the values of the critical exponents are close to those reported for epoxy systems crosslinked by a step polymerization mechanism.

DMA and swelling experiments confirm large variations of the crosslink density depending on the nature of the additives and the mono- to di-epoxides ratio. In all cases, it also reveals the presence of networks defects such as loops and dangling chains.

All in all, these polymerizable formulations results in a very versatile system where both the curing process and the mechanical properties of the material can be tailored. Interestingly, the curing temperature is close to the ambient $\left(40^{\circ} \mathrm{C}\right)$ and only a very short post-curing step ( $2 \mathrm{~h}$ at $120{ }^{\circ} \mathrm{C}$ ) is necessary to make sure that the material is fully cured. These are key points to prevent evaporation of the volatile mono-epoxide and to limit energy consumption during the curing process. The sol fractions are also small. For all these reasons, the system might be practically relevant to produce tough and rubber-like materials.

\section{Supporting Information:}

Procedure for monitoring of the curing reaction, FTMS method, Winter and Chambon criterion, evaluation of chain growth reaction probabilities, critical exponent values in gelation models, calculation of MX, estimations of solubility parameters, polymer density, and polymer-solvent interaction parameters. Solvent screening for swelling experiments, measurements of the linear swelling ratio, the soluble fraction and polymer volume fraction in 
the network after curing. Data about the homopolymerization of PGE. Fitting of $\tan \delta$ peaks in DMA, tensile tests and cyclic loading data 


\section{References}

1. Pascault, J. P.; Williams, R. J. J., Epoxy Polymers: New Materials and Innovations. Weinheim, Germany, 2010.

2. Guo, Q., Thermosets: Structure, Properties, and Applications. Woodhead Publishing: 2017.

3. Chen, J. S.; Ober, C. K.; Poliks, M. D., Characterization of thermally reworkable thermosets: materials for environmentally friendly processing and reuse. Polymer 2002, 43 (1), 131-139.

4. Carter, J. T.; Emmerson, G. T.; Lo Faro, C.; McGrail, P. T.; Moore, D. R., The development of a low temperature cure modified epoxy resin system for aerospace composites. Composites Part a-Applied Science and Manufacturing 2003, 34 (1), 83-91.

5. Pascault, J.-P.; Sautereau, H.; Verdu, J.; Williams, R. J. J., Thermosetting Polymers. New York, 2002.

6. Vidil, T.; Tournilhac, F.; Musso, S.; Robisson, A.; Leibler, L., Control of reactions and network structures of epoxy thermosets. Progress in Polymer Science 2016, 62, 126-179.

7. Hill, L. W., Calculation of crosslink density in short chain networks. Progress in Organic Coatings 1997, 31 (3), 235-243.

8. $\quad$ Berchtold, K. A.; Hacioglu, B.; Lovell, L.; Nie, J.; Bowman, C. N., Using changes in initiation and chain transfer rates to probe the kinetics of cross-linking photopolymerizations: Effects of chain length dependent termination. Macromolecules 2001, 34 (15), 5103-5111.

9. Elliott, J. E.; Bowman, C. N., Monomer functionality and polymer network formation. Macromolecules 2001, 34 (13), 4642-4649.

10. Lu, H.; Lovell, L. G.; Bowman, C. N., Exploiting the heterogeneity of cross-linked photopolymers to create High$\mathrm{T}(\mathrm{g})$ polymers from polymerizations performed at ambient conditions. Macromolecules 2001, 34 (23), 8021-8025.

11. Zhao, S.; Abu-Omar, M. M., Renewable Epoxy Networks Derived from Lignin-Based Monomers: Effect of CrossLinking Density. Acs Sustainable Chemistry \& Engineering 2016, 4 (11), 6082-6089.

12. Toscano, A.; Pitarresi, G.; Scafidi, M.; Di Filippo, M.; Spadaro, G.; Alessi, S., Water diffusion and swelling stresses in highly crosslinked epoxy matrices. Polymer Degradation and Stability 2016, 133, 255-263.

13. Katritzky, A. R.; Ramsden, C. A.; Joule, J. A.; Zhandkin, V. V., Handbook of Heterocyclic Chemistry. Amsterdam, 2010 .

14. Flick, E. W., Epoxy resins, curing agents, compounds, and modifiers: an industrial guide. 2nd ed.; Noyes publication: New Jersey, 1993; p 519.

15. Wan, J.; Bu, Z. Y.; Xu, C. J.; Li, B. G.; Fan, H., Preparation, curing kinetics, and properties of a novel lowvolatile starlike aliphatic-polyamine curing agent for epoxy resins. Chemical Engineering Journal 2011, 171 (1), 357-367.

16. Nakka, J. S.; Jansen, K. M. B.; Ernst, L. J.; Jager, W. F., Effect of the epoxy resin chemistry on the viscoelasticity of its cured product. J. Appl. Polym. Sci. 2008, 108 (3), 1414-1420.

17. Huang, Y. Z.; Tian, Y. Z.; Li, Y. Y.; Tan, X. C.; Li, Q.; Cheng, J.; Zhang, J. Y., High mechanical properties of epoxy networks with dangling chains and tunable microphase separation structure. Rsc Advances 2017, 7 (77), 49074-49082.

18. Heux, L.; Halary, J. L.; Laupretre, F.; Monnerie, L., Dynamic mechanical and C-13 nmr investigations of molecular motions involved in the beta relaxation of epoxy networks based on DGEBA and aliphatic amines. Polymer 1997, 38 (8), 1767-1778.

19. Merritt, M. E.; Heux, L.; Halary, J. L.; Schaefer, J., Determination of the extent of reaction of amine cross-linked epoxy resins by solid-state C-13 and N-15 NMR. Macromolecules 1997, 30 (22), 6760-6763. 
20. Blanco, M.; Lopez, M.; Alvarez De Arcaya, P.; Angel Ramos, J.; Kortaberria, G.; Cristina Riccardi, C.; Mondragon, I., Thermoplastic-Modified Epoxy Resins Cured with Different Functionalities Amine Mixtures: Morphology, Thermal Behavior, and Mechanical Properties. Journal of Applied Polymer Science 2009, 114 (3), 1753-1760.

21. Matejka, L.; Chabanne, P.; Tighzert, L.; Pascault, J. P., Cationic polymerization of diglycidyl ether of bisphenol-A. Journal of Polymer Science Part a-Polymer Chemistry 1994, 32 (8), 1447-1458.

22. Matejka, L.; Dusek, K.; Chabanne, P.; Pascault, J. P., Cationic polymerization of diglycidyl ether of Bisphenol A .2. Theory. Journal of Polymer Science Part a-Polymer Chemistry 1997, 35 (4), 651-663.

23. Matejka, L.; Dusek, K.; Chabanne, P.; Pascault, J. P., Cationic polymerization of diglycidyl ether of Bisphenol A .3. Comparison of the theory with experiment. Journal of Polymer Science Part a-Polymer Chemistry 1997, 35 (4), 665 672 .

24. Radl, S.; Roppolo, I.; Polzl, K.; Ast, M.; Spreitz, J.; Griesser, T.; Kern, W.; Schlogl, S.; Sangermano, M., Light triggered formation of photo-responsive epoxy based networks. Polymer 2017, 109, 349-357.

25. Ollier, R. P.; Victorel, M.; Arenas, G. F.; Oyanguren, P. A.; Galante, M. J.; Schroeder, W. F., Epoxy-Based Azopolymers with Enhanced Photoresponsive Properties Obtained by Cationic Homopolymerization. Macromolecular Materials and Engineering 2017, 302 (11).

26. Al Mousawi, A.; Poriel, C.; Dumur, F.; Toufaily, J.; Hamieh, T.; Fouassier, J. P.; Lalevee, J., Zinc Tetraphenylporphyrin as High Performance Visible Light Photoinitiator of Cationic Photosensitive Resins for LED Projector 3D Printing Applications. Macromolecules 2017, 50 (3), 746-753.

27. Vidil, T.; Hampu, N.; Hillmyer, M. A., Nanoporous Thermosets with Percolating Pores from Block Polymers Chemically Fixed above the Order-Disorder Transition. Acs Central Science 2017, 3 (10), 1114-1120.

28. Bouillon, N.; Pascault, J. P.; Tighzert, L., Epoxy prepolymers cured with boron trifluoride-amine complexes .2. Polymerization mechanisms. Makromolekulare Chemie-Macromolecular Chemistry and Physics 1990, 191 (6), $1417-1433$.

29. Vidil, T.; Tournilhac, F., Supramolecular Control of Propagation in Cationic Polymerization of Room Temperature Curable Epoxy Compositions. Macromolecules 2013, 46 (23), 9240-9248.

30. Hartwig, A.; Schneider, B.; Luhring, A., Influence of moisture on the photochemically induced polymerisation of epoxy groups in different chemical environment. Polymer 2002, 43 (15), 4243-4250.

31. Vidil, T.; Tournilhac, F.; Leibler, L., Control of cationic epoxy polymerization by supramolecular initiation. Polymer Chemistry 2013, 4 (5), 1323-1327.

32. Arnebold, A.; Plander, F.; Thiel, K.; Wellmann, S.; Hartwig, A., Control of reaction mechanisms in cationically polymerized epoxy resins facilitates the adjustment of morphology and mechanical properties. Journal of Polymer Science Part B-Polymer Physics 2016, 54 (21), 2188-2199.

33. Dillman, B.; Jessop, J. L. P., Chain transfer agents in cationic photopolymerization of a bis-cycloaliphatic epoxide monomer: Kinetic and physical property effects. Journal of Polymer Science Part a-Polymer Chemistry 2013, 51 (9), 20582067.

34. Schulzel, M. W.; Hillmyer, M. A., Tuning Mesoporosity in Cross-Linked Nanostructured Thermosets via Polymerization-Induced Microphase Separation. Macromolecules 2017, 50 (3), 997-1007.

35. Gao, H.; Li, W.; Matyjaszewski, K., Synthesis of polyacrylate networks by ATRP: Parameters influencing experimental gel points. Macromolecules 2008, 41 (7), 2335-2340.

36. Kannurpatti, A. R.; Anseth, J. W.; Bowman, C. N., A study of the evolution of mechanical properties and structural heterogeneity of polymer networks formed by photopolymerizations of multifunctional (meth)acrylates. Polymer 1998, 39 (12), 2507-2513.

37. Katahira, C.; Morishita, N.; Ikeda, J.-I.; Lim, P. B.; Inoue, M.; Iwasaki, Y.; Aota, H.; Matsumoto, A., Mechanistic Discussion of Cationic Crosslinking Copolymerizations of 1,2-Epoxycyclohexane with Diepoxide Crosslinkers Accompanied by Intramolecular and Intermolecular Chain Transfer Reactions. Journal of Polymer Science Part a-Polymer Chemistry 2010, 48 (20), 4445-4455.

38. Holly, E. E.; Venkataraman, S. K.; Chambon, F.; Winter, H. H., Fourier-Transform Mechanical Spectroscopy Of 
Viscoelastic Materials With Transient Structure. Journal of Non-Newtonian Fluid Mechanics 1988, 27 (1), 17-26.

39. Winter, H. H.; Chambon, F., Analysis Of Linear Viscoelasticity Of A Cross-Linking Polymer At The Gel Point. Journal of Rheology 1986, 30 (2), 367-382.

40. Eloundou, J. P.; Gerard, J. F.; Harran, D.; Pascault, J. P., Temperature dependence of the behavior of a reactive epoxy-amine system by means of dynamic rheology .2. High-T-g epoxy-amine system. Macromolecules 1996, 29 (21), 69176927.

41. Eloundou, J. P.; Feve, M.; Gerard, J. F.; Harran, D.; Pascault, J. P., Temperature dependence of the behavior of an epoxy-amine system near the gel point through viscoelastic study .1. Low-T-g epoxy-amine system. Macromolecules 1996, $29(21), 6907-6916$.

42. Hartwig, A.; Koschek, K.; Luhring, A.; Schorsch, O., Cationic polymerization of a cycloaliphatic diepoxide with latent initiators in the presence of structurally different diols. Polymer 2003, 44 (10), 2853-2858.

43. Wang, Z.; Lin, X.; Liu, W., Synthesis of bis(2,3-epoxycyclohexyl) and its cationic photopolymerization in the presence of different diols. Polymer International 2009, 58 (1), 74-80.

44. Jan, N.; Coniglio, A.; Herrmann, H. J.; Landau, D. P.; Leyvraz, F.; Stanley, H. E., On The Relation Of Kinetic Gelation And Percolation. Journal of Physics a-Mathematical and General 1986, 19 (7), L399-L404.

45. Stauffer, D.; Coniglio, A.; Adam, M., Gelation And Critical Phenomena. Advances in Polymer Science 1982, 44, 103-158.

46. Martin, J. E.; Adolf, D.; Wilcoxon, J. P., Viscoelasticity Of Near-Critical Gels. Physical Review Letters 1988, 61 (22), 2620-2623.

47. Lairez, D.; Adam, M.; Emery, J. R.; Durand, D., Rheological Behavior Of An Epoxy Amine System Near The Gel Point. Macromolecules 1992, 25 (1), 286-289.

48. Tanaka, Y.; Stanford, J. L.; Stepto, R., Interpretation of Gel Points of an Epoxy-Amine System Including Ring Formation and Unequal Reactivity: Measurements of Gel Points and Analyses on Ring Structures. Macromolecules 2012, 45 (17), 7197-7205.

49. Mortimer, S.; Ryan, A. J.; Stanford, J. L., Rheological behavior and gel-point determination for a model Lewis acid-initiated chain growth epoxy resin. Macromolecules 2001, 34 (9), 2973-2980.

50. Muthukumar, M., Screening Effect On Viscoelasticity Near The Gel Point. Macromolecules 1989, 22 (12), 46564658 .

51. Grulke, E. A., Solubility parameters values. In Polymer handbook, $4^{\text {th }}$ ed.; Brandrup, J.; Immergut, E. H.; Grulke, E. A., Eds. John Wiley \& Sons: New York, pp VII / 675-VII / 714.

52. Flory, P. J.; Rehner, J., Statistical mechanics of cross-linked polymer networks II Swelling. Journal of Chemical Physics 1943, 11 (11), 521-526.

53. Nam, C.; Li, H. X.; Zhang, G.; Chung, T. C. M., Petrogel: New Hydrocarbon (Oil) Absorbent Based on Polyolefin Polymers. Macromolecules 2016, 49 (15), 5427-5437.

54. Flory, P. J., Principles of polymer chemistry. Cornell university press: Ithaca, NY, 1953.

55. Rubinstein, M.; Colby, R. H., Polymer physics. Oxford university press: New York, 2003.

56. Hild, G., Interpretation of equilibrium swelling data on model networks using affine and 'phantom' network models. Polymer 1997, 38 (13), 3279-3293.

57. Dale, J. A.; Millar, J. R., Cross-Linker Effectiveness In Styrene Copolymerization. Macromolecules 1981, 14 (5), $1515-1518$

58. Hild, G., Model networks based on 'endlinking' processes: Synthesis, structure and properties. Progress in Polymer Science 1998, 23 (6), 1019-1149.

59. Ilavsky, M.; Bogdanova, L. M.; Dusek, K., Formation, Structure, And Elasticity Of Loosely Crosslinked Epoxy- 
Amine Networks .2. Mechanical And Optical-Properties. Journal of Polymer Science Part B-Polymer Physics 1984, 22 (2), 265-278.

60. Gao, H.; Min, K.; Matyjaszewski, K., Determination of gel point during atom transfer radical copolymerization with cross-linker. Macromolecules 2007, 40 (22), 7763-7770.

61. Asgarzadeh, F.; Ourdouillie, P.; Beyou, E.; Chaumont, P., Synthesis of polymer networks by "Living" free radical polymerization and end-linking processes. Macromolecules 1999, 32 (21), 6996-7002.

62. Ge, X. P.; Ye, Q.; Song, L. Y.; Misra, A.; Spencer, P., The influence of water on visible-light initiated freeradical/cationic ring-opening hybrid polymerization of methacrylate/epoxy: polymerization kinetics, crosslinking structure and dynamic mechanical properties. Rsc Advances 2015, 5 (95), 77791-77802.

63. Hill, D. J. T.; Perera, M. C. S.; Pomery, P. J.; Toh, H. K., Dynamic mechanical properties of networks prepared from siloxane modified divinyl benzene pre-polymers. Polymer 2000, 41 (26), 9131-9137.

64. Ge, X. P.; Ye, Q.; Song, L. Y.; Misra, A.; Spencer, P., Visible-Light Initiated Free-Radical/Cationic RingOpening Hybrid Photopolymerization of Methacrylate/Epoxy: Polymerization Kinetics, Crosslinking Structure, and Dynamic Mechanical Properties. Macromolecular Chemistry and Physics 2015, 216 (8), 856-872.

65. Di Lorenzo, F.; Hellwig, J.; von Klitzing, R.; Seiffert, S., Macroscopic and Microscopic Elasticity of Heterogeneous Polymer Gels. Acs Macro Letters 2015, 4 (7), 698-703.

66. Tehrani, M.; Sarvestani, A., Effect of chain length distribution on mechanical behavior of polymeric networks. European Polymer Journal 2017, 87, 136-146.

67. Vergara, J. H.; La Scala, J. J.; Henry, C. K.; Sadler, J. M.; Yadav, S. K.; Palmese, G. R., The effect of pendant alkyl chain length on the barrier properties of epoxy/amine crosslinked networks. Polymer 2017, 132, 133-142.

68. Patel, S. K.; Malone, S.; Cohen, C.; Gillmor, J. R.; Colby, R. H., Elastic-Modulus And Equilibrium Swelling Of Poly(Dimethylsiloxane) Networks. Macromolecules 1992, 25 (20), 5241-5251.

69. Syed, I. H.; Stratmann, P.; Hempel, G.; Kluppel, M.; Saalwachter, K., Entanglements, Defects, and Inhomogeneities in Nitrile Butadiene Rubbers: Macroscopic versus Microscopic Properties. Macromolecules 2016, 49 (23), 9004-9016.

70. Strobl, G., Deformation, Yielding and Fracture. In The physics of polymers, $3^{\text {rd }}$ ed.; Strobl, G., Ed. Springer Berlin Heidelberg: Berlin, 2007; pp 415-461.

71. Bowden, P. B., In The physics of glassy polymers, Haward, R. N., Ed. Wiley: New York, 1973; pp 279-339.

72. Kinloch, A. J.; Young, R. J., Fracture behavior of polymers. Applied Science Publishers: London, 1983.

73. Lemay, J. D.; Swetlin, B. J.; Kelley, F. N., Structure And Fracture Of Highly Cross-Linked Networks. Acs Symposium Series 1984, 243, 165-183.

74. Crawford, E. D.; Lesser, A. J., Brittle to ductile: Fracture toughness mapping on controlled epoxy networks. Polymer Engineering and Science 1999, 39 (2), 385-392.

75. Cook, W. D.; Mayr, A. E.; Edward, G. H., Yielding behaviour in model epoxy thermosets - II. Temperature dependence. Polymer 1998, 39 (16), 3725-3733.

76. Urbaczewskiespuche, E.; Galy, J.; Gerard, J. F.; Pascault, J. P.; Sautereau, H., Influence Of Chain Flexibility And Cross-Link Density On Mechanical-Properties Of Epoxy Amine Networks. Polymer Engineering and Science 1991, 31 (22), $1572-1580$

77. Robertson, R. E., Theory For Plasticity Of Glassy Polymers. Journal of Chemical Physics 1966, 44 (10), 3950.

78. Ortiz, C.; Kim, R.; Rodighiero, E.; Ober, C. K.; Kramer, E. J., Deformation of a polydomain, liquid crystalline epoxy-based thermoset. Macromolecules 1998, 31 (13), 4074-4088.

79. Kontou, E., Viscoplastic deformation of an epoxy resin at elevated temperatures. J. Appl. Polym. Sci. 2006, 101 (3), 2027-2033. 
81. van Melick, H. G. H.; Govaert, L. E.; Meijer, H. E. H., On the origin of strain hardening in glassy polymers. Polymer 2003, 44 (8), 2493-2502.

82. Burattini, S.; Greenland, B. W.; Hayes, W.; Mackay, M. E.; Rowan, S. J.; Colquhoun, H. M., A Supramolecular Polymer Based on Tweezer-Type pi-pi Stacking Interactions: Molecular Design for Healability and Enhanced Toughness. Chemistry of Materials 2011, 23 (1), 6-8.

83. Dusek, K.; Ilavsky, M., Epoxide Networks As Model Networks. Colloid and Polymer Science 1980, 258 (5), $605-$ 611.

84. Gupta, V. B.; Drzal, L. T.; Lee, C. Y. C.; Rich, M. J., The Temperature-Dependence Of Some MechanicalProperties Of A Cured Epoxy-Resin System. Polymer Engineering and Science 1985, 25 (13), 812-823.

85. King, N. E.; Andrews, E. H., Fracture Energy Of Epoxy-Resins Above Tg. Journal of Materials Science 1978, 13 (6), 1291-1302.

86. Sharifi, M.; Jang, C.; Abrams, C. F.; Palmese, G. R., Epoxy Polymer Networks with Improved Thermal and Mechanical Properties via Controlled Dispersion of Reactive Toughening Agents. Macromolecules 2015, 48 (20), $7495-7502$.

87. Jang, C.; Sharifi, M.; Palmese, G. R.; Abrams, C. F., Toughness enhancement of thermosetting polymers using a novel partially reacted substructure curing protocol: A combined molecular simulation and experimental study. Polymer 2016, 90, 249-255.

88. Tian, N.; Ning, R. C.; Kong, J., Self-toughening of epoxy resin through controlling topology of cross-linked networks. Polymer 2016, 99, 376-385. 


\section{Supporting information}

\section{Control of gelation and network's properties of cationically copolymerized mono- and di-glycidyl ethers.}

Thomas Vidil, ${ }^{\dagger}$ Michel Cloître ${ }^{\dagger}$ and Francois Tournilhac ${ }^{\dagger *}$

$\dagger$ Matière Molle et Chimie, UMR 7167 CNRS ESPCI Paris, PSL Research University, 10 rue Vauquelin 75005 Paris, France.

* Corresponding author : francois.tournilhac@espci.fr

1. Detailed procedure for the monitoring of the curing reaction $S 2$

2. FTMS method S4

3. The Winter and Chambon criterion S7

4. Calculation the probability that the active end of the propagating chain adds another monomer to the growing chain, $q$. S8

5. Summary of critical exponent values in gelation models $S 10$

6. Calculation of $M_{X, c}$ $S 11$

7. Estimation of the solubility parameter of the polymer network, $\delta$, the density of the polymer, $\rho_{p}$ and the polymer-solvent interaction parameter, $\chi$. S12

8. Solvent screening for the swelling experiment $S 13$

9. Measure of the linear swelling ratio, $\lambda$ $S 14$

10. Measure of the soluble fraction, ws and the polymer volume fraction in the network obtained after the curing reaction, $v c$. S14

11. Homopolymerization of $P G E: D G E B A_{0} P G E_{100}$ and $D G E B A_{0} P G E_{100} P E O$ $S 15$

12. Fitting of tan $\delta$ peaks S17

13. Tensile tests: cyclic loading S18

14. References S20 


\section{Detailed procedure for the monitoring of the curing reaction}

The isothermal curing process was monitored using a Bruker-Tensor 37 IR spectrometer at a resolution of $4 \mathrm{~cm}^{-1}$, equipped with a thermally controlled SPECAC Goldengate ATR accessory. Samples were deposited on the ATR diamond in the center of a Teflon seal covered with a metallic lid held in place by pressure, resulting in a leak-proof cavity presenting very good atmosphere tightness. The disappearance of the $914 \mathrm{~cm}^{-1}$ absorption peak (epoxy bending) was monitored to determine the epoxy conversion. The peak at $1605 \mathrm{~cm}^{-1}$ (DGEBA phenyl groups) was chosen as an internal standard. Conversion was determined by the Lambert-Beer law from the change of normalized absorbance at 914 $\mathrm{cm}^{-1}$ :

$$
\alpha_{\text {epoxy }}=1-\left(\frac{\bar{A}_{914}^{t}}{\bar{A}_{914}^{0}}\right) \quad \text { Eq. }(\mathrm{S} 1)
$$

where $\alpha_{\text {epoxy }}$ is the epoxy conversion; $\bar{A}_{914}^{0}=A_{914}^{0} / A_{1605}^{0}$ and $\bar{A}_{914}^{t}=A_{914}^{t} / A_{1605}^{t}$ are the normalized absorbances of the epoxy groups before curing and after the reaction time $t$, respectively.

Rheological measurements under isothermal conditions were monitored using an Anton Paar Physica MCR 501 rheometer operating in the parallel plates geometry. Disposable plates were preheated in the environmental chamber of the rheometer for approximately $30 \mathrm{~min}$ at the set temperature before loading the samples. The gap between plates was fixed at $1 \mathrm{~mm}$. The experiments were performed in the multiwave mode using Fourier transfrom mechanical spectroscopy (FTMS). A multiwave strain signal of $1 \%$ amplitude for the $1 \mathrm{rad} \mathrm{s}^{-1}$ component was applied in order to collect $G^{\prime}, G^{\prime \prime}$ data every $30 \mathrm{~s}$ for eight different frequencies: 1, 2, 4, 8, 16, 32, 64, and $128 \mathrm{rad} \mathrm{s}^{-1}$ (more details below). Samples were placed under a nitrogen atmosphere $\left(\mathrm{N}_{2} 99.99 \%, \mathrm{H}_{2} \mathrm{O} \leq 5 \mathrm{ppm}\right)$ during the whole procedure to avoid the potential moisture effect.

The uniformity of the reaction kinetic on the IR stage and in the rheometer was investigated for the following system: DGEBA ${ }_{100} \mathrm{PGE}_{0}$ with the addition of 18-crown-6 (0.061 eq. per epoxy functions) and 1,4-butanediol ( 0.061 eq. per epoxy functions). These additives were used in a previous study. ${ }^{1}$ They provide a curing system with a curing rate that is slow enough to stop and quench the reaction for various curing times before completion of the reaction.

A first batch was prepared and studied via IR and rheology according to the protocol reported above. For the sample crosslinked on the IR stage, an IR spectrum was recorded every 3 min until completion of the reaction. 
For the sample crosslinked in the rheometer, after a given amount of time $(t=360 \mathrm{~min})$, the sample was taken out of the rheometer and quenched in liquid nitrogen. It was then stored in a freezer $\left(-30{ }^{\circ} \mathrm{C}\right)$.

Three other batches of the same composition were prepared and crosslinked in the rheometer (in each case, prior to curing in the rheometer, an IR spectrum of the sample was acquired for $t=0$ ). Similarly, the reaction was quenched after a given amount of time $(t=600 \mathrm{~min}, t=780 \mathrm{~min}$ and $t=900 \mathrm{~min})$.

The four samples crosslinked in the rheometer and quenched in liquid nitrogen were then analyzed by IR spectrometry. The epoxy conversion (at the curing time corresponding to the quenching time) was then calculated by comparison with the spectrum acquired for $\mathrm{t}=0$.

The data are reported in the following Figure (Figure S1). The red line represents the epoxy conversion obtained for the sample crosslinked on the IR stage (Batch number 1). The black squares represent the epoxy conversion obtained for the samples crosslinked in the rheometer and quenched after a given amount of time.

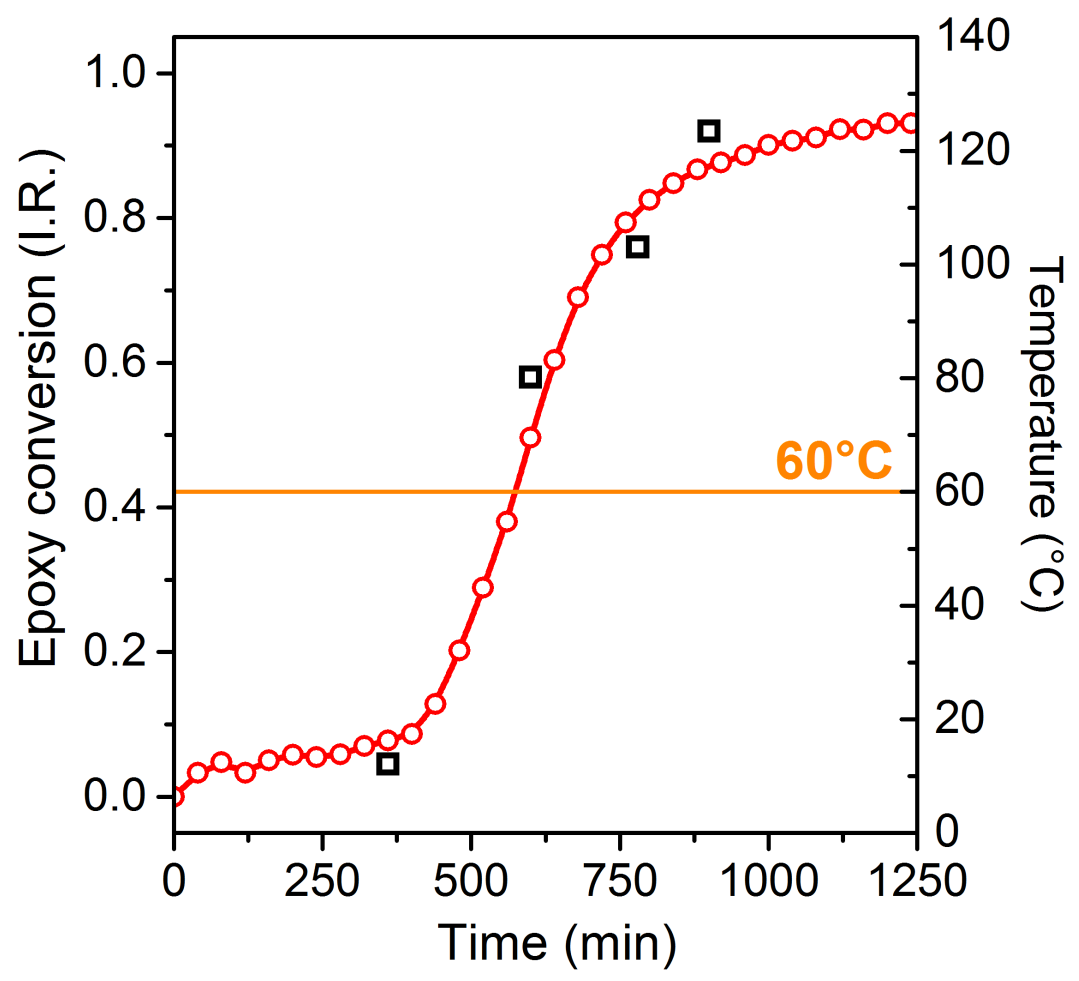

Figure S1: Epoxy conversion as a function of time for various batches of DGEBA100PGE0 with the addition of 18-crown-6 (0.061 eq. per epoxy functions) and 1,4-butanediol (0.061 eq. per epoxy functions). The red line represents the epoxy conversion for a sample crosslinked on the IR stage (a spectrum was collected every $3 \mathrm{~min}$ ). The black squares represent the epoxy conversion for samples crosslinked in the rheometer and quenched in liquid nitrogen after a given amount of time (corresponding to the abscise of the square). For these samples, the epoxy conversion was measured by comparing the IR spectrum collected for the liquid mixture (prior to curing) and the IR spectrum for the sample obtained after quenching in liquid $\mathrm{N}_{2}$. 
The very good agreement between the two sets of data indicates that the reaction is proceeding at the same rate in the rheometer and on the IR stage.

Note: the uniformity of the reaction from one batch to another was already investigated in a previous study. ${ }^{1}$

\section{FTMS method}

In order to make use of the Winter-Chambon criterion, the dynamic moduli must be obtained at different frequencies as crosslinking progresses. One possible way of accomplishing this is to realize dynamic mechanical measurements at constant frequency for various frequency values (=time sweep at various frequency). ${ }^{2}$ This requires the preparation of a new sample for each frequency. As a result, this approach is a bit tedious.

Another possibility is to realize frequency sweeps at certain time intervals. ${ }^{3}$ In that case, measurement time has to be short as compared to the curing kinetic so that no appreciable changes occur during a given frequency sweep. Thus, this method is inappropriate in most of the configuration where curing is performed in cationic mode (fast reactions).

One possible alternative to circumvent the drawbacks of the two aforementioned methods is to use Fourier transform mechanical spectroscopy (FTMS). ${ }^{4}$ This technique is based on the Boltzmann superposition principle, which in simplified terms, states that two or more mechanical waves can simultaneously pass through a material independent of each other (providing they are in the linear viscoelastic range).

Thus, it is possible to apply a compound waveform on the sample of the type:

$$
\sum_{i=1}^{m} \gamma_{i} \sin \left(\omega_{i} t\right) \quad \text { Eq. }(\mathrm{S} 2)
$$

Where $m$ is the number of frequency of the compound waveform, $\gamma_{i}$, the amplitude of the $i$ th component and $\omega_{i}$ the frequency of the $i$ th component (which is an integer multiple of the fundamental frequency $\left.\omega_{0}\right)$.

By measuring the resulting stress from this compound strain, FTMS permits to effectively decouple the frequency dependence and the time dependence of the fluid properties. This enables to directly obtain the complex moduli, $G^{\prime}(\omega)$ and $G^{\prime \prime}(\omega)$, at several frequencies simultaneously as the system structure evolves with time (see Figures S2 and S3 for a comparison of the mono- and multiwave methods). The minimal duration between two successive measurements is determined by the fundamental frequency, $\omega_{0}$. Indeed, measurements at higher frequencies do not require additional time since they are conducted simultaneously. 
Among possible limitations of this approach, one has to consider that the total strain applied is related to the sum of the Fourier series described by each individual strain. Thus, if individual $\gamma_{i}$ are too elevated, then it is possible to go beyond the linear viscoelastic domain of the material. On the other hand, if individual $\gamma_{i}$ are too small, the contribution of each mode would be too small to be detectable with sufficient accuracy.

For these reasons, this experimental approach was inappropriate for the study of DGEBA homopolymerization (for which the viscoelastic domain is very narrow due to the high $T_{g}$ of the cured material). Furthermore, for the study of PGE and DGEBA copolymerization, it was necessary to use large cell geometry ( $\Phi=50 \mathrm{~mm}$, i.e. two times larger as compared to the cells usually used for this type of measurements) in order to increase the signal of the strain of small amplitude components.

FTMS was used on an Anton Paar Physica MCR 501 rheometer operating in the parallel plates geometry (disposable cell with a diameter $\Phi=50 \mathrm{~mm}$ ). $G^{\prime}, G^{\prime \prime}$ data were obtained every 30 s for frequencies ranged from 1 to $100 \mathrm{rad} / \mathrm{s}(1,2,4,8,16,32,64,100 \mathrm{rad} / \mathrm{s})$ and for a strain amplitude fixed at $1 \%$ for the fundamental angular frequency $\left(\omega_{0}=1 \mathrm{rad} \mathrm{s}^{-1}\right)$.

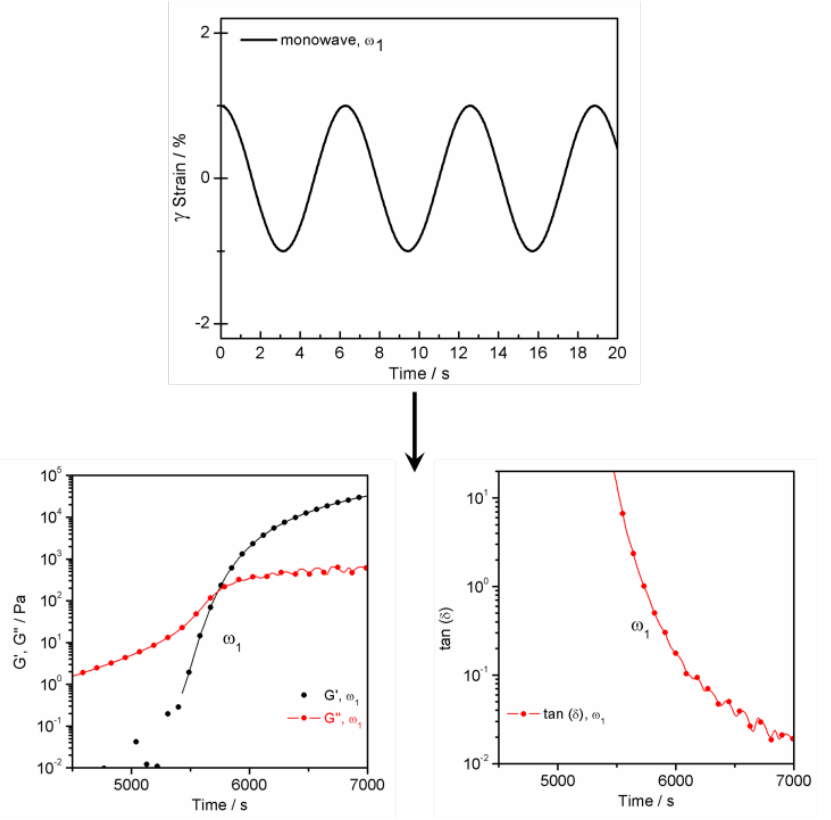

Figure S2: Rheometric measurements in the monowave mode. The sample is subjected to a simple sinusoidal oscillatory strain $\left(\cos \left(\omega_{1}, t\right)\right)$. The measurement of the material response yields the evolution of $\mathrm{G}^{\prime}, \mathrm{G}^{\prime}$, and $\tan (\delta)$ for a single angular frequency, $\omega_{1}$. 

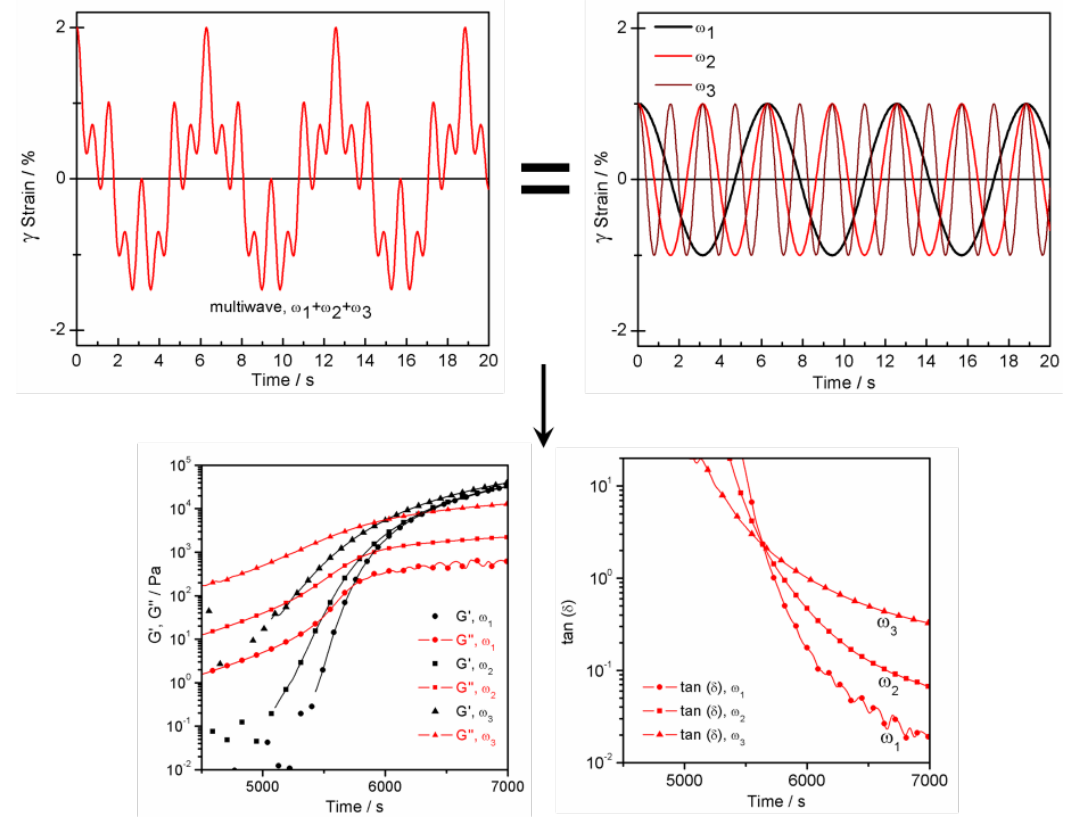

Figure S3: Rheometric measurements in the multiwave mode. The sample is subjected to a complex multiwave sinusoidal oscillatory strain $\left(A_{1} \cos \left(\omega_{1} \cdot t\right)+A_{2} \cos \left(\omega_{2} \cdot t\right)+A_{3} \cos \left(\omega_{3} \cdot t\right)\right)$ resulting from the superposition of several monosinusoidal oscillatory strains. After treatment (Fourrier transform) of the signal resulting from the material response, the evolution of G', G' ' and $\tan (\delta)$ is obtained for the three angular frequencies, $\omega_{1}, \omega_{2}$ and $\omega_{3}$. 


\section{The Winter and Chambon criterion}

An accurate estimation of the gel point is given by the criterion introduced by Winter and Chambon. ${ }^{4-8}$ They revealed that the stress relaxation of a network polymer at the gel point follows a power law:

$$
G(t)=S t^{-n} \quad \text { Eq. }(\mathrm{S} 3)
$$

Where $\mathrm{S}$ is the strength of the gel and is dependent on the flexibility of molecular chains and on the crosslink density at the gel point. $t$ is the time. $n$ is called the relaxation or critical exponent. By considering the Fourrier transform of the above equation, i.e. the complex shear modulus $G^{*}(\omega)$, it can be deduced that, at the gel point, the storage, $G^{\prime}(\omega)$, and loss, $G^{\prime \prime}(\omega)$ modulus $\left(G^{*}(\omega)=\right.$ $F T(G(t))=G^{\prime}(\omega)+i \cdot G^{\prime \prime}(\omega)=f(n) \cdot S \cdot \omega^{n}(\cos (n \pi / 2)+i \cdot \sin (n \pi / 2))$, depend on frequency in an identical manner:

$$
G^{\prime \prime}(\omega) \sim G^{\prime \prime}(\omega) \sim \omega^{n} \quad \text { Eq. }(\mathrm{S} 4)
$$

Additionally, the phase angle, $\delta$, between stress and strain is independent of the frequency $(\omega)$ but is proportional to the relaxation exponent.

$$
\delta=n \pi / 2 \text { or } \tan (\delta)=\frac{G \prime \prime}{G \prime}=\tan (n \pi / 2) \quad \text { Eq. }(\mathrm{S} 5)
$$

As a result, the gel point may be identified either by studying the evolution of $G^{\prime}(\omega)$ and $G^{\prime \prime}(\omega)$, or of their ratio, the loss tangent $\tan (\delta)$ as a function of time and angular frequency:

- In the former case, the gel point is revealed by $G^{\prime}(\omega)$ and $G^{\prime \prime}(\omega)$ curves as a function of the angular frequency, $\omega$, that correspond to parallel lines over a wide frequency spectrum for a given time.

- In the later case, the various curves at different frequencies of $\tan (\delta)$, as a function of cure time, would coincide at a single point corresponding to the gel point.

In both cases, it is possible to estimate the relaxation exponent, $n . n$ values are well predicted by various model based on scaling theory that further corroborate the validity of the Winter criterion. ${ }^{9-12}$ By using these models, $n$ can be related to the geometry of cluster existing at the gel point. ${ }^{13}$ 


\section{Calculation the probability that the active end of the propagating chain adds another monomer to the growing chain, $q$.}

By using the methods developed for the simple modelisation of ideal chainwise copolymerization of bifunctional and $f$-functional monomers, it comes: ${ }^{14}$

$$
\alpha_{\text {gel }}=(1-q) /\left[2 a_{f}(q+\xi / 2)\right] \quad \text { Eq. }(S 6)
$$

Where $\mathrm{a}_{\mathrm{f}}$ is the molar fraction of the $f$-functional monomer and is given by:

$$
\mathrm{a}_{\mathrm{f}}=\frac{f \times \mathrm{x} / \mathrm{M}_{\mathrm{XL}}}{2(1-\mathrm{x}) / \mathrm{M}_{\mathrm{m}}+f \times \mathrm{x} / \mathrm{M}_{\mathrm{XL}}} \quad \text { Eq. (S7) }
$$

with $M_{\mathrm{XL}}$, the molecular weight of the $f$-functional monomer (the crosslinker, XL), $M_{\mathrm{m}}$ the molecular weight of the bifunctional monomer and $x$ the weight fraction of the crosslinker, XL. In the present study, $\mathrm{XL}=$ DGEBA and $f=4$.

The parameter $\xi$ gives the probability that the termination of active species takes place through a mechanism resulting in longer chains than the active chains before termination. Typically, "chain combination" is an example of termination step that results in an increase of $M_{n}$ for the free radical polymerization of vinylic monomers. In this latter case, when termination takes place by combination exclusively, $\xi=1$. On the other hand, when termination takes place by chain transfer or disproportionation exclusively (termination mechanism with no change of $M_{n}$ ), $\xi=0$.

In the case of the cationic polymerization of epoxy monomers, the situation is a bit more complex because of the many transfer reactions (in particular when alcohols are added to the compositions). They generally result in the formation of alcohols that will either stay unreacted ("dead") or that will react with an activated chain or an activated monomer to provide a longer chain (AM mechanism). In any case, the termination of active species (monomer or chain end) results in the formation of an alcohol that is also a potential active species in the cationic polymerization of epoxy. Another possible mechanism of termination is back-biting ${ }^{15}$ but it is an intramolecular reaction that is outside the scope of ideal systems.

Overall, it is very difficult to predict $\xi$ values or even to suggest an estimation of it and the best option seems to consider the two limit cases, i.e. $\xi=1$ (terminations with increase of chain size) and $\xi=0$ (terminations without increase of chain size).

For these two cases, the calculated values of $q$ are reported in Table S1, along the calculate values of $a_{4}$ : 


\begin{tabular}{|c|c|c|c|c|c|}
\hline Materials & $t_{g e l}(\min )$ & $\alpha_{g e l}(\%)$ & $a_{4}$ & $q(\xi=1)$ & $q(\xi=0)$ \\
\hline DGEBA $_{15} \mathrm{PGE}_{85}$ & 63 & 73 & 0.13 & 0.75 & 0.84 \\
\hline $\mathrm{DGEBA}_{25} \mathrm{PGE}_{75}$ & 8.5 & 47 & 0.23 & 0.74 & 0.82 \\
\hline DGEBA $_{35} \mathrm{PGE}_{65}$ & 6.5 & 32 & 0.32 & 0.74 & 0.83 \\
\hline DGEBA $_{100} \mathrm{PGE}_{0}$ & 2 & 7 & 1.00 & 0.82 & 0.88 \\
\hline $\mathrm{DGEBA}_{25} \mathrm{PGE}_{75} \mathrm{PEO}$ & 130 & 77 & 0.23 & 0.61 & 0.74 \\
\hline DGEBA $_{35} \mathrm{PGE}_{65} \mathrm{PEO}$ & 99 & 68 & 0.32 & 0.54 & 0.70 \\
\hline $\mathrm{DGEBA}_{45} \mathrm{PGE}_{55} \mathrm{PEO}$ & 78 & 46 & 0.42 & 0.58 & 0.72 \\
\hline $\mathrm{DGEBA}_{100} \mathrm{PGE}_{0} \mathrm{PEO}$ & 73 & 43 & 1.00 & 0.31 & 0.54 \\
\hline DGEBA $_{35} \mathrm{PGE}_{65} \mathrm{MeOPEO}$ & 94 & 65 & 0.32 & 0.56 & 0.70 \\
\hline DGEBA $_{100} \mathrm{PGE}_{0} \mathrm{MeOPEO}$ & 53 & 30 & 1.00 & 0.44 & 0.63 \\
\hline $\mathrm{DGEBA}_{35} \mathrm{PGE}_{65} \mathrm{PPO}$ & 32 & 61 & 0.32 & 0.58 & 0.72 \\
\hline $\mathrm{DGEBA}_{100} \mathrm{PGE}_{0} \mathrm{PPO}$ & 29 & 46 & 1.00 & 0.28 & 0.52 \\
\hline $\mathrm{DGEBA}_{35} \mathrm{PGE}_{65} \mathrm{PPD}$ & 45 & 57 & 0.32 & 0.60 & 0.73 \\
\hline
\end{tabular}

Table S1: Calculated values of $a_{4}$, the molar fraction of DGEBA and $q$, the probability that the active end of the propagating chain adds another monomer to the growing chain. 


\section{Summary of critical exponent values in gelation models}

In gelation models based on the percolation theory, ${ }^{16-18}$ polymerization and gelation are described through the random connection of monomers occupying sites on a lattice of arbitrary dimensions, leading to polydisperse distributions of clusters with fractal geometries. At the gel point an infinite cluster is formed, with a size and a mass that diverge. On the basis of this model, calculations have been reported that consider the clusters under various approximations (Rouse-like dynamics, electrical network analogy). They all result in power law dependences for properties of interest close to the gel point : shear modulus : $G^{\prime} \sim \varepsilon^{z}$, viscosity $: \eta \sim \varepsilon^{-k}$, weight average molecular weight $: M_{w} \sim \varepsilon^{-\gamma}$ where $\varepsilon$ is a dimensionless parameter characterizing the distance to the gel point, defined as

$$
\varepsilon=\frac{\left|\alpha_{g e l}-\alpha\right|}{\alpha} \quad \text { Eq. (S8) }
$$

with $\alpha$ the chemical conversion and $\alpha_{g e l}$ its value at the gel point. Previously reported values of critical exponents (predictions and experiments) are summarized in Table S2.

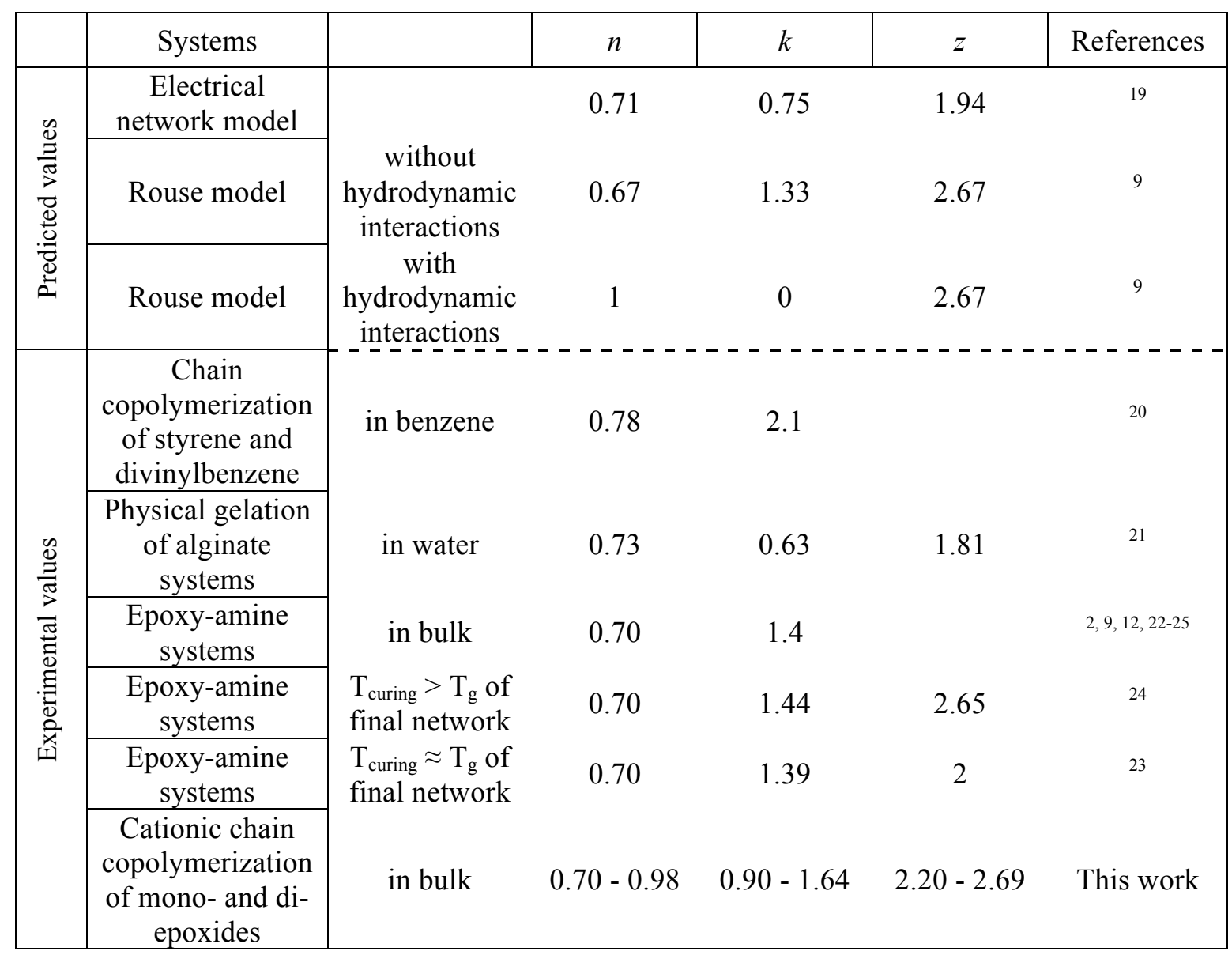

Table S2: Predicted and experimental values of critical exponents for the gelation of crosslinked networks. 


\section{Calculation of $M_{X, c}$}

For the copolymerization of a monomer with a polyfunctional cross-linking agent, $X L$, the calculation of $M_{X, c}$ can proceed as follow:

Assuming a quantitative reaction of cross-linking and a formation of a network with very few free ends as compared to the number of cross-linking, the concentration of cross-linked chains is expected to be the number of functional group, $n_{f}$, of the cross-linking agent $X L$, times its concentration, $[X L]^{: 26,27}$

$$
v_{e}=n_{f}[X L] \quad \text { Eq. (S9) }
$$

Thus, it comes:

$$
M_{X, c}=\frac{\rho}{v_{e}}=\frac{\rho}{n_{f}[X L]}=\frac{m_{t o t}}{n_{f} \cdot n_{X L}}=\frac{m_{t o t}}{n_{f} \cdot \frac{m_{X L}}{M_{X L}}}=\frac{100 \cdot M_{X L}}{n_{f} \cdot w t \%_{X L}} \quad \text { Eq. (S10) }
$$

where $m_{t o t}$ is the mass of the network polymer one considers. $m_{X L}, w t \%_{X L}$ and $n_{X L}$ are respectively the mass, the mass fraction and the number of mole of cross-linking agent within the network polymer one considers. $M_{X L}$ is the molecular weight of the cross-linking agent.

From the resulting formula, it is evident that $M_{X, c}$ can be calculated without an experimental density.

Note: additives can be considered as a monomer like PGE. Indeed, diols are inserted in the network just like PGE. Their concentration and molecular weight impact the value of $w t \%_{X L}$ and thus the value of $M_{X, c}$. The only special case is MeO-PEO-OH. This is a monoalcohol. It is thus inserted in the network

\begin{tabular}{|c|c|c|c|c|c|c|}
\hline Materials & $\begin{array}{c}x_{D G E B A} \\
(\mathrm{wt} \%)\end{array}$ & $\begin{array}{c}x_{P G E} \\
(\mathrm{wt} \%)\end{array}$ & $\begin{array}{c}x_{\text {additive }} \\
(\mathrm{wt} \%)\end{array}$ & $\begin{array}{c}M_{X, c} \\
\left(\mathrm{~g} \mathrm{~mol}^{-1}\right)\end{array}$ & $\begin{array}{c}\delta \\
\left(\mathrm{MJ} / \mathrm{m}^{3}\right)^{1 / 2}\end{array}$ & $\chi$ \\
\hline DGEBA $_{15} \mathrm{PGE}_{85}$ & 15 & 85 & 0 & 1135 & 22.3 & 0.345 \\
\hline DGEBA $_{25} \mathrm{PGE}_{75}$ & 25 & 75 & 0 & 681 & 22.3 & 0.345 \\
\hline DGEBA $_{35} \mathrm{PGE}_{65}$ & 35 & 65 & 0 & 486 & 22.3 & 0.345 \\
\hline $\mathrm{DGEBA}_{25} \mathrm{PGE}_{75} \mathrm{PEO}$ & 22 & 67 & 11 & 761 & 22.2 & 0.344 \\
\hline $\mathrm{DGEBA}_{35} \mathrm{PGE}_{65} \mathrm{PEO}$ & 31 & 58 & 11 & 543 & 22.2 & 0.344 \\
\hline $\mathrm{DGEBA}_{45} \mathrm{PGE}_{55} \mathrm{PEO}$ & 40 & 49 & 11 & 422 & 22.2 & 0.344 \\
\hline $\mathrm{DGEBA}_{35} \mathrm{PGE}{ }_{65} \mathrm{MeOPEO}$ & 31 & 57 & 12 & 553 & 22.2 & 0.344 \\
\hline $\mathrm{DGEBA}_{35} \mathrm{PGE}_{65} \mathrm{PPO}$ & 30 & 56 & 14 & 562 & 22.1 & 0.342 \\
\hline $\mathrm{DGEBA}_{35} \mathrm{PGE}_{65} \mathrm{PPD}$ & 33 & 61 & 6 & 518 & 22.3 & 0.345 \\
\hline
\end{tabular}
as a pendant chain. We assumed it does not have a significant impact on the calculation of $M_{X, c}$.

Table S3: Calculated values of $M_{X, c}, \delta$ and $\chi$ for the polymer networks used in this study 


\section{Estimation of the solubility parameter of the polymer network, $\delta$, the density of the polymer, $\rho_{p}$ and the polymer- solvent interaction parameter, $\chi$.}

In order to have a composition dependent estimation of the solubility parameter of the networks, $\delta_{\text {polymère }}$ was estimated on the basis of the simple equation that is usually employed for the calculation of mixtures' solubility parameter: ${ }^{28}$

$$
{ }^{i j} \delta={ }^{i} \phi{ }^{i} \delta+{ }^{j} \phi{ }^{j} \delta \quad \text { Eq. }(\mathrm{S} 11)
$$

The systems DGEBA ${ }_{x} \mathrm{PGE}_{100-\mathrm{x}} \mathrm{Y}$ were considered as a mixture of the resin (DGEBA+PGE) and an additive (Y). Using the numerical values of $\delta_{\text {resin }}$ and $\delta_{\text {additive }}$ tabulated in Polymer Handbooks, $\delta_{\text {polymer }}$ was calculated as follow:

$$
\delta_{\text {polymer }}=\phi_{\text {resin }} . \delta_{\text {resin }}+\phi_{\text {additive }} . \delta_{\text {additive }} \quad \text { Eq. }(\mathrm{S} 12)
$$

The polymer-solvent interaction parameter, $\chi$, was subsequently calculated by employing the Bristow and Watson equation that yields: $:^{29,30}$

$$
\chi=\beta+\frac{V_{S}}{R T}\left(\delta_{\text {polymer }}-\delta_{\text {Solvent }}\right)^{2}
$$

where $\beta$ is the lattice constant whose numerical value is classically taken as 0.34 for rubbery networks. $R$ and $T$ have their usual significance and $V_{S}$ is the molar volume of the solvent.

The values of $\delta$ and $\chi$ are reported in Table S3.

$\rho_{p}$ the density of the polymer network was experimentally estimated after measuring the volume of weighted samples with a pycnometre. Whatever the composition of the sample (cross-linker content and additives), repeated measurements yield similar values of $\rho_{p}$ that is about $1.19 \mathrm{~g} \mathrm{ml}^{-1}$. This value is very close to previously reported estimation of the density of cationically polymerized epoxy resins. ${ }^{31}$ 


\section{Solvent screening for the swelling experiment}

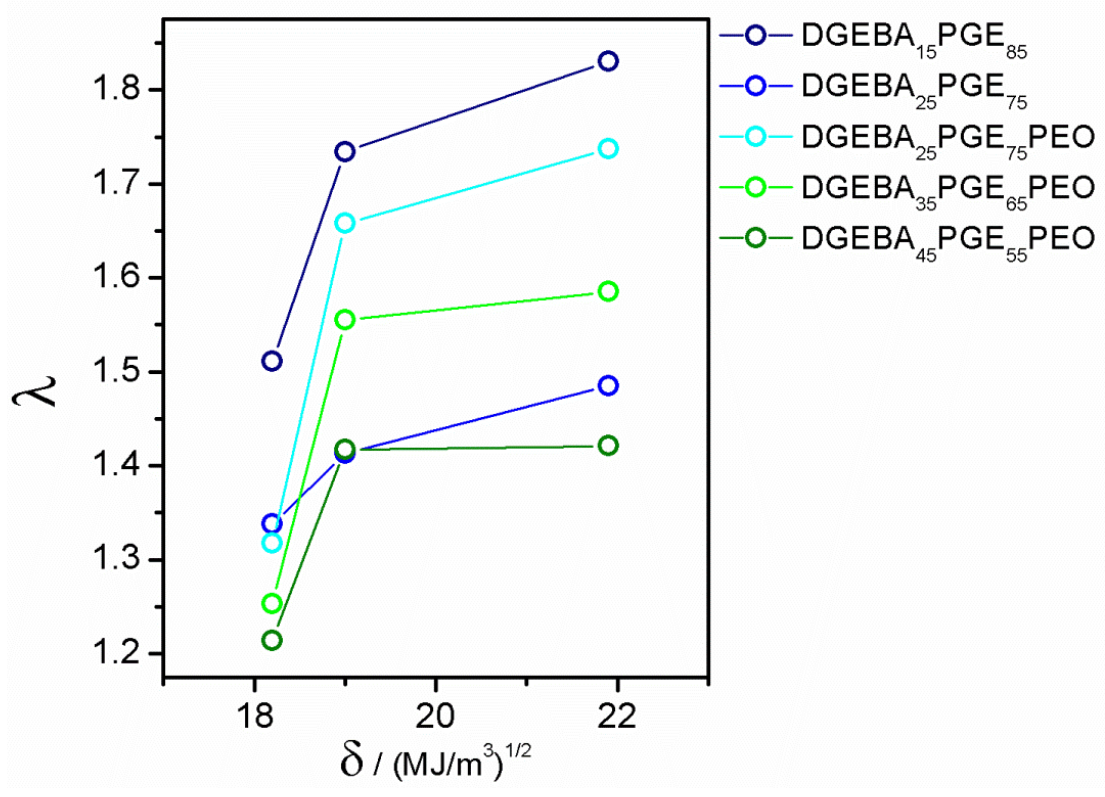

Figure S4: $\boldsymbol{\lambda}$ versus $\boldsymbol{\delta}$ for various compositions DGEBA ${ }_{\mathrm{x}} \mathrm{PGE}_{100-\mathrm{x}} \mathrm{X}$. Three solvents are tested: toluene $\delta=18.2 \mathrm{MPa}^{1 / 2}$, chloroform, $\delta=19 \mathrm{MPa}^{1 / 2}$ and pyridine, $\delta=21.9 \mathrm{MPa}^{1 / 2}$

Figure S4 represents the variation of the swelling ratio, $\lambda$, as a function the solubility parameter, $\delta$, for various network compositions in three solvents with increasing solubility parameter: toluene, $\delta=$ 18.2 $\mathrm{MPa}^{1 / 2}$, chloroform, $\delta=19 \mathrm{MPa}^{1 / 2}$ and pyridine, $\delta=21.9 \mathrm{MPa}^{1 / 2}{ }^{29}$

For each composition, maximal $\lambda$ is obtained with pyridine. This is in accordance with the solubility parameter of conventional epoxy resin that one can find in the Polymer Handbook, $\delta=22.3 \mathrm{MPa}^{1 / 2}$ 29 


\section{Measure of the linear swelling ratio, $\lambda$}

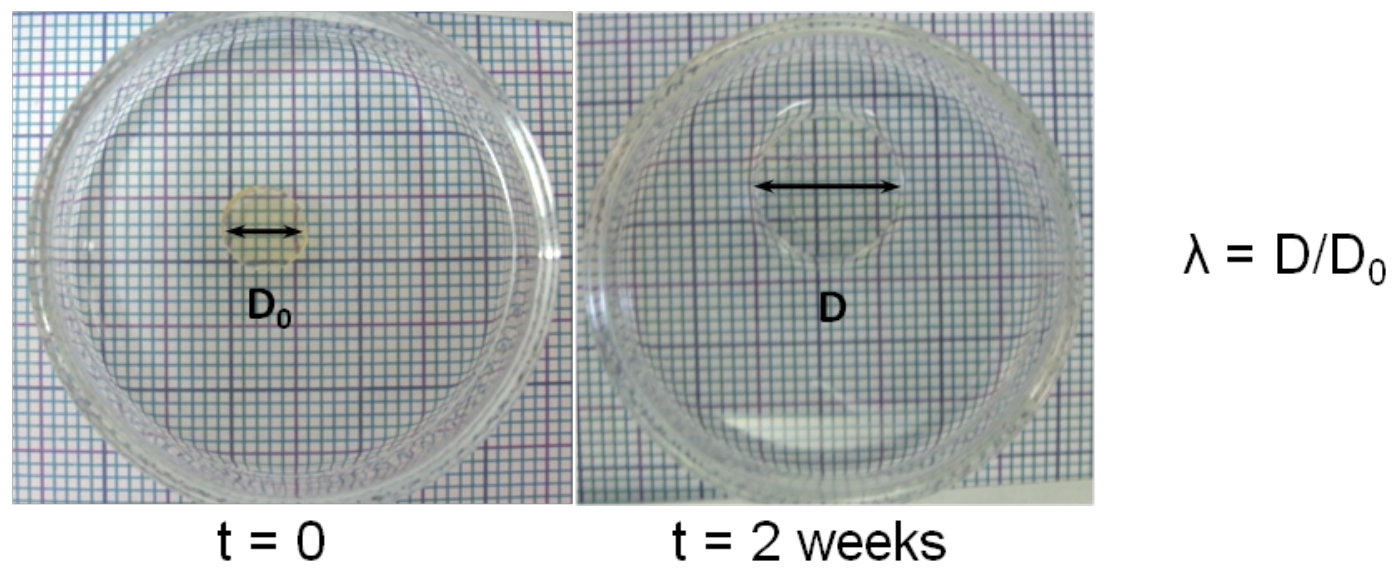

Figure S5: Procedure for the measurement of the swelling ratio. The sample used in this illustration is DGEBA $_{15} \mathrm{PGE}_{85}$, before and after 2 weeks immersed in pyridine.

\section{Measure of the soluble fraction, $w_{s}$ and the polymer volume fraction in the network obtained after the curing reaction, $v_{c}$.}

In order to take it into account the presence of the sol fraction inside the cured network, Eq. (5) (the Flory-Rhener equation) and Eq. (7) (expression of the rubbery plateau modulus) have been modified with $v_{c}$, the polymer volume fraction in the network obtained after the curing reaction and partially swollen by the sol fraction: $v_{c}=1-v_{s}=1-w_{s} . v_{s}$ and $w_{s}$ are respectively the volume fraction and the weight fraction of the sol fraction with $v_{s}=w_{S}$ assuming that the density of the soluble fraction is equal to the density of the network chains (classical approximation). ${ }^{32}$

$w_{s}$ was measured for each sample by comparing the weight of the sample before swelling equilibrium and after 2 weeks in pyridine followed by overnight vacuum drying. Similar values were obtained after swelling the samples in a large excess of toluene at $70^{\circ} \mathrm{C}$ during 5 days.

These values were then used to calculate $v_{c}$. They are reported in Table S4. 


\begin{tabular}{|c|c|c|c|}
\hline Materials & $\begin{array}{c}w_{s}, \text { swelling in } \\
\text { Pyridine at RT } \\
\left(\mathrm{wt}^{\circ} \%\right)\end{array}$ & $\begin{array}{c}w_{s}, \text { swelling in } \\
\text { Toluene at } 70{ }^{\circ} \mathrm{C} \\
(\mathrm{wt} \%)\end{array}$ & $v_{c}$ \\
\hline DGEBA $_{15} \mathrm{PGE}_{85}$ & 18 & 19 & 0.82 \\
\hline DGEBA $_{25} \mathrm{PGE}_{75}$ & 7.9 & 8.2 & 0.92 \\
\hline DGEBA $_{35} \mathrm{PGE}_{65}$ & 0.9 & 1.1 & 0.99 \\
\hline $\mathrm{DGEBA}_{25} \mathrm{PGE}_{75} \mathrm{PEO}$ & 14 & 13 & 0.86 \\
\hline $\mathrm{DGEBA}_{35} \mathrm{PGE}_{65} \mathrm{PEO}$ & 5.3 & 5.0 & 0.95 \\
\hline $\mathrm{DGEBA}_{45} \mathrm{PGE}_{55} \mathrm{PEO}$ & 4.5 & 4.3 & 0.96 \\
\hline DGEBA $_{35} \mathrm{PGE}_{65} \mathrm{MeOPEO}$ & 6.9 & 6 & 0.93 \\
\hline $\mathrm{DGEBA}_{35} \mathrm{PGE}_{65} \mathrm{PPO}$ & 3.2 & 3.2 & 0.97 \\
\hline $\mathrm{DGEBA}_{35} \mathrm{PGE}_{65} \mathrm{PPD}$ & 5.7 & 6.3 & 0.94 \\
\hline
\end{tabular}

Table S4: Measured values of the soluble fraction $\left(w_{s}\right)$ according to two procedures (swelling in pyridine at RT for 2 weeks and swelling in toluene at $70{ }^{\circ} \mathrm{C}$ for 5 days) and calculated values of the polymer volume fraction in the network obtained after the curing reaction, $v_{c}$, by using $w_{s}$ measured in pyridine.

\section{Homopolymerization of PGE: DGEBA $\mathrm{PGE}_{100}$ and DGEBA $_{0}$ PGE $_{100}$ PEO}

$\underline{\text { Procedure for DGEBA }} \underline{\underline{P_{G E}}} \underline{\underline{100}} \underline{\mathrm{PEO}}$ :

A schlenck was flame dried under vacuum before use and maintained under nitrogen atmosphere. The initiator $4 \mathrm{CA}^{+}-\mathrm{BF}_{4}^{-}$(0.026 equiv. per epoxy) and $\mathrm{HO}-\mathrm{PEO}-\mathrm{OH}(0.061$ eq. equiv. per epoxy) were weighted in separated vials and. PGE ( $2 \mathrm{~g}, 1$ eq.) was added to HO-PEO-OH and stirred to provide an homogeneous mixture. The resulting solution was added to 4CA+-BF4-. Solubilization is immediate. Then, the resulting mixture was introduced in the schlenk, equipped with a magnetic stir bar, and the reaction mixture was allowed to stir under nitrogen atmosphere. Reaction is monitored through IR spectroscopy (decrease of the epoxy bending at $914 \mathrm{~cm}^{-1}$ ). After completion of the reaction, the crude viscous polymer was analyzed by SEC.

\section{Procedure for DGEBA $0 \underline{P G E}_{100}$ :}

Similar to $\mathrm{DGEBA}_{0} \mathrm{PGE}_{100} \mathrm{PEO}$ without $\mathrm{PEO}$ addition.

$\underline{\text { Size exclusion chromatography: }}$

Size exclusion chromatography (SEC) analyses were performed in $\mathrm{THF}$ at $35^{\circ} \mathrm{C}$, at a flow rate of $1 \mathrm{ml}$ $\min ^{-1}$, with a setup consisting of a Malvern GPC1000 pump and a Viscoteck TDA 305 triple detection array using three thermostated columns set (LT5000L). The apparent molecular weights $\left(M_{n}\right.$ and $\left.M_{w}\right)$ 
and dispersities $\left(M_{w} / M_{n}\right)$ were obtained with a calibration based on low dispersity polystyrene (PS) standard.

$\underline{\text { Results: }}$

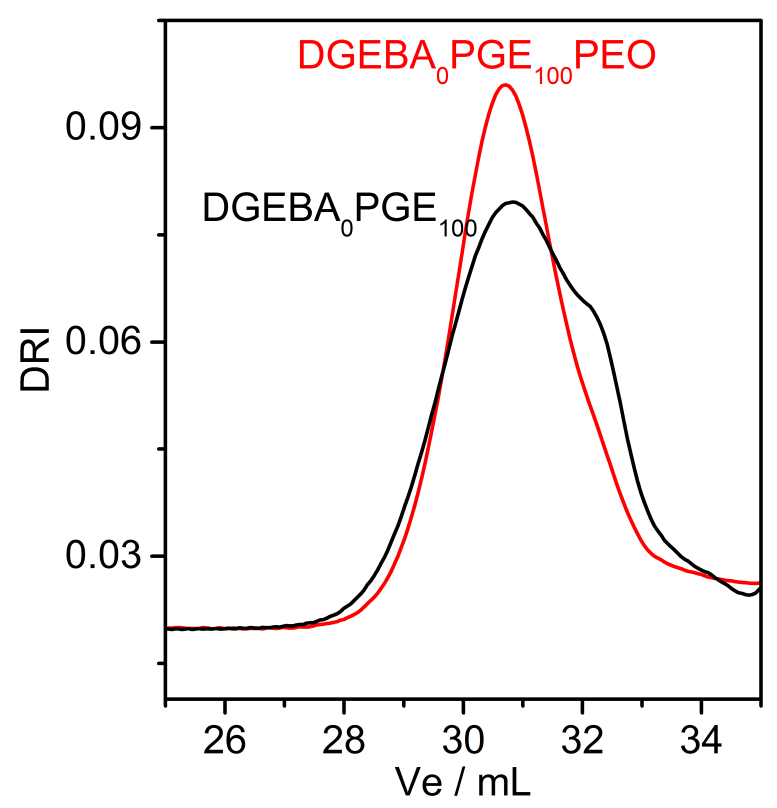

Figure S6: Size exclusion chromatography for $\mathrm{DGEBA}_{0} \mathrm{PGE}_{100}$ and $\mathrm{DGEBA}_{0} \mathrm{PGE}_{100} \mathrm{PEO}$.

Molecular properties for DGEBA ${ }_{0} \mathrm{PGE}_{100}$

$$
M_{n}=2500 \mathrm{~g} \mathrm{~mol}^{-1}, M_{w} / M_{n}=1.5
$$

Molecular properties for $\mathrm{DGEBA}_{0} \mathrm{PGE}_{100} \mathrm{PEO}$

$$
M_{n}=2560 \mathrm{~g} \mathrm{~mol}^{-1}, M_{w} / M_{n}=1.9
$$




\section{Fitting of $\tan \delta$ peaks}

The $\tan \delta$ peaks obtained in DMA were fitted in order to get an accurate estimation of the height and the full-width-at-half-maximum (FWHM) of the peaks. To do so, we used the "peak analyser" function of OriginPro 8.0.

For each peak, a baseline was defined (see Figure S7, blue line) and the maximum of the curve was automatically detected by the software. For most of the samples, the tan $\delta$ peaks are asymmetric. Based on studies previously reported in the literature, ${ }^{33,34}$ the peaks were fitted with an asymmetric double sigmoid. The corresponding mathematical function is given by:

$$
\tan \delta(T)=A(1+\exp (a))^{-1} \times\left[1-(1+\exp (b))^{-1}\right] \quad \text { Eq. }(\mathrm{S} 14)
$$

Where $a=(T-\mu) / \sigma_{1}$ and $b=(T-\mu) / \sigma_{2}$. When $\sigma_{1}=\sigma_{2}$, the function is symmetric about $\mu$ but is asymmetric otherwise. The peak height is determined by A.

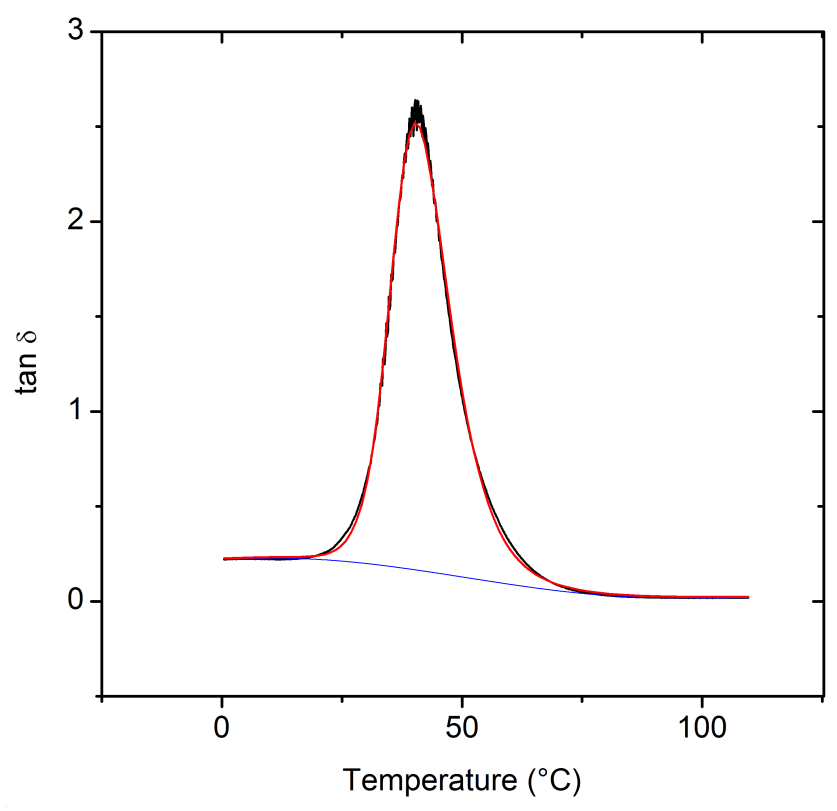

Figure S7: Fitting of the tan $\delta$ peak for $\mathrm{DGEBA}_{25} \mathrm{PGE}_{75}$, using an asymmetric double sigmoid function. 


\section{Tensile tests: cyclic loading}

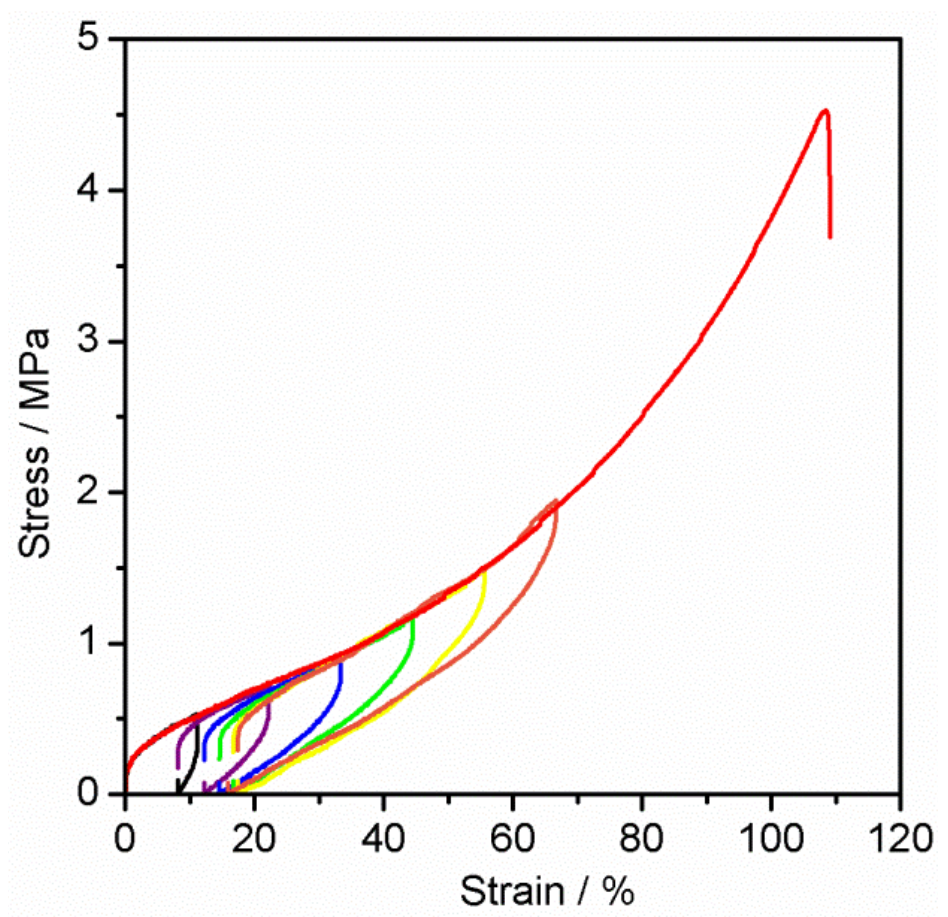

Figure S8: Cyclic loading for $\mathrm{DGEBA}_{25} \mathrm{PGE}_{75}$ at room temperature and for a crosshead speed of $5 \mathrm{~mm}$ $\mathrm{mn}^{-1}$. During a cycle, the specimen is extended of $\mathrm{L} \mathrm{mm}$ ( $\mathrm{L}$ is increased of $3 \mathrm{~mm}$ per cycle), then the crosshead is asked to go backward $\left(5 \mathrm{~mm} \mathrm{~m}^{-1}\right)$ until the load reaches $0 \mathrm{~N}$. 


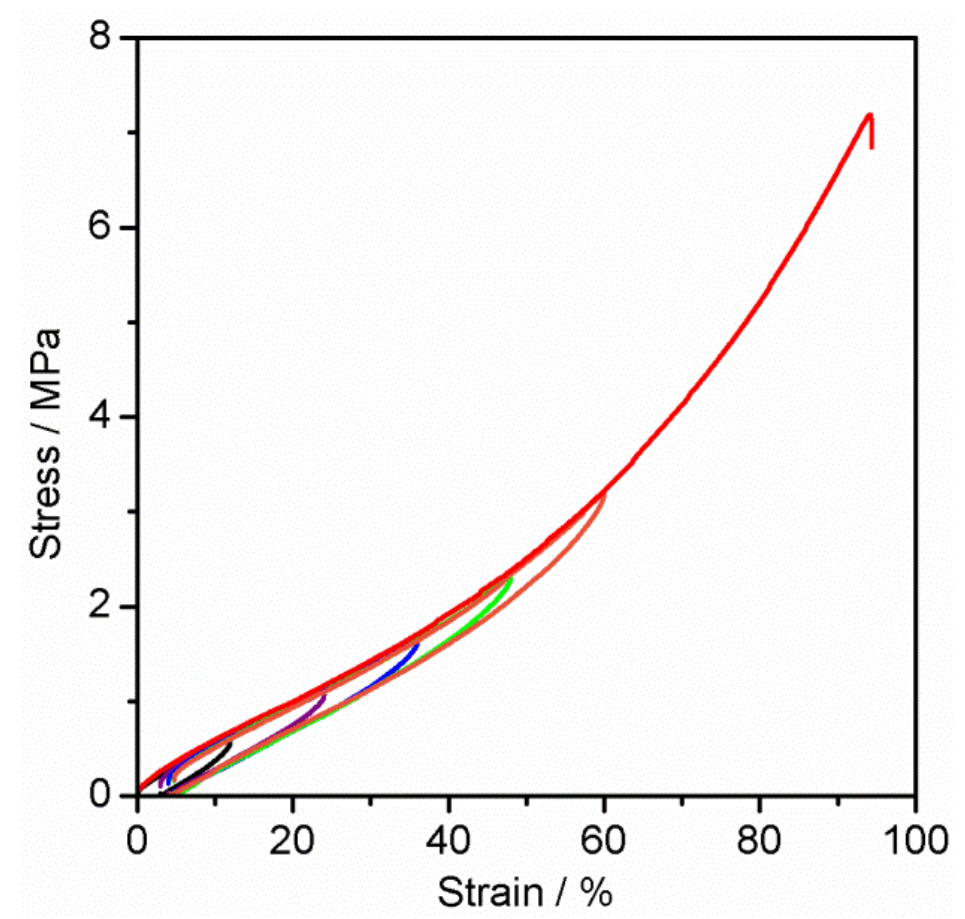

Figure S9: Cyclic loading for $\mathrm{DGEBA}_{35} \mathrm{PGE}_{65} \mathrm{PEO}$ at room temperature and for a crosshead speed of 5

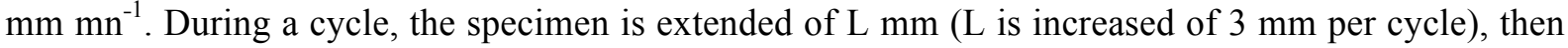
the crosshead is asked to go backward $\left(5 \mathrm{~mm} \mathrm{mn}^{-1}\right)$ until the load reaches $0 \mathrm{~N}$. 


\section{References}

1. Vidil, T.; Tournilhac, F., Supramolecular Control of Propagation in Cationic Polymerization of Room Temperature Curable Epoxy Compositions. Macromolecules 2013, 46 (23), 9240-9248.

2. Matejka, L., Rheology Of Epoxy Networks Near The Gel Point. Polymer Bulletin 1991, 26 (1), 109-116.

3. Muller, R.; Gerard, E.; Dugand, P.; Rempp, P.; Gnanou, Y., Rheological Characterization Of The Gel Point - A New Interpretation. Macromolecules 1991, 24 (6), 1321-1326.

4. Holly, E. E.; Venkataraman, S. K.; Chambon, F.; Winter, H. H., Fourier-Transform Mechanical Spectroscopy Of Viscoelastic Materials With Transient Structure. Journal of Non-Newtonian Fluid Mechanics 1988, 27 (1), 17-26.

5. Chambon, F.; Winter, H. H., Stopping Of Crosslinking Reaction In A Pdms Polymer At The Gel Point. Polymer Bulletin 1985, 13 (6), 499-503.

6. Chambon, F.; Petrovic, Z. S.; Macknight, W. J.; Winter, H. H., Rheology Of Model Polyurethanes At The Gel Point. Macromolecules 1986, 19 (8), 2146-2149.

7. Winter, H. H.; Chambon, F., Analysis Of Linear Viscoelasticity Of A Cross-Linking Polymer At The Gel Point. Journal of Rheology 1986, 30 (2), 367-382.

8. Chambon, F.; Winter, H. H., Linear Viscoelasticity At The Gel Point Of A Cross-Linking Pdms With Imbalanced Stoichiometry. Journal of Rheology 1987, 31 (8), 683-697.

9. Martin, J. E.; Adolf, D.; Wilcoxon, J. P., Viscoelasticity Of Near-Critical Gels. Physical Review Letters 1988, 61 (22), 2620-2623.

10. Martin, J. E.; Adolf, D.; Wilcoxon, J. P., Rheology Of The Incipient Gel - Theory And Data For Epoxies. Abstracts of Papers of the American Chemical Society 1989, 197, 83-POLY.

11. Martin, J. E.; Adolf, D.; Wilcoxon, J. P., Viscoelasticity Near The Sol-Gel Transition. Physical Review A 1989, 39 (3), 1325-1332.

12. Adolf, D.; Martin, J. E.; Wilcoxon, J. P., Evolution Of Structure And Viscoelasticity In An Epoxy Near The Sol-Gel Transition. Macromolecules 1990, 23 (2), 527-531.

13. Muthukumar, M.; Winter, H. H., Fractal Dimension Of A Cross-Linking Polymer At The Gel Point. Macromolecules 1986, 19 (4), 1284-1285.

14. Pascault, J.-P.; Sautereau, H.; Verdu, J.; Williams, R. J. J., Thermosetting Polymers. New York, 2002.

15. Katahira, C.; Morishita, N.; Ikeda, J.-I.; Lim, P. B.; Inoue, M.; Iwasaki, Y.; Aota, H.; Matsumoto, A., Mechanistic Discussion of Cationic Crosslinking Copolymerizations of 1,2Epoxycyclohexane with Diepoxide Crosslinkers Accompanied by Intramolecular and Intermolecular Chain Transfer Reactions. Journal of Polymer Science Part a-Polymer Chemistry 2010, 48 (20), 44454455.

16. Stauffer, D.; Coniglio, A.; Adam, M., Gelation And Critical Phenomena. Advances in Polymer Science 1982, 44, 103-158. 
17. Jan, N.; Coniglio, A.; Herrmann, H. J.; Landau, D. P.; Leyvraz, F.; Stanley, H. E., On The Relation Of Kinetic Gelation And Percolation. Journal of Physics a-Mathematical and General 1986, 19 (7), L399-L404.

18. Herrmann, H. J.; Stauffer, D.; Landau, D. P., Computer-Simulation Of A Model For Irreversible Gelation. Journal of Physics a-Mathematical and General 1983, 16 (6), 1221-1239.

19. Gennes, P. G. D., Scaling Concepts in Polymer Physics. New York, 1979.

20. Adam, M.; Delsanti, M.; Durand, D.; Hild, G.; Munch, J. P., Mechanical-Properties Near Gelation Threshold, Comparison With Classical And 3d Percolation Theories. Pure and Applied Chemistry 1981, 53 (8), 1489-1494.

21. Lu, L.; Liu, X.; Tong, Z.; Gao, Q., Critical exponents and self-similarity for sol-gel transition in aqueous alginate systems induced by in situ release of calcium cations. Journal of Physical Chemistry $B$ 2006, 110 (49), 25013-25020.

22. Lairez, D.; Adam, M.; Emery, J. R.; Durand, D., Rheological Behavior Of An Epoxy Amine System Near The Gel Point. Macromolecules 1992, 25 (1), 286-289.

23. Eloundou, J. P.; Gerard, J. F.; Harran, D.; Pascault, J. P., Temperature dependence of the behavior of a reactive epoxy-amine system by means of dynamic rheology .2. High-T-g epoxy-amine system. Macromolecules 1996, 29 (21), 6917-6927.

24. Eloundou, J. P.; Feve, M.; Gerard, J. F.; Harran, D.; Pascault, J. P., Temperature dependence of the behavior of an epoxy-amine system near the gel point through viscoelastic study .1. Low-T-g epoxy-amine system. Macromolecules 1996, 29 (21), 6907-6916.

25. Tanaka, Y.; Stanford, J. L.; Stepto, R., Interpretation of Gel Points of an Epoxy-Amine System Including Ring Formation and Unequal Reactivity: Measurements of Gel Points and Analyses on Ring Structures. Macromolecules 2012, 45 (17), 7197-7205.

26. Elliott, J. E.; Bowman, C. N., Monomer functionality and polymer network formation. Macromolecules 2001, 34 (13), 4642-4649.

27. Hasa, J.; Janacek, J., Effect Of Diluent Content During Polymerization On Equilibrium Deformational Behavior And Structural Parameters Of Polymer Network. Journal of Polymer Science Part C-Polymer Symposium 1967, (16PC), 317-\&.

28. Barton, A. F. M., Regular solutions and the hildebrand parameter. In Handbook of solubility parameters and other cohesion parameters, $2^{\text {nd }}$ ed.; CRC press: Boca Raton, 1991; pp 55-68.

29. Grulke, E. A., Solubility parameters values. In Polymer handbook, $4^{\text {th }}$ ed.; Brandrup, J.; Immergut, E. H.; Grulke, E. A., Eds. John Wiley \& Sons: New York, pp VII / 675-VII / 714.

30. Bristow, G. M.; Watson, W. F., Cohesive Energy Densities Of Polymers .1. Cohesive Energy Densities Of Rubbers By Swelling Measurements. Transactions of the Faraday Society 1958, 54 (11), 1731-1741.

31. Bouillon, N.; Pascault, J. P.; Tighzert, L., Epoxy Prepolymers Cured With Boron TrifluorideAmine Complexes .3. Polymerization Mechanism Of A Prepolymer Containing Epoxy Groups. Makromolekulare Chemie-Macromolecular Chemistry and Physics 1990, 191 (6), 1435-1449.

32. Patel, S. K.; Malone, S.; Cohen, C.; Gillmor, J. R.; Colby, R. H., Elastic-Modulus And Equilibrium Swelling Of Poly(Dimethylsiloxane) Networks. Macromolecules 1992, 25 (20), 52415251. 
33. Arrighi, V.; McEwen, I. J.; Qian, H.; Prieto, M. B. S., The glass transition and interfacial layer in styrene-butadiene rubber containing silica nanofiller. Polymer 2003, 44 (20), 6259-6266.

34. Vodovotz, Y.; Chinachoti, P., Glassy-rubbery transition and recrystallization during aging of wheat starch gels. Journal of Agricultural and Food Chemistry 1998, 46 (2), 446-453. 